\title{
Induction -year mentors' self -perceptions and reflections on their training and administrative support
}

Joy Rise Cowdery

West Virginia University

Follow this and additional works at: https://researchrepository.wvu.edu/etd

\section{Recommended Citation}

Cowdery, Joy Rise, "Induction -year mentors' self -perceptions and reflections on their training and administrative support" (2002). Graduate Theses, Dissertations, and Problem Reports. 2411.

https://researchrepository.wvu.edu/etd/2411

This Dissertation is protected by copyright and/or related rights. It has been brought to you by the The Research Repository @ WVU with permission from the rights-holder(s). You are free to use this Dissertation in any way that is permitted by the copyright and related rights legislation that applies to your use. For other uses you must obtain permission from the rights-holder(s) directly, unless additional rights are indicated by a Creative Commons license in the record and/ or on the work itself. This Dissertation has been accepted for inclusion in WVU Graduate Theses, Dissertations, and Problem Reports collection by an authorized administrator of The Research Repository @ WVU.

For more information, please contact researchrepository@mail.wvu.edu. 
Induction-year Mentors' Self-perceptions and Reflections on Their Training and Administrative Support

\author{
Joy Cowdery
}

Dissertation submitted to the College of Human Resources and Education At West Virginia University in partial fulfillment of the requirements for the degree of

Doctor of Education
in
Educational Leadership

Linda Spatig, Ed.D., Chair

Teresa Eagle, Ed.D.

Dorothy Erb, Ph.D.

Helen Hazi, Ed.D.

Barbara Nicholson, Ph.D.

Educational Leadership

Morgantown, West Virginia

2002

Keywords: Critical Theory, Reflection, Mentor, Induction-year, Administration Copyright 2002 Joy Cowdery 


\section{ABSTRACT \\ Induction-year Mentors' Self-perceptions and Reflections on Their Training and Administrative Support}

\section{Joy Cowdery}

The purpose of this qualitative study was to examine how induction-year mentors in Ohio, Pennsylvania, and West Virginia perceived their jobs as mentors, reflected upon their training, and assessed their administrative support. By asking mentors to reflect upon their experiences as trained mentors, administrators may use this information to determine the extent to which what is happening in the field is perceived as effective and valuable by the participants charged with success of the mentoring programs. Mentoring, in this study, was examined through the lens of critical theory to determine if what was experienced by mentors in their training programs perpetuated or challenged the status quo in terms of enhancing learning opportunities for all students. Nine experienced, female, elementary mentors, three from each state, were interviewed three times over the course of three months. Additionally, field notes from both training sessions and interviews and documents from each state's training program were used as data in the study. The results of this study support current literature that building principals are perceived by mentors as being able to enhance the success of mentoring programs by controlling factors such as released time for mentoring partners, careful selection of mentors, and assurance that mentors are in the same building as mentees. Other results of this study offer empirical evidence that training may influence mentors' self-perceptions and practice as mentors and as teachers, and that different training programs are perceived by mentors differently. Because training has the potential to influence mentoring practice, the focus and framework of the mentor-training program determines in large part how they see their roles as mentors and whether they begin to critically examine their own teaching. In this study, only the Ohio mentors who were trained using the Pathwise mentor-training program reported using what they had learned in their training to critically examine and change their own teaching practices in ways that enhanced opportunities for learning for all students. The implication of this study is that selected training programs will affect how mentoring is perceived and practiced by mentors. 
The author wishes to thank her committee members: Dr. Teresa Eagle, Dr. Dottie Erb, Dr Helen Hazi, and Dr. Bobbie Nicholson for their time, patience, and help during the research and writing of this dissertation. The author wishes to especially thank her chair, Dr. Linda Spatig, for the many, many hours of consultation, advising, editing, support, and encouragement she has given to this project during the last two years. Finally, the author wishes to thank her family for their patience and support, especially the help and dedication of her husband, Joe Cowdery, for never giving up on her and encouraging her to persevere. 


\section{TABLE OF CONTENTS}

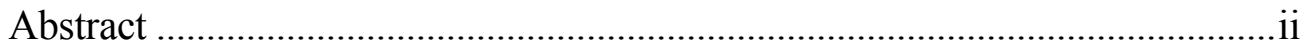

Acknowledgements......................................................................................ii

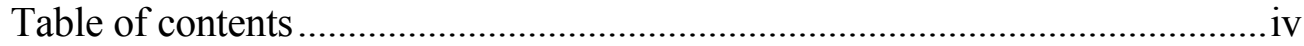

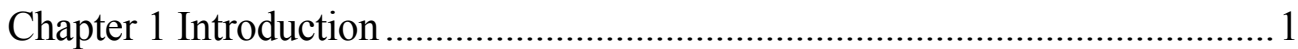

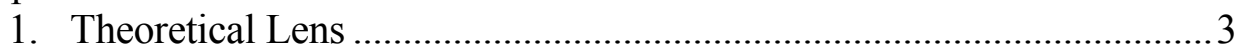

2. Statement of Problem ........................................................................ 9

3. Definition of Terms ......................................................................... 11

4. The Purpose of the Study and Research Questions ................................13

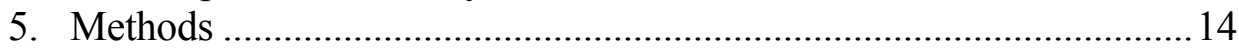

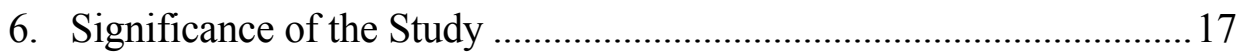

7. Limitations of the Study ………………………….............................. 18

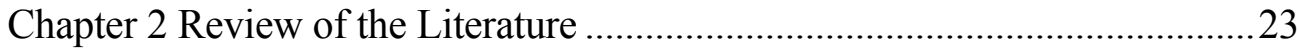

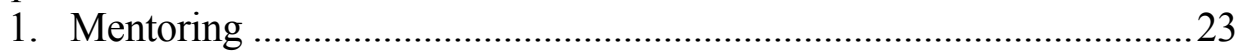

2. Mentoring, Diversity, and Reform .......................................................28

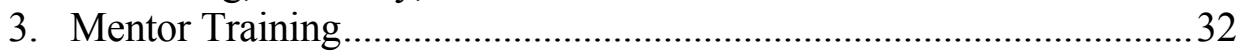

4. Principal Support of Mentoring …………………………………........34

5. Mentors' Perceptions of Mentoring …………………........................38

Chapter 3 Methods ....................................................................................... 43

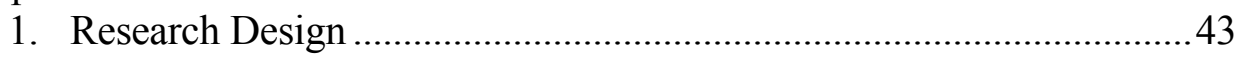

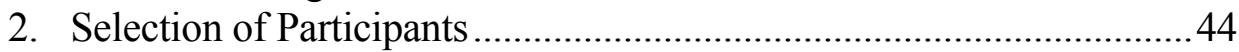

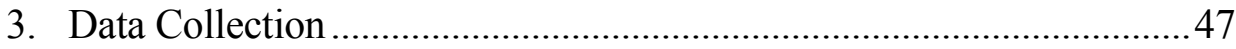

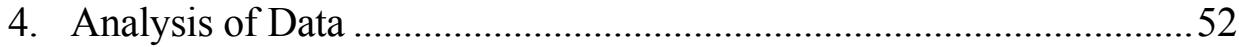

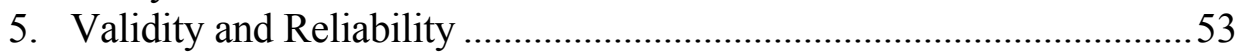

Chapter 4 Mentors and Training..........................................................................58

1. Introduction to the Mentors: Teachers by Default ..................................58

2. Examination of Training ..................................................................

Chapter 5 Research Questions ......................................................................92

1. Self-perceptions as Influenced by Mentor Training .............................92

2. Perceptions of Successful Mentoring ...................................................99

3. Administrative Support......................................................................101

4. The Lens of Critical Theory ……………………….........................112

Chapter 6 Implications and Questions for Further Study ...............................124

1. Implications of the Self-perceptions of Mentors..................................124

2. Administrative Support and Perceived Success...................................125

3. Implications for Administrators about Training .................................128

4. Mentor training as Transformational.................................................129

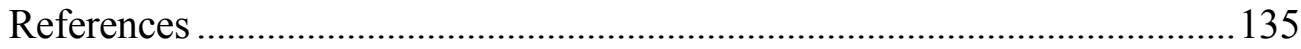

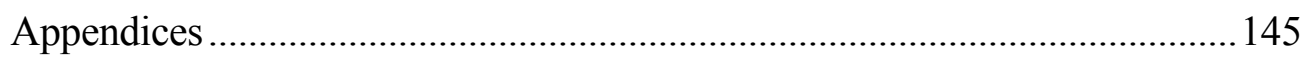

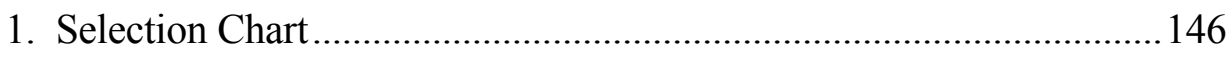

2. Demographic Chart...........................................................................147

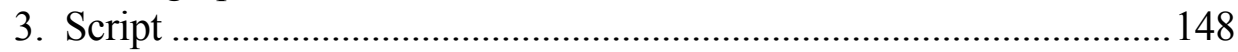

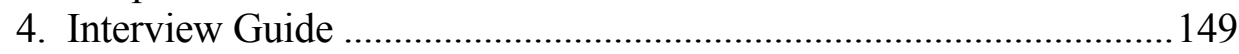




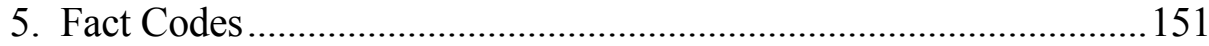

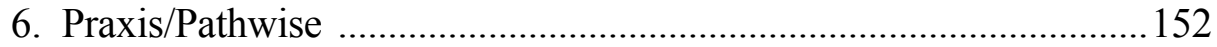

7. Pathwise Assessment Criteria............................................................ 153

8. West Virginia Beginning Educator Internship Program....................154

9. West Virginia Duties and Responsibilities ..................................... 155

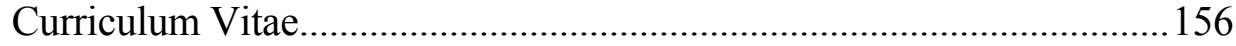




\section{CHAPTER ONE \\ Introduction}

The National Center for Research on Teacher Learning reports that the quality of educators is the largest single factor influencing student learning (Pennsylvania Department of Education, 2001). Commitment to this idea is evidenced by the backing of the U.S. Department of Education in the form of grants to 31 states to enhance teacher quality (Hirsch, 2002). West Virginia received 2.28 million dollars for teacher quality enhancement "designed to increase student achievement by improving teacher quality" (West Virginia Department of Education Impact Grant, 2000). Ensuring quality instruction for students by qualified teachers, then, must be a priority of educational administrators (Haller \& Kleine, 2001).

Unfortunately, without support from colleagues and principals, the most talented new educators are the most likely group to leave the profession (National Center for Research, 1992). Students' learning suffers if new teachers do not receive support. Over two million new K-12 teachers will need to be employed over the next decade as the rate of retirement accelerates among the aging teacher population of which over half are currently 45 years old or older (Hirsch, 2002). Other contributing factors are the rate of public school student enrollment increasing, especially in low-income, urban areas (Darling-Hammond, 1996). While teacher preparation programs have experienced no decline in teacher candidates, those candidates are less likely to take teaching jobs at the completion of their education and much less likely to stay in teaching than ever before. Only about $60 \%$ of those prepared to teach actually do so. (Hirsch, 2002). Current estimates are that $30 \%$ to $50 \%$ of new teachers leave teaching within the first three years (Hirsch, 2002) and almost 10\% quit before finishing the first year (Darling-Hammond, 
1997). New teachers leave the field citing discipline problems and lack of support from colleagues and administrators as their major reasons for leaving (Jambor \& Patterson, 1997). In addition to being educationally disruptive for the students and the academic program in general, the revolving door syndrome of teachers is costly to districts. The recruitment, hiring, and training of new teachers erodes both monetary and administrative resources.

To address this issue, at least thirty states, including West Virginia, Ohio, and Pennsylvania, have mandated induction-year programs which include a mentored experience for the first year teacher (Evertson \& Smithey, 2000; Jambor \& Patterson, 1997). Mentored first-year teachers reportedly use instructional practices that improve student achievement, assign more challenging work to diverse student populations, and to use state or national standards in constructing curriculum than unmentored first-year teachers (National Center for Research on Teacher Learning, 1992).

However, having a mentoring program in place in the majority of states does not necessarily mean that new teachers are provided with the support they need to become successful educators. Induction-year and mentoring programs vary from loosely constructed suggestions to rigidly designed mandates from state to state. According to Little (1990), many programs provide assistance, but not true mentoring, partially because mentors do not fully understand their jobs as mentors (Salzman, 2000). The purpose of this study was to examine the perceptions of experienced mentors about their roles in facilitating quality teaching for enhancing student learning and providing equitable educational opportunities for all students. Specifically, mentors were asked to critically reflect upon their mentor-training program, as provided by their states, their 
administrative support, and the extent to which both of these informed and were manifested in mentoring relationships which enhanced teacher quality and increased student learning. This study sought to understand how mentor teachers perceive their roles in contributing to enhancing student learning through the mentoring of induction year teachers. It also sought to clarify how mentor-training programs influenced that perception. Using qualitative research methods of interviewing, observation, and documentation review, I asked mentor teachers to articulate their perceptions of their roles as mentors and how they conceptualized what is expected of them from their preparation and training.

Administrators, specifically school principals, who are charged with the task of selection, training, and supporting mentor teachers, need the feedback that these perceptions provide if they are to assess the value and role of different mentor-training programs. They will be able to examine their own support to insure, if desired, that the mentoring process is a transformative experience which could promote individual learning in a diverse student population. If training programs and types of administrative support played little role in mentor-teacher experiences or in their perceptions of their roles, then the monetary and time costs of such programs needed to be weighed against the benefits.

Theoretic Lens: Critical Theory

Education and educators can only succeed if teachers know why they are teaching. Teachers goals and objectives must be guided by ideals (Arnstine, 1995), and these ideals need to be clearly articulated by the teachers. If teachers are unaware of the societal implications of the system of education, then the inequities that have always been 
perpetuated will continue. If teachers see schools through the "rose-colored glasses of the meritocractic myth" (Villegas \& Lucus, 2002, p. 23) they will unwittingly continue to support social reproduction. Critical theory examines education in regard to social reproduction, justice, and equity. John Dewey's vision of an educational system in which the first obligation of schools in a democracy is to instill democratic ideals in the next generation is reflected in critical theory and rooted in the idea of social justice (Dewey, 1916). By using critical theory as a way to interpret the findings of this study, I can better determine if mentoring is a means of furthering these democratic ideals or a means of social reproduction. Applying the lens critical theory to education, makes it possible to see interests that are being served or not served, and values and agendas that are condoned or condemned in everyday practices by practitioners (Beyer, 2001).

Critical theory is a lens through which societal structures may be examined to discover in what ways and for whom the structure is beneficial or detrimental in terms of power and oppression. Fundamentally a social theory, it is often used to determine the breach between ideas and reality. It is particularly concerned with unchallenged assumptions about knowledge and power implicit in our institutions. In the United States educational system, critical theory can be used to understand the process of social reproduction and what should and should not be reproduced in terms of fostering equitable opportunities for all students. Too many times schools foster inequity in the manner through which they promote and reward students. They reinforce the patterns of social class, racial and sexual roles and identity with relationship to dominance and subordination found in society at large (Sleeter \& Grant, 1999). Schools tend to prepare students to assume roles "appropriate" to their stations in life through "tracking," and the 
separation of college preparatory students and vocational students. Middle and upperclass students tend to dominate academic activities while minority students dominate sports (Sleeter \& Grant, 1999). Education policies too often promote only middle class, Euro-American-heritage values such as, wealth and opportunity are open to anyone who tries, history flows from east to west, and past social problems have been solved and future ills can be solved with technology (Sleeter, \& Grant, 1999). This tends to reproduce forms of consciousness that help maintain social inequities to support the status quo (Beyer, 2001). Our school structures reproduce prevailing race, social class, and gender patterns that still place more value on being white and male to make decisions in schools. Ninety-five percent of all superintendents are white and male, only $27 \%$ of principals are women, $90 \%$ of all teachers are white, and $90 \%$ of all secretaries are women (Sleeter \& Grant, 1991).

Currently, one out of every three elementary students is of a racial or ethnic minority background, and one in seven speaks a language other than English at home. One in five lives in poverty (National Center for Educational Statistics, 2002). Our students are increasingly perceiving a gap between their homes and their schools. The message of power is clear; it is not for them. Teachers have the opportunity to bridge that gap by grasping the differences in student cultures and interpreting student behavior in that light. Recognizing the power gap in the structure of schools is the first step in changing the system.

The use of critical theory as a means of critical examination of the relationships of power and knowledge in the classroom is one way to begin to transform those aspects of our educational system which negate opportunities for some students. Using critical 
theory as a lens through which to examine mentors' self-perceptions of their roles, training, and support can inform educators about the ways in which mentors may be passive conveyors of the status quo or transforming catalysts to education.

Much of critical theory in the examination of education as an institution deals with the contradictions of practices in the schools and in the classrooms (Popkewitz \& Brennan, 1997), especially in light of the unparalleled explosion of students who have not traditionally experienced success in schools. The gap widens between the academic, social, and emotional needs of a diverse student population and the often ineffective instructional practices in many public schools (Cline \& Necochea, 1997). Historically, teacher mentoring focused on conformity, homogeneity, and the perpetuation of the status quo because the status quo was meeting the societal expectations for schooling a homogeneous population of students (Cline \& Necochea, 1997). With a shift in student population and expansion of legal protections to include students who are disadvantaged, marginalized, or differently prepared, and the realization that all students need to succeed if we as a nation are to succeed, the status quo is no longer seen as satisfactory (Cline \& Necochea, 1997).

If, in fact, as the National Center for Research on Teacher Learning (1992) claims, the largest single factor in student learning is the quality of the teacher, then it stands to reason that the teacher is a tremendous influence on what is learned by students, which students learn it, and under what circumstances. Kemmis and McTaggert (1988) concluded that if serious democratic reform is to occur, then the teacher must be a major player in the transformation. Teachers who see all students in an affirming light, not just those from the dominant group, have been shown to increase student achievement (Neito, 
1996). These teachers tend to see their roles as adding rather than replacing what students bring to learning with a commitment that students are capable learners who bring a wealth of knowledge and experiences to school (Villegas \& Lucus, 2002). The mentoring process has the potential to place veteran teachers in positions to make the changes called for by those who seek reform.

Giroux and McLaren (1996) suggested that teacher preparation become more concerned with how moral and ethical commitments guide a teacher in the field than with procedures and organizational concerns. A first-year teacher, guided by a mentor, may be in the best position to begin to question his or her own educational philosophies and his or her own relationship with democratic values. While mentoring may appear to be the perfect vehicle for social reproduction, if the dialogue of mentoring is not limited to skill acquisition or cultural immersion, a move toward transformative practice may be achieved by both the mentor and the mentee. Field (1994) asserted that challenging the status quo must be part of the dialogue between mentor and mentee. Such dialogue, based in critical theory, would include how to analyze and question aspects of school life, the effects of sex, race, and other demographic factors (e.g. economic status, religion, sexual orientation, disabilities) on classroom interactions, and the justifiability and consequences of believing the way they do about curriculum (Field, 1994).

That information flows in only one direction from veteran to novice must be rethought in considering mentoring through the lens of critical theory. If schools assume the mentor always knows best, innovative practices of new teachers may be ignored and new teachers may experience the mentoring relationship as oppressive (Hargreaves \& Fullan, 2000). The concept of co-learning suggests that the mentor and mentee transcend 
their roles and interact as colleagues using tacit knowledge to enhance both professionals' teaching (Darwin, 2000). Together, experienced and novice teachers through collaborative, supportive roles may encourage one another to begin to critically examine how democratic ideals can be encouraged in their students. Teachers who collaborate develop a common purpose, cope better with uncertainties, and develop stronger senses of teacher efficacy (Hargreaves \& Fullan, 2000). The implications of looking at mentoring in this way as an on-going professional learning experience include an institutional obligation to continuous learning, an active integration of and synergy between theory and practice, and collegial professionalism dedicated to critical pedagogy (Hargreaves \& Fullan, 2000).

Only building principals are in a position to create leader-management learning environments wherein students and teachers are empowered and expected to become lifelong learners (Cline \& Necochea, 1997). The principal, as the educational leader in the construction and support of the mentoring relationship, needs to be concerned with the "critical" decisions required to ensure an environment wherein critical pedagogy can exist. Critical leadership requires reflection, analysis and a willingness to examine the purpose and consequences of decisions on students with respect to equity of learning opportunities and social justice. According to William Foster (1986), in a school committed to critical theory, "The administrator, the teacher, and the school work not to reproduce a given social world but to remove the limits set by it..." ( p.191).

Critical theory provides a way of conceptualizing reality and addressing social change through critically examining the mentoring environment and how that environment consciously or unconsciously influences the outcome of the mentoring 
experience as transformative or reproductive. It is a way of raising questions about how mentors perceive their roles in perpetuating or challenging the status quo and how that impedes the learning or promotes the progress of students (Foster, 1986). Critical theory asks how mentors see themselves in making a difference in student learning through the mentoring process.

\section{Statement of Problem}

Concerned with the rate of attrition during the first three years of teaching, policy makers have turned to induction year programs as a means of supporting and retaining new teachers. Retention of promising teachers is perceived as one way to improve overall teacher quality, and research has shown that mentoring as part of an induction year plan is a highly useful strategy to improve a new teacher's sense of belonging and to increase retention. In fact, urban districts reported a 93\% retention rate for new teachers who participated in an induction year program (Darling-Hammond, 1996). The National Commission on Teaching \& America's Future published by the Teachers College, Columbia University (1996), reported that mentored novice teachers tend to focus on student learning sooner and leave teaching at a lower rate than novice teachers without mentors (Darling-Hammond, 1996). Within the last 10 years, 30 states have mandated some type of mentoring program to be in place in all public schools (Evertson \& Smithey, 2000). New York Representative Carolyn McCarthy introduced the Teacher Mentoring Act of 1999 (H.R. 1662), an amendment to the Elementary and Secondary Act of 1965, on May 4, 1999 which would federally mandate mentoring programs in all public schools for first year teachers (Congresswoman Carolyn McCarthy, 1998). Mentoring is being seen as the panacea for all the ills of teacher attrition; 
however, few mentoring programs have been subjected to rigorous empirical scrutiny to study the effectiveness of mentoring on improving teaching practice or in reforming teaching as a profession (Feiman-Nemser, 1996).

In fact, some studies show that mentoring may have a negative impact on teaching practices and educational reform. If mentors do not practice learning-centered, democratic methods as suggested by critical reformers, then mentoring may have a "conservative effect on new teachers' practice, introducing and helping to support the status quo instead of encouraging new teachers to explore innovative practice" (Evertson \& Smithey, 2000, p. 294). Some studies show that mentors promote conventional norms and practices, thus limiting reform (Feiman-Nemser, 1996). Inadequate or nominal mentoring may actually be worse than no program at all. A study conducted in Queensland, Australia in 1992 found that when "buddy mentors," those experienced teachers assigned to new teachers to provide emotional and instructional support, lacked knowledge of different teaching strategies and supported only traditional styles that conflicted with the new teacher's pedagogy learned in teacher preparation programs, the beginning teachers became more authoritarian, more rigid, and less pupil-centered as the semester progressed. They also responded that they felt guilty and frustrated in abandoning learned theory in practice (Ballantyne \& Hansford, 1995). Experience, caring, and good intentions by mentors are not enough to ensure that new teachers are helped to become teachers focused on student learning and equity of opportunities for all students. A 1992 study by Elliott and Calderhead in Great Britain revealed that mentors described their roles most commonly as being one of a supporter who nurtures the new 
teacher. No reference to themselves as conveyers of craft knowledge or challengers of the status quo were articulated.

Mentoring, then, can be considered one of the most critical issues confronting educators today, not only as a means of retention, but to determine if it is being used as a way to lay the foundation for innovative practice rather than to promote conventional practices and limited reform. Mentoring may fall short of its ideals because policy makers see it as a simple means of keeping new teachers in the profession rather than as an integral approach to teaching and professionalism. Mentoring can only reach its full potential if it is treated as central to transforming the teaching profession itself (Hargreaves \& Fullan, 2000) and increasing teacher effectiveness in terms of student learning. Mentoring can go beyond the classroom, school, and district to "encourage social change and quality education" (Foster, 1986, p. 78). Little (1990) argued that the promise of mentoring lies not in easing new teachers' entries into the profession, but in helping her or him confront difficult problems of the practice. By examining how mentors see themselves in this process, a better understanding of the influences of the training and administrative support on mentor perception and practice can be achieved. Administrators can reflect on the purpose of mentoring and make better-informed decisions about evaluating induction-year mentoring programs. Mentors can better understand the relationships and expectations of mentoring, and finally, mentors can reflect on how their perceptions of themselves as mentors, their training, and administrative support informs their decisions as mentors.

\section{Definition of Terms}

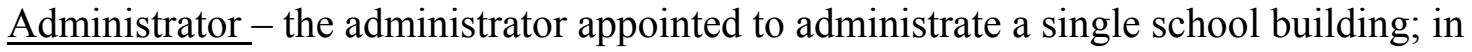


most cases it would be the principal.

Collective case study - the process of "studying multiple cases in one research study" (Johnson \& Christensen, 2000, p.329).

Critical Pedagogy - a strategy for recognizing and transforming oppressive conditions by critically examining the relationship between power and knowledge in the classroom, a disciplined questioning of the ways in which power works through the practices of schools (Giroux \& McLaren, 1996).

Critical Theory - a theory based upon a system of looking critically at the discrepancies between reality and beliefs in terms of social justice, in this study, looking at what a mentor is supposed to be and what the process is actually like for mentors and looking at mentor training in terms of its effect on social reproduction.

Data triangulation - the use of "multiple data sources in a single research study" (Johnson \& Christensen, 2000, p. 213).

Equality - the state of being equal, to each the same

Equitable - the state of bringing into balance, to each according to need

Induction year - the first professional teaching year of a teacher

Interview guide approach - a system of structuring an interview using "Specific topics and open ended questions ... asked in any order.” (Johnson \& Christensen, 2000, p. 144).

Mentee - an induction-year teacher who is assigned a mentor.

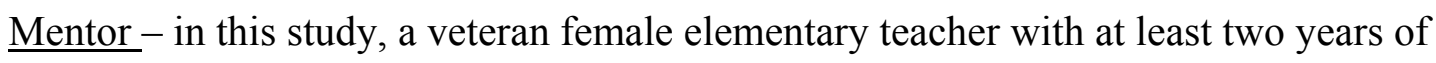
mentoring experience, and 15 years of teaching experience.

Phenomenological study - a study designed to describe one or more individuals' 
experiences with a specific phenomenon (Johnson \& Christensen, 2000); in this study the phenomenon is mentoring.

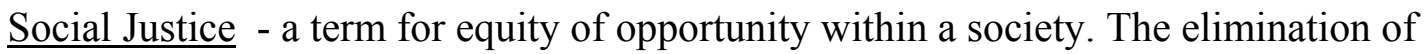
systematic oppression and injustices for segments of that society.

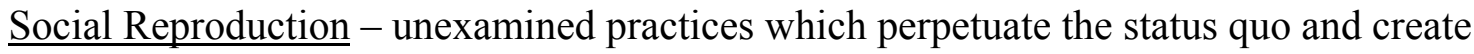
inequities and injustices for segments of society and justify oppression.

Tacit knowledge - a way of knowing in action, metacognition.

Transformative - a process to change the condition of the status quo; in this study, transformative refers to changing constructs in teaching that perpetuate the status quo and social reproduction.

The Purpose of the Study and Research Questions

The purpose of this study was to examine how induction-year mentors think about what they do, their training, and their administrative support as mentors. By asking mentors to reflect upon their experiences as trained mentors, educators can better determine the extent to which what is happening in the field is perceived as effective and valuable by the participants charged with success of the mentoring programs. This reflection will provide a basis for understanding the ways mentoring serves a transformative and or reproductive function in schooling.

Questions:

How do these mentors perceive themselves as mentors?

How do these mentors assess their success at mentoring?

What kinds of differences in perceptions exist among the mentors who were trained in three different mentoring programs from three different states? 
How do induction-year mentors perceive their training and their administrative support as influencing their perceptions of their roles and the practice of mentoring?

\section{Methods}

Because mentor training varies considerably, from a two-year training program in Great Britain (Reid \& Jones, 1997) and a university certification requirement in Australia (Certificate in mentoring, New South Wales Department of Education, 2000) and 30 unique, state-adopted programs in the U.S., different mentors have experienced different training and may be influenced in their perceptions of their roles by the training that they have received. In order to explore the mentors' perspectives of different types of training, I interviewed nine mentors, three each from three states' mentor-training programs: Ohio, Pennsylvania, and West Virginia.

In 1996, The Ohio State Department of Education adopted a performance-based assessment for licensing, the Praxis III from the Educational Testing Systems (ETS). It became effective January 1, 1998. Teacher Education and Licensure Standards, Section 3301-24-04 declared that all districts have in place an Entry Year Teacher Program that must have a formal program of support that includes mentoring, and that all Entry Year Teachers must successfully complete the program and assessment (Ohio Department of Education). Because new teachers must pass a performance-based evaluation during the first year of teaching to become licensed, Ohio offers an ETS developed mentor training program that shares the same criteria as the Praxis III. This two-day training program is called Pathwise and recently a more intense version of Pathwise, Ohio First. While school districts may choose any mentor training program they wish, the state 
recommends and monetarily supports through grants the Pathwise training. In effect, the entire state uses the same mentor-training program with state department-trained Pathwise trainers. Only one district in Ohio does not use an ETS developed program. Hamilton County uses a Vanderbilt program (Carroll, 2002).

In Pennsylvania, since 1992, the state department of education has required that all districts have an induction year program in place which includes mentoring according to the Professional Practice and Conduct Code for Educators (2.2, PA Code 235). The state reimburses the cost of the program for mentors to the districts. Additionally, they issue criteria for mentor selection and training, and each district must annually submit a report on their programs to the State Department of Education's Chief Executive Officer for approval. According to state documents on the requirements of a districts' mentoring program, mentors are to be trained in the purpose of the induction year, the role of the mentor, communication skills, effective teaching skills, problem solving, and knowledge of adult learning and development (Pennsylvania Department of Education). District programs may include stipends, released time, tuition wavers, or extra compensation. All first-year teachers are required to have an induction year coordinator, a plan and timeline, and a description of mentoring and evaluations (Pennsylvania Department of Education). This plan is to be updated by the districts every six years.

In West Virginia, all individual schools must mentor new teachers. Since 1992, WV Policies 2320, 5899 and 5900 under the WV Code 18A-3-2b have required that all beginning educators participate in a three year internship program with an assigned mentor with a support team consisting of the mentor, building principal, and mentee. While suggestions which are "as agreed upon by the principal" are given by the State 
Department of Education for giving stipends ( $\$ 600)$ and released time to mentors, no criteria are established for establishing or measuring the success of any individual program, nor do individual schools need to submit reports on their programs (WV Department of Education). Training by West Virginia Department of Education is done by the division of Professional Education and in one county, by the county itself.

As described in state department documents, the three induction-year programs vary in terms of their structure and flexibility. Ohio is highly structured and centralized. Pennsylvania offers more autonomy and flexibility to districts; and finally, West Virginia, which is in the process of revising their program, is more loosely structured with almost total autonomy at the district level. My first goal was to discover if the descriptions of the programs of training were what my participants in each state experienced. My next goal was to find out how the type of training received influenced the mentors' perceptions of their roles.

I interviewed the participants in three separate interviews as to their perceptions of what role administrative support played in the mentoring process. I also used observation and field notes. I observed one state training session in Ohio and one in West Virginia. Pennsylvania did not have any mentor training in the two districts in which I interviewed. I examined official documents from the state and local districts and training manuals produced by ETS, the West Virginia Department of Education, Ohio and Marshall Counties. According to Patton (1990), “ By using a combination of observations, interviewing, and data analysis, the fieldworker is able to use different data sources to validate and cross check findings" (p. 244). It was very important to include document research in my study to flesh out understanding of the interview and 
observational data. Patton pointed out that, "Document analysis provides a behind the scenes look at a program that may not be directly observable and about which the interviewer may not ask appropriate questions without leads provided through the documents" (p. 245). Both the observational field notes and the official documents were inductively coded and analyzed with the interview transcripts from the interviews using QRS Nud*Ist 4 for Windows software.

Significance of the Study

According to Haller and Kleine (2001), "the fundamental purpose of (administrative) research should be to improve administrative practice" and the "practice of school administration consists of deliberately establishing, maintaining, and changing programs that have prescribed effects on learners" (p.12). Gulick and Urwick (1937) described the tasks of administrators in any setting as consisting of Planning, Organizing, Staffing, Developing, Coordinating, Reporting, and Budgeting (POSDCoRB). In educational administration, the primary task of the administrator is not an adherence to emphasizing any of these individual components, but to coordinating the system as a whole (Haller \& Kleine, 2001) and fostering a relationship among them to the end of "establishing, maintaining, and changing programs that have prescribed effects on learners" (p. 12).

By examining the perceptions of experienced mentors about the environment in which they practice and how that does or does not translate into the improvement of classroom teaching, administrators can make more informed decisions that impact learners. A critical and qualitative study of this phenomenon allows all educators including mentors, administrators, and induction year mentees to discover the variable 
meanings, applications, and consequences of the mentoring process. It allows those involved in the phenomenon to voice their own understanding of the reality of the situation. More importantly the purpose is to "understand the social processes by which particular end results are created rather than to just describe the results themselves" (Locke, Spirduso \& Silverman, 2000, p. 99).

This study employed a critical theory framework in a qualitative study of the phenomenon of induction-year mentoring to provide insights into how mentors see themselves as teacher mentors in enhancing student learning. This study contributes to the literature by suggesting data-based criteria for assessing and implementing mentortraining programs and for making decisions about administrative support. It also allows mentors to examine their own mentoring situations by critically examining the results of the study and applying the conclusions to those situations.

\section{Limitations of the Study}

Being qualitative and using a small, purposeful sample, rather than quantitative and using a large, random sample, the results of this study are not suitable for generalizing about the larger population of teacher mentors, but the results are transferable (Bogdan \& Biklen, 1998). Rather than aspiring to use "statistical generalibility, qualitative research usually aims to reflect the diversity within a given population" (Barbour, 2001). Recognition of this diversity can give administrators and educators insight into the perceptions of mentors in three different state-established induction year programs and use that knowledge to further investigate their own induction-year programs or to reflect on their own mentoring practices. A much more 
extensive study would be necessary to draw conclusions about the general effects of mentor training nationwide on mentor perceptions.

The second limitation is the scope of the study. I interviewed and observed training in only three states. I had specifically chosen these three states (Ohio, Pennsylvania, and West Virginia) for convenience and, more significantly, for variety. These three states have three different types of induction year plans and mentor preparation programs. This allowed me to compare the way mentors who have experienced the three different types of training view their training programs and how their training programs had influenced their own perceptions of mentoring. According to the state documents, the training programs ranged from highly structured to moderately structured to loosely structured. Using these three states enabled me to answer my third research question, "What kinds of differences in perceptions exist among the mentors who were trained in three different mentoring programs from three different states?" Additionally, a limitation was that I used interviewing as my primary collection strategy. The only observations were during the training sessions for mentoring programs in two of the three states. This limited the triangulation possibilities; however, I supplemented the interviews and observations with official and personal document review.

The final limitation of the study was that other variables might have influenced mentor teacher self-perceptions besides that of their training. Factors such as the sex of the mentee, the age of either participant, the mentor's years of experience, and political or religious leanings may have affected the mentors' perceptions of their roles. A study of first-year teachers being mentored, however, reveals that the mentees did not perceive 
having the same planning period, having similar teaching styles, or being of the same sex as particularly important to the success of the mentoring (Whitaker, 2000). No study discussed the mentors' perceptions on these factors. To minimize the effects of these other factors, I concentrated my interviews on the mentors' self-perceptions, their perceptions of the training they received, and their perceptions of the types of administrative support they received. I tried to minimize the differences in the selected participants by using teachers in similar geographic locations, rural or small city (a population of less than 50,000) schools. These schools were accessible to me and onefourth of all American children go to school in rural or small city schools (Jehlen, 2001). The teacher shortage, which prompted mentoring programs, is worse in rural areas than in suburban schools and is as bad as urban school shortages (Jehlen, 2001). I also limited my participants to female elementary teachers who had been teaching longer than fifteen years and had been a mentor for at least two years.

I selected female mentors because previous studies demonstrate that there are differences between male and female mentors. Female mentors tend to help mentees establish networks and support systems while male mentors often "focus on career functions in mentoring" (Schwiebert, Deck, Bradshaw, Scot \& Harper, 1999). I wanted to look at all aspects of mentoring. Women mentors as participants were more likely to perceive their roles in broader terms. While several studies on mentoring in business demonstrated remarkable differences in male and female mentors (Burke \& McKeen, 1996) there are few studies to show this in public education. Some studies report similar differences in cross-sex mentoring in higher education where the roles are more similar to business than in public education where typically mentors are not peers, but those with 
higher status (Burke \& McKeen, 1996). Mentoring goals in both business and higher education are linked to career advancement and higher pay (Burke \& McKeen, 1996). In public education the goals are not advancement but increased ability to perform the same job better. Some studies do show that women mentored by women gain greater benefits from the same-sex relationship, and same-sex mentoring relationships reduced the desire for distance to avoid romantic entanglement (Schwiebert, et al., 1999), but it is beyond the scope of this study to assess sex as a factor in mentoring. My choice of women mentors is to make the study more consistent and to hold extraneous variables more constant. Also, this selection of women mentors addressed the more typical mentoring situation in public education. Most public education mentors are women (FeimanNemser, 1996).

In order to hold extraneous variables constant, I chose to interview elementary mentors because they are less influenced by their identification with one particular subject area. According to Dr. Gerald Tirozzi, executive director of the National Association of Secondary School Principals, "Elementary teachers have a more general education background and work with students in the more formative years of their education. A high percentage of secondary teachers tend to be 'academicians' who tend to focus on their respective subjects as opposed to being more 'student centered."' (Lewis, 1999, p. 274). By selecting elementary teachers, I again tried to hold constant the variables of having mentors in different academic subjects that might influence their first perceptions of mentoring. The possibility of a secondary mentor and mentee combining classes and knowing each others' students is made difficult by the number of students each teacher sees each day (Berrill, 1995). 
There are also attitudinal differences between secondary and elementary teachers in regard to the role of in loco parentis each plays. Secondary teachers tend to back off from accepting this responsibility of being more than a "role model," or authority to students, whereas elementary teachers tend to see themselves in a parental position of taking on more needs of the students including feeding and clothing by referring students to social agencies (Conte, 2000). Stodolsky and Grossman (2000) found more relevant materials and activities to promote connections between students' backgrounds, ethnicity and their community in elementary schools than in secondary schools. They asserted that little research has explored how students' diversity intersects with concerns of subject matter in high schools ( Stodolsy \& Grossman, 2000). In a recent dissertation, Hanby of Miami University, Oxford, Ohio, recommended that future studies should examine the differences between elementary and secondary preparation programs in terms of mentoring needs (2000).

Because such obvious differences in focus, scheduling, and facilities, as well as attitude toward students and diversity exist between elementary and secondary teachers, my study attempted to limit those extraneous factors which might come into play by using both secondary and elementary teachers by focusing on only female, elementary teachers in rural or small city settings. 


\section{CHAPTER TWO}

\section{Review of the Literature}

In this chapter, I examined the literature related to different aspects of mentoring. First, I examine the etymology of the word "mentor." As I trace the history of the use of the word, a clearer picture of the connotations associated with the word emerges. I also review the literature related to mentoring and diversity as it relates to my conceptual framework of critical theory. Finally, I examined the studies that have been done on the three main areas of concern of this study, mentor training, administrative support for mentoring, and mentors' perceptions of what mentoring is and should be.

\section{Mentoring}

The word "mentor" itself is open to interpretation and has undergone an evolution since its inception. It is important to trace these changes to understand what is generally accepted in education today by this term. The connotation of the word itself has the potential to impact the self-perceptions of the mentors.

To the modern world, Mentor was recorded first as the name of the advisor to Telemachus, son of Odysseus in Homer's Odyssey, (trans. Bates, 1957) but it is difficult to ascertain if it was an original concept at the inception of the epic, or if it developed through the course of years based on events and people who lived after the origins of the Odyssey. It is certain that the idea of a mentor or advisor is well-rooted in Greek philosophy through the writings of Socrates, Plato, and Aristotle. All were teachers; all were mentors. Plato described in detail the Socratic method of study by his mentor, Socrates, in The Republic (trans. Freeman, 1949). Greek dramatists such as Sophocles described the downfall of heroes for not heeding the advice of their advisors, such as Creon in Antigone ( trans. O'Sheel, 1931)and Oedipus in Oedipus Rex (trans. Cook, 
1948). Aeschylus attributed Agamemnon's descent to ignoring his mentor Chryses. So the notion of a wise advisor critical to achieving success is integral to the Greek way of thinking for powerful or potentially powerful men.

While the first literary reference to Mentor, as guide-friend, is in the Odyssey we owe more of the modern interpretation of the word, which implies counselor or teacher, to a work of a $17^{\text {th }}$ century French clergyman. Francois de Slignac di La Mothe Fenelon, the Archbishop of Cambri, re-told the tale of the first four books of the Odyssey which describe Telemachus's emergence into a king (Davis, 1979). This book focused not so much on Telemachus, but on Mentor. He becomes the central force of instruction for the young prince. In Les Aventures de Telemaque (1699), Telemachus and Mentor travel on a psychological and physical journey of their own. This several volume piece of work was the most reprinted book of the eighteenth century and enjoyed enormous success in both Europe and the American colonies (Clark, 1984). One pamphlet declared a "Telemacomanie" as translation after translation followed well into the nineteenth century (Clark, 1984). The book was not only reprinted for the masses, but adapted into both an opera and a ballet. In fact, it is believed to be one of the ballets that inspired Abigail Adams during her unhappy residence in Paris (Levin, 1987). Adams first used the word as an adjective to describe an acquaintance in Familiar Letters (1875): " your venerable colleague, whose Mentor-like appearance." It is possible that Adams' idea and language had been influenced by her seeing either the opera or ballet based on Fenelon's work in Paris.

The books Les Adventures de Telemaque (1699) were written to impress the duties and responsibilities of kingship for Fenelon's young charge, the future king of 
France, making it a novel of instruction. Erziehungsroman is the term used to define this type of literature. Literally, it means erziehen (bring up, tutor), ziehen (draw,pull). Erziehungsroman, therefore, is a novel of instruction, even more than a novel of education (Clark, 1984). It assumes there is a wealth of wisdom to which a male mentor is privy, and he will undertake to impart this knowledge to his male charge. Hence, until the late $20^{\text {th }}$ century, "mentor" usually referred to an older male counselor giving advice and protection to a younger male person, although this view of a "mentor" was challenged by succeeding writers and philosophers in the 17th century such as Voltaire and Rousseau.

Because different societies and different times require different mentors, postFenelonian mentors came in many guises (Clark, 1984). In Rousseau's Emile, ou de l'education Emile's tutor acts as a Fenelonian mentor; however, because of Rousseau's belief in the freedom and social rights of the masses his mentor speaks, not to a future king, but to "everyman" (Clark, 1984). The idea of a "mentor" being all knowing began to change as the Enlightenment movement took hold of France and Europe. This cautionary type of literature is known as Bildungsroman, bildung (forming, creating) roman (novel) (Clark, 1984). The hero may be guided by an unreliable mentor, and experience becomes the teacher. Charles Dickens' heroes of Pip and David Copperfield are examples of this. In France, Honore de Balzac (1799-1850) demonstrated the most obvious type of this literature growing in post-Revolutionary France. In his Comedie Humaine (1834), he cannot conceive of education without a mentor, but his mentor only structures situations for his charge, supporting the belief that experience teaches best (Clark, 1984). He feels he must justify the mentor's authority, and he does this by 
crediting his wisdom to his own experiences. He knows that every mentor was once a student and that this experience justifies the present advice (Clark, 1984).

Throughout the 19th century, the idea of mentor took on various connotations, but the idea that a singular male advisor, someone older and wiser advising a younger male companion remained intact and rooted in paternalism and dependency (Darwin, 2000). In the latter part of the twentieth century, the word was incorporated first into the business realm to promote (as had been the tradition) white male leaders who would carry on the organization's mission. As the educational system began to model itself after the business world, the idea of mentoring teachers began to be explored. Thirty years ago, education did not subscribe to the notion of a need for mentoring for classroom teachers. Teachers were given books, rosters, keys and told in effect, "go forth and teach" (Chase, 1998).

But as social reform movements of the latter part of the 20th century influenced many aspects of equality in education (Title IX, American Disabilities Act) so did they change the concept of mentoring as exclusive to white males. The notion that mentoring was reserved as a relationship between an older male and younger male is no longer apparent in business ( Darwin, 2000). It never has been the case in teaching. Today, it is widely accepted that all new teachers need mentors in the schools. Both NEA and AFT support mentoring programs (Pathwise, 1995). But, the concept of what mentoring should be is widely interpreted. Progressive ideas of the modern society have influenced the new definition of mentor. No longer does age have a bearing on the choice of a mentor. Experience has become the criterion. Mentoring has become a process viewed as interdependent, mutual, and dynamic. 
The idea of mutuality in learning seems to be widely accepted as the objective of a mentor-mentee relationship, especially in the public school setting. In a project conducted by the Texas Center for Reading and Language Arts, pre-service teachers and their mentors/ cooperating teachers, in this instance one and the same, were interviewed to enable them to share their views of the mentoring situation. Jessica, a student teacher described various relations she negotiated with her mentor. She portrayed herself as both a colleague and a student. She seemed to want a relationship in which she could find guidance, mutual learning, and friendship:

I have felt like a student because [Mary] is teaching me so many things and so sometimes we're in that role. But it's not me sitting on the other side of the desk. I'm kind of like sitting beside her being a student. And, I have felt like we're colleagues when we share...we were able to feed off each other. It wasn't so much me learning, I mean I was learning, we were learning from each other (Fairbanks, 2000).

Grace, a mentor, in the same study, compared her relationship with her mentee to that of learning to dance with a new partner:

I have difficulty in adjusting to the rhythm and music of a new partner. When Wynne glided into my classroom, I had to learn new dance steps. I had become comfortable with my solo performances. Having a partner changed the music and the cadence of the class. When do I lead and when do I follow are the questions that I had as Wynne and I began the process of learning to dance together (Fairbanks,Freidman, \& Kalm, 2000). 
Good mentors are persistent in their own search for better answers and more effective solutions to educational problems. They model commitment for their mentees through a desire for professional development activities (Rowley, 1999). Mentors, therefore, need to be provided with training and knowledge for mentoring and for continuing education (Salzman, 2000).

Mentoring supports what is currently known about learning. According to constructivist theory, learning is most effective when situated in a context in which new knowledge and skills are tested so that the individual constructs meaning for herself or himself through interaction with others (Kerka, 1997). The basic idea that a novice can gain in some way from the influence of a veteran remains intact. What has changed is now the perception that a veteran may also gain professionally from a mentoring relationship. This mutual learning and enhancement of skills is one of the goals of the modern mentoring program in education (Field, 1994). How mentors view themselves as enhancing teaching quality and increasing student learning may reveal if mentoring is reaching this goal.

\section{Mentoring, diversity, and reform}

Much of the literature on mentoring is descriptive with little analysis or theory applied to the studies. Many studies examine the management of mentoring, but few examine the intricacies of mentoring relationships or the effects of mentoring on student learning or educational reform (Hawkey, 1997). Functionalist models of mentoring dominate the studies (Darwin, 2000). Taken-for-granted practices and unchallenged assumptions in training and supporting mentors need to be critically examined. The traditional view of the older and wiser sage handing down knowledge to the protégé in a 
hierarchical relationship as a means of reproducing social norms and maintaining the status quo seems out of alignment with current reforms in education and the move toward a more democratic school environment. "Site-based management," "teams," "cooperative learning," and "empowerment" are just some of the language that suggest a move toward a cooperative and horizontal organizational framework in education. The Praxis III has evidence that a recognition of the need to address traditionally marginalized students is imperative in good teaching (Pathwise Orientation Guide, 1995), and National Council for Accreditation of Teacher Education (NCATE) evaluates teacher preparation institutions in terms of how well they prepare future teachers for diverse students by examining the curriculum and field experiences which allow candidates to gain understanding and experience with diverse populations of students, colleagues, and professors (NCATE Program Standards, 2000).

Additionally, we are at the beginning of a new era in teaching in the United States when students are more diverse, and historically marginalized social groups have more influence in the educational process. An increasing number of students are classified as "at risk" because of their inability to benefit from the types of opportunities traditionally offered by school systems (Cline \& Necochea, 1997). Children who see no relationship between the school and their own world are likely to see school as devoid of personal meaning and relevance (Villegas \& Lucus, 2002). Schools which conduct "business as usual" in the face of these changes in student populace and attitude fail to address the needs of all students and, as a result, become schools "at risk." The resistance of schools to change in light of the demographic shifts toward increasingly low-income and minority students has resulted in a corresponding increase in the perception of educational failure 
(Cline \& Necochea, 1997). Some states are imposing monetary sanctions on these schools (Ohio State Department of Education Standards, 2001). All teachers need to develop new strategies for inclusiveness and to learn from one another how to best meet the challenges and changes in the nature of teaching.

Teaching successfully in a diverse society includes a recognition that while middle-class, Euro-centered values dominate in society and schools, this status derives not from inherent superiority or moral attributes, but from historic hegemony of the dominant groups (Nieto, 1996). Teachers who validate all students and a plurality of thinking, talking, behaving, and learning shape their students' attitudes and raise the expectations of learning (Villegas \& Lucus, 2002). These teachers can become change agents in the schools. If teacher mentors believe that schools can change, and the proof is in the slow progress to more equitable institutions over time (e.g. more female administrators, English as a Second Language (ESL) classes, critical pedagogy taught in teacher preparation programs) they may pass this belief to new teachers. Teachers can prepare the mentee to become change agents by introducing them to the obstacles in the system and providing evidence that schools can become more equitable (Villegas \& Lucus, 2002). Moir and Gless (2001) argued that new teachers must be supported in taking responsibility for both the classroom and the greater educational community. They believe that induction-year mentoring programs have the potential to become one of the most powerful forces for educational change and professional renewal in education today.

Cline and Necochea (1997) were not as optimistic. They see an apparent contradiction between the demands of school reform and those of mentoring. Sustained systematic change will take an in-depth analysis and examination of mentoring for its 
impact on educational reform and restructuring of our educational system. While they, too, see the "potential" for mentoring to become a "driving force in socializing the transformational leaders being sought by calls for reform" (Cline \& Necochea, 1997, p. 147) they also perceive a trend toward conformity and the perpetuation of the status quo in current mentoring practice. In contrast, a study of 77 first-year teachers by the University of Illinois at Urbana-Champaign in a Novice Teacher Support Project (NTSP) revealed the importance of recognizing the role of novice teaches in the process of change leading to reform (Chubbuck, Clift, Allard \& Quinn, 2001). While transformative practice may not be a goal of most mentoring programs, the possibility for change exists within the program because the ability to affect new teachers is inherent in the program and new teachers can effect change that can benefit all students.

School administrators, especially principals, on the other hand, are in a pivotal position to help meet the needs of all students by influencing instructional practices and modifying organizational structures to build skills and knowledge to effectively address diversity and inequitable practices (Ganser, 2001; Janas, 1996). By critically looking at the present mentoring practices as they are experienced and perceived by mentors trained in different programs and supported by administrators to different extents and in different ways, an assessment of what works toward these ends and what negates them can be articulated.

Mentoring is a process that has the potential to place the social justice issue in the forefront of discussions of equity in education. Mentoring can become a "collaborative, dynamic, and creative partnership of coequals, founded on openness" (Darwin, 2000). It can switch from an historically accepted authoritarian mode of roles of parent/child to a 
more equitable relationship which is adult/adult and interdependent. While new teachers greatly benefit from an effective mentor, mentors also develop new insights into their own teaching and renew their enthusiasm and commitment to their profession through mentoring (Hargreaves \& Fullan, 2000). Induction year mentoring can serve as an "engine to drive educational reform" and "capitalize on [mentors'] wisdom and expertise" (Moir \& Gless, 2001). It allows the veteran teacher to observe different teaching situations and to reflect upon their own teaching. Mentoring provides points of intersection where the mentor and mentee can learn together, collaborate, and become catalysts for change in providing high quality and equitable instruction for all students (Moir \& Gless, 2001).

\section{Mentor training}

Recent large-scale research demonstrates that teacher preparation and ability influence student achievement more than any other school factor (Greenwald, Hedges \& Laine, 1996). Important in mentoring, then, is educating a mentor in a training program that encourages a cooperative relationship between mentor and mentee and focuses on developing an opportunity to enhance teacher preparation to increase innovative teaching practices to benefit all students. A positive induction experience that involves systematic contact with mentee with the intention of engaging the new teacher in collegial conversation and professional activities can have a positive impact on the school as a whole (Hope, 1999). Unfortunately, a recent study with interviews of beginning special education teachers in South Carolina revealed that most of the assistance provided to the first year teachers by mentors concentrated only on the mechanics of the job rather than on actual classroom teaching (Whitaker, 2000). 
No widely accepted criteria for assessing the results of the varied mentor training programs currently exist. One study in Ohio included interviews with 27 Pathwisetrained mentors $(12,000$ Ohio teachers have received this two day training) three weeks after training and after one observation to determine their thoughts about the contribution of the training to their ability to mentor an induction year teacher (Salzman, 2000). While most of the teachers felt they had successfully learned the Pathwise criteria, most still felt unsure of their preparedness to actually help a first year teacher become successful in the classroom (Salzman, 2000).

With this in mind, the training that mentors receive becomes an issue in how the mentors see their roles. Whitaker (2000) also concluded that mentors needed more information and more guidelines as to the form and content perceived as most effective in mentoring for student learning to maximize the impact of the mentoring process. One of the keys to a successful mentoring program, then, is most likely the training and the support for that training from administrators (Mills, Moore, \& Keane, 2001). According to McKenna (1998), the principal of Dean Street School in Woodstock, Illinois, training should include peer observation, characteristics of successful teaching, sensitivity to new teachers' wishes, effective communication and conferencing skills, and data collection.

In a Michigan study, 550 interviewed mentors reported that their training involved sessions on emotional support, communication skills, and school culture and politics (Mills, Moor, \& Keane, 2001). Other studies echo the call for inclusion of these desired skills in a mentor-training program as well as listening techniques, coaching, and conflict resolution (Ganser, 2001; Janas, 1996). However, Hargreaves and Fullan (2000) worried that the drive to standardize teaching loses sight of the emotional dimension that makes 
teaching great. They contended that mentorship involves more than guiding new teachers through learning standards and skills. It extends to providing strong and continuous emotional support (Hargreaves \& Fullan, 2000). While most of the literature on teacher mentors recommends training (Chase, 1998; Darling-Hammond, 1996; Field, 1994; Mills, Moor, \& Keane, 2001), there is conflicting and varied opinion on what a teachermentor training program should include. Most agree though, that it should not be a one shot inservice, but a continuous instruction, sharing, and support that extends over several years (Feiman-Nesmser, 1996; McKenna, 1998; Mills, Moor, \& Keane, 2001).

Supporting new teachers is demanding and complex work. It involves learning skills other than those teachers learned during their own teacher preparation courses. Exactly what those skills should be is debated in most of the literature, but the outlines of mentoring training are primarily prescriptive and functional (Darling-Hammond, 1996; Ganser, 2001; Moir \& Gless, 2001; Salzman, 2000). This study examined in detail what three of these programs involve and how they are perceived by nine teacher mentors who received that training.

\section{Principal support of mentoring}

If principals are no longer the main source of information and support for new teachers, they may believe they play a small role in the induction process. Nothing could be farther from the truth (Stansbury, 2001). Principals remain key individuals as instructional leaders, initiators of change, problem solvers and stewards of the induction year (Shen, 2001). The Effective Schools Movement identified the principal as the cornerstone for change and innovation at the school site (Cline \& Necochea, 1997). First-year teachers still identified the school principal as their key source of support and 
guidance (Brock \& Grady, 1998). In a study of 809 public school teachers using openended questionnaires to describe the characteristics of the principals who influenced their classroom instruction, those who promoted professional growth through integrated collaboration, peer coaching, inquiry, and reflective discussion to promote professional dialogue were described as some of the most influential (Blasé, 2001). The principal who selects and supports the mentor-training program, then, becomes an important part of the equation for successful mentorship programs.

Principals can play a pivotal role in all steps of the mentoring process. In fact, principals often "play a make-or-break" role in the success of teacher mentoring programs in that successful mentoring requires full administrative support and an ability to match mentors and protégés (Monsour, 2000). First-year teachers are often given the most difficult teaching assignments (larger classes, more preparations, "at risk" students) and the most challenging duties (Darling-Hammond, 1996). First-year teachers are not given the luxury of "easing into" their jobs. The public has high expectations for firstyear teachers to perform at the level of a veteran teacher (Johnson, 2001). While teachermentor training programs are important in allowing mentor teachers to feel prepared to help a first-year teacher, initial and on-going administrative support during the mentoring is also of vital importance to the success of the induction-year program.

One of the first steps in building a support structure is to create an environment to provide one-on-one time for observation, modeling, and reflection for both participants (Janas, 1996). Making physical and logistical arrangements for a successful mentoring relationship and clearly defining the roles in assessment and monitoring is an important job of the principal in contributing to the success of a mentoring program (Janas, 1996). 
Too often new teachers are assigned difficult students and several preparations as well as many extra-curricular responsibilities (Hope, 1999). Many new teachers enter their assigned rooms to find that other teachers have descended upon it during the summer and removed materials, leaving a barren classroom to begin the year ( Hanby, 2000). A principal interested in the success of a first year teacher will guard against these factors that lead to a feeling of being overwhelmed and isolated. Principals also need to be aware that the summative assessment tool used to evaluate a new teacher should be reflective of the formative evaluation tool and the coaching that the mentee receives from his or her mentor (Hope, 1999). One of the most important roles principals have in supporting a teacher mentoring program is to provide a link between the mentoring pairs and other professionals in the district (Hope, 1999). If a principal fails to support the mentoring process, new teachers may turn to other means of support within the school which may or may not be positive in creating an equitable and valuable learning environment for all students.

Physical and logistic support structures are vital for a mentoring program that would address the needs of first-year teachers (Janas, 1996). Principals can support first year teachers in an induction-year program by reducing responsibility for the first year in terms of class size and preparation assignments. The principal can also moderate the new teacher's enthusiasm for volunteering for additional responsibilities by stressing the importance of classroom teaching (Stansbury, 2001).

Time is the most precious resource in schools today, and there are many competing demands for a new teacher's time. The principal can have some control over these demands by facilitating both meeting and observation times for mentors and 
induction-year teachers (Stansbury, 2001). The principal should find ways for mentors and mentees to see each other teaching. They can schedule both teachers in close proximity to one another and create reflection conference time during assemblies, or by using rotating substitutes or common preparation times (Stansbury, 2001). Even insuring common lunch times will facilitate regular and informal discussion. Without regular, daily contact, the possible benefits of a mentor program are compromised (Ganser, 2001).

A system of monitoring the mentoring process, itself, must be built into the program to provide opportunities for more guidance and program assessment (Janas, 1996). Principals are more likely to be supportive of mentoring and less likely to subconsciously undermine it if they are included in mentor training and understand the program's impact not only on mentors and mentees, but on the whole school community and on learning (Ganser, 2001). It becomes the responsibility of the principal to inform the school community of the benefits of mentoring and how it fits in with other forms of professional development (Ganser, 2001).

The success of beginning teachers is critical to student success and both successes are the responsibility of the principal (Brock, 1999). Shaping the minds and behavior of young people is the primary purpose of schools, and achieving those purposes is the central responsibility of administrators (Haller \& Kleine, 2001). Haller and Kleine (2001) defined the practice of school administrating as "consisting of deliberately establishing, maintaining, and changing programs that have prescribed effects on learners" (p.12). With the creation of a mentoring program, the role of the principal has switched from direct to indirect support, but that does not diminish the importance of the support that is needed. Principals can increase the effectiveness of the mentoring programs in their 
schools (Stansbury, 2001). It is the principal who can critically examine the needs of the induction-year teacher, the goals of the educational program, and then make appropriate decisions about selecting and implementing induction-year programs.

\section{Mentors' perceptions of mentoring}

In 1996, 28 states required districts to have a mentoring program in place as part of the induction-year program, five were revising their mentoring program and eight more states were in the process of implementing such plans (Feiman-Nemser, 1996). This induction-year push is part of a national effort to "improve the quality of teaching and learning in schools by focusing on the recruitment, preparation, induction, and renewal of teachers" (Darling-Hammond, 1997). While this national initiative supports mentoring in an induction-year program, very little empirical literature exists that examines the perceptions of mentors about their training, administrative support, and their role.

One such study conducted in Great Britain in 1993, revealed varied conceptions of mentors about their roles (Williams, 1993). The mentors described themselves as advisors, leaders, guides, role models, supervisors, tutors, and facilitators (Williams, 1993). Other literature has mentors describing themselves as models, teachers, coaches and protectors (McKenna, 1998). An implication of using the term guide could be that mentors see themselves as "guiding" the novice to the "right" methods. A 1992 British study concluded that there was a "diversity of perceptions" (p.176) of mentors on their roles (Elliott \& Calderhead, 1992). Mentors seem destined to be all things to all mentees. Similar confusion was experienced by a mentor in a study in Ohio who said, "There is so much uncertainty about what being a mentor would entail" (Salzman, 2000). 
Sometimes the expectations of the building administrator can contribute to the confusion about what a mentor understands about her role. In a study in which principals were asked about their expectations of first-year teachers, much variance was discovered among the participants in various areas. One area of greatest variance had to do with the training programs of mentors assigned to the first-year teachers (Brock \& Grady, 1998). While $29 \%$ of the 56 principals surveyed had formal training for mentors in their programs, (which leaves $71 \%$ of the mentor programs with no formal training) none had had formal training in selecting mentors themselves or assessing mentor training programs.

More recently, Ganser (1998) surveyed 124 mentor-teachers in Wisconsin asking them to describe their experiences in metaphors. This study showed the same variance, and even confusion, in perceptions. While one mentor described the experience as a "breath of fresh air," more commonly, mentors described the experiences as "entering a contest and never finding out if you had won the prize," or "playing Russian roulette." Another likened the experience to "fixing an old car with no parts." Ganser (1998) concluded that the metaphors reflect uncertainty about their roles and the support or lack of support and resources for mentoring. Lacking opportunities for shared experience, mentors limit their support to workroom conversations and functionality (Rowley, 1999). It indicates that the training these mentors received and the support from the administration did not clarify the roles for them. The most common metaphors for the entire group concentrated on interpersonal relationships rather than professional concerns. Ganser (1998) suggested that mentoring, which is a very different role from 
classroom teaching, warrants special preparation beyond the brief workshops or one-time graduate courses common for training mentors.

The most problematic role for mentors that the literature explored was that of assessor. While mentoring is usually viewed as separate from evaluation, the Pathwise mentoring program is designed to "coach" new teachers for licensure evaluations. Part of the coaching process is evaluative in assessing how well the mentee meets the 19 criteria required to pass the Praxis III. Additionally, most mentors believe that observation implies evaluation (Jones, 2000). The creation of a power differential can seriously interfere with the relationship of trust and confidentiality (Evertson, \& Smithey, 2001). A study in Germany and England revealed that the use of a mentor as an assessor not only had a detrimental effect on the relationship of the mentor and mentee, but restricted the mentees in developing their own style and creativity (Evertson \& Smithey, 2001). One mentee in the University of Illinois at Urbana-Champaign Novice Teacher Support Project reported, "I do feel a little paranoia about what they [mentor] think of me and my teaching style" (Chubbuck et al., 2001, p. 375).

Being a good classroom teacher of children does not ensure that a teacher is a good mentor for an adult peer. Few teachers have had training in peer observation, coaching, or communication skills (Salzman, 2000). A clinical supervisor who does the same job for a teacher education institute has usually had extensive education in data collection, interviewing, goal setting, journaling effectiveness, and modeling techniques (Sergiovanni \& Starratt, 1993). The literature reveals a lack of consistency in the expectations of and definition of good mentoring practice. 
Most mentoring programs are not supported with monetary rewards for mentoring. While mentors generally do this important work without compensation, an investigation into the relationship between compensation and commitment needs to be undertaken (Rowley, 1999). Programs that provide stipends and compensation in time, make important statements about the value of the work and its significance in the school community (Rowley, 1999). This may have an impact on how teachers view their value and obligations as mentors.

One of the few meta-analyses of mentoring literature was a 12 year study done in 1994 by The Mentoring Leadership and Resource Network (MLRN), an affiliate of the Association for Supervision and Curriculum Development (ASCD), which "contributes to the international mentoring initiative by supporting mentors, local and state/provincial mentoring programs, and the leaders and policy makers who design and administer programs" (Sweeny, 1994). The report found some basic assumptions about mentoring and mentoring programs repeated in most studies. Some of the most conclusive were that all participants gained from the experience, but that many mentor programs do not achieve their potential because they lack a conceptual base. Without a conceptual base, the role of the mentor is not well defined and mentors don't know the expectations for the interaction with their proteges (Sweeny, 1994). Some contributing factors to perceived success of a mentoring relationship were as follows: selected mentors, similar job assignments, close proximity, common planning times, age differences of $5+$ years, reduced loads for both partners, stipends and substitutes for released time, and recognition. Some drawbacks that studies sited were undefined goals and conflicting roles of mentor as assessor (Sweeny, 1994). 
While there is widespread support in education and in the political arena for induction-year mentoring, according to Feidman-Nemser (2001), "we still know relatively little about what thoughtful mentors do and how they think about their work," (p.17). There is a need to examine these thoughts and to establish some criteria for looking at mentor training and its influence on mentor perceptions. One way in which to begin to understand what is perceived as helpful by the experienced teacher is to examine the perceptions of induction-year mentors as to if and how their training and support from their administrators contributed to their readiness and effectiveness as mentors. 


\section{CHAPTER THREE}

\section{Methods}

Chapter three describes the research procedures that were used for this study. Included in this section are the discussion of the research design, participant selection, data collection procedures, analysis of the data, and validity and reliability considerations.

Research Design

This study is basic research aimed at "generating fundamental knowledge and theoretical understanding" (Johnson \& Christensen, 2000, p.6) of a human experience. It is a phenomenological case study, heuristic in nature, to help add to the knowledge of the phenomenon of induction-year mentoring. As a qualitative study, it is naturalistic, inductive, personal, and context sensitive ( Bogdan \& Biklen, 1998; Johnson \& Christensen, 2000; Merriam, 1991). The qualitative data I collected shows multiple meanings and realities of a human experience. The purpose of this type of study was to obtain a personal view of a phenomenon from active participants in the phenomenon, and to allow those participants to voice their own understanding of the reality of the situation (Locke, Spirduso \& Silverman, 2000). The phenomenon I studied is the mentoring process, influenced by different training programs and administrative support, from the trained and experienced mentors' points of view.

While qualitative research designs can intersect (Creswell, 2000), this was primarily a "multi-site, multi-case" study (Bogdan \& Biklen, 1998, p.63) or "collective case study" (Johnson \& Christensen, 2000). According to Patton (1990), "Case analysis involves organizing the data by specific cases for in-depth study. Cases can be 
individuals, programs, institutions, or groups" (p.384). The "layered-case study" (Patton, 1990), a type of collective case study, is one in which a single program may be studied using several participants. This is a two-layered case study. One layer was the individual cases of each mentor and the second layer was the case study of each of the three states' mentor-training programs. While each case stood alone holistically, each was then compared and contrasted in a case study of the program. In my study, the issue was the ways in which specific types of mentor-training programs and support by administrators were seen by participants as influencing their perceptions of their experiences as mentors. While this type of study cannot be directly generalized to a larger population of teachers, phenomenologists generally assume that there is some commonality in human experiences. This commonality of experience is "essence," an essential characteristic of an experience, (Johnson \& Christensen, 2000) which may be present in particular instances of the phenomenon. The expectation of this study was that the phenomenon of mentoring and mentor training experienced by the participants was related in some ways through a wide array of social, political, and personal contexts (Stake, 1995).

\section{Selection of Participants}

Johnson and Christensen recommend using "In-depth interviews with up to 10 people" (2000, p. 314) for a phenomenological study. I used nine participants from three sites and three participants in each state of Ohio, West Virginia, and Pennsylvania because each state represents a different type of training for mentor teachers. I selected the participants purposefully (Johnson \& Christensen, 2000) using a fairly homogeneous sample for intensive study. All participants were female elementary teachers who have had the mentor training program provided by their state or school district. They had been 
teaching for at least 15 years and mentoring for at least two years. All were teaching in small cities (below 50,000) or rural schools. I hoped to minimize the other influences that might have been a factor in how they see themselves as mentors (such as sex, elementary vs. secondary, urban vs. rural, geographic discrepancies, etc.) by using this seemingly homogenous group.

Teachers were selected for this study in the following manner. All teachers were willing volunteers. I asked two colleges of education, one in Ohio and one in West Virginia, who place students in at least two of the three states, for the names of elementary schools where they placed student teachers. This helped to ensure that the schools were ones with which colleges had had successful access and rapport. I felt that these schools would be more willing to participate in a study because of their relationship with higher education institutions, and each was very cooperative. I selected two schools in at least two different districts in each state. I asked the principal of each school to recommend a mentor teacher whom they thought would be a willing participant. In this way, I hoped to get mentors, perceived as successful at mentoring by administrators, who willingly filled the role of mentor. A limitation of this was that the principals may have handpicked mentors who already adhered to the principals' own philosophies of education (more typically reproductive) and the study would not include "maverick" teachers who saw themselves as change agents. Since one of my research questions was to determine if mentoring as influenced by their training in these cases was primarily reproductive or transformative, I needed to include some mentors who may have had a different perception of their role initially. One of the abilities of qualitative research is to deliberately seek "outliers" discounted in quantitative studies to allow deviant cases to 
illuminate subtle, but important differences of the exceptions (Barbour, 2001). In the first meetings with only the first mentor teacher I contacted in each state, I asked them to refer a mentor teacher who met the study's criteria, but who would "see and do things differently than you in the mentoring process" to get an alternative-case sampling, as well.

This worked well in both Ohio and West Virginia. In Ohio, I selected the "maverick" mentor from the same district as recommended by the first mentor and in West Virginia the maverick selected was from a different district as recommended by the first mentor. In both states all three mentors readily agreed to participate in the study. In Pennsylvania, the first contacted mentor recommended two, not one, other teachers in the same district and required that I meet them as a group to explain the study further. She would not select just one other mentor because they were all teaching in the same building and she would not agree to meet without both. Upon meeting with them and explaining the study, two of the mentors, including the first principal-recommended mentor and one of the mavericks she had suggested, pulled out. They explained that they did not have time to devote to the interview process. The remaining maverick mentor agreed to continue. Before committing to the study, I then asked the principal if she would also recommend this remaining mentor for the study as well as her first choice mentor. Her reaction was that both were good teachers and fine mentors, and that she could not see any differences in them. She had recommended the first because it was the first name that had come to mind. I then asked the remaining mentor to recommend another mentor who saw and did things differently than she, and she recommended a teacher in her own district. This teacher agreed to participate in the study. 
In Pennsylvania, then, I had a slightly different situation, a supposed maverick recommending a more traditional mentor. Because I was looking for differences in mentoring perceptions and the ability to interpret what was meant by "seeing and doing mentoring differently" was subjective in itself, I felt comfortable with the one principalrecommended, teacher-recommended mentor and one maverick or traditional mentor suggested by her from the same district and a third principal-selected mentor from another district. After all, rather than aspiring to representativeness, I had selected mentors to represent diversity in a given seemingly homogenous group (Barbour, 2001) and this met my initial requirements of the study. All mentors were female, elementarycertified teachers, who had been teaching for 15 years or longer and had mentored for at least two years, most of them much longer. Three mentors, one in each state, were not principal recommended.

I assured each participating mentor of the confidentiality of their identities. States are named because that is how I distinguish the mentor training programs, but individual schools and districts are designated by the state and a pseudonym with a general description of the demographics of the school. Teachers are described but given pseudonyms.

\section{Data Collection}

According to resources on qualitative research, the best way to study a phenomenon is through interviewing (Johnson \& Christensen, 2000). To gain subjective understanding of a phenomenon it is necessary to examine the phenomenon through the words of the participant. I used interviewing as the primary method of data collection. eidman (1991) recommended that a three-interview structure be used in such studies to 
adequately uncover the participants' meaning (1991). I followed that recommended procedure in that each participant was interviewed in her school for 60 and 90 minutes on three different occasions separated by a three-day to one-week time span. This allowed time for the participant to "mull over the preceding interview, but not enough time to lose the connection between the two" (Seidman, 1991, p.14). Each of the three interviews had a specific purpose. While an interview guide was used, as Seidman suggested, most of the questions during the interviews followed from what the participant said (Seidman, 1991, p.69). The purpose of the first interview was to build rapport and have the participants talk about themselves and their relationship to the situation and setting. It also allowed them to talk about general perceptions of education, teaching, and mentoring to get a feel for their general philosophies. The second interview asked them in-depth questions about training and administrative support. It also asked them to reconstruct typical experiences in the phenomenon of mentoring. Spradley (1979) called this type of questioning the grand tour for each question has them retrace in detail a typical day or event. Finally, the third interview encouraged them to reflect on the meaning of the experiences (Seidman, 1991). By using the three in-depth interviews, spaced by time, more detailed and rich data emerged. An interview between 60 and 90 minutes provided enough time to allow comfort for the participants to open up and make them feel as if they were being taken seriously. It was a short enough period of time that the interview did not unravel or the participants lose interest (Seidman, 1991). Most interviews approximated 60 minutes with a few running over to 90 and one cut short to 45 minutes because of her scheduled appointment following our interview. It was typical that the first 
and second interviews ran almost 70-90 minutes and the third was shorter because the mentors had thought through their perceptions and were more articulate.

The format of the interview used the "Interview Guide" approach (Johnson \& Christensen, 2000). While topics and issues to be covered were specified in advance, during the course of the interview I sequenced and modified questions to allow the interviewee to expound on those issues that she felt were important. While open-ended, this gave structure to the interview and provided some consistency from interview to interview (Johnson \& Christensen, 2000). During the interviewing the prepared guide helped me stay on track. It would have been easy without it to fall into conversations that were enjoyable to the mentor and me but were not related to the issues I really wanted to understand. I felt that I gave each participant a chance to really expound on topics of interest, but I was able to bring the interview back to the intended purpose.

Each interview was audio-taped and then transcribed verbatim. Each tape was dated, and each tape contained the coded identification of the mentor and place of the interview. Field notes were added to the transcript. All notes and tapes were stored together for easy retrieval during the writing of the study to check accuracy. Because some of the interruptions in a typical school setting during the interview (such as bells ringing, P.A. announcements, students, other teachers running the copier) parts of tapes were unintelligible and required many reviews to understand some responses. I had a colleague recheck and listen to any questionable parts of the tapes to insure I had accurately transcribed their responses. Still some are words were not retrievable. I did not use any data that I could not fully understand. This was very little of the 
approximately 40 hours of interview tapes. I believe that I have accurately recorded and transcribed the mentors perceptions in their own words.

In addition to interviewing participants, I observed in two states' typical mentortraining session. I attended both a district and a state mentor training session in West Virginia and a mentor (Pathwise Plus) and an evaluator (Praxis III) training session in Ohio. I could not attend any Pennsylvania mentor-training sessions because they did not exist. Neither Pennsylvania district conducted training for mentors. This will be more fully explained in my findings. My observations of the training provided insight into the perceptions of the mentors about their training. In both states it offered the opportunity for triangulation or "crystallization" (Barbour, 2001, p. 1116) because it collaborated different data from different sources through multiple methods.

Qualitative research designs frequently involve collection of data from different sources and methods for the purpose of triangulation (Locke, Spirduso, \& Silverman, 2000). Triangulation conveys the idea that "to establish a fact you need more than one source of information. Basically, many sources of data [are] better in a study than a single source because multiple sources lead to a fuller understanding of the phenomenon" (Bogdan \& Biklen, 1998). Johnson and Christensen (2000) refered to this as data triangulation and stated that even the use of more than one interview is an example of data triangulation. A similar study at Miami University looking just at Pathwise mentoring used interviews, journals, and observations of three seminars of Pathwise training as a means of triangulation (Hanby, 2000). I also used secondary data in the form of official documents on the states' mentoring programs, local school or district guides for mentors, and field notes from interviewing the mentors and observing school 
context. By using interviewing, observation, and document analysis, one approach helped to compensate for the possible weakness of another approach (Patton, 1990).

I began this study in October 2001, near the beginning of the school year for the mentors and concluded it during January 2002. As with all qualitative studies, the timeline was dependent upon the availability of the participants and the quantity and quality of the data. Data saturation, commonly associated with grounded theory, in which the theorist has finished collecting and analyzing the theoretical data when "no new concepts are emerging from the data" (Johnson \& Christensen, 2000, p, 336) was not a part of this phenomenological study. I left the field when I felt I had "accomplished what I set out to do" ( Bogdan \& Biklen, 1998) and concluded the collection of data. After the 27 initial interviews, I only went back into the field with one mentor to clarify some of her perceptions for myself, and to check that I had interpreted what she had said correctly. This was during my coding and analysis. She had talked in contradictory terms about union participation and I wanted to be clear about her feelings. As it turned out, she did have conflicting feelings about the role of the union in political change.

I used the 27 interviews and field notes, one follow up interview, training session observations, and public document data. I also started a list-serve and gave each participant the address and posted questions; however, none of the participants used the list-serve. Most reported not using the Internet much at all and lack of access, technical know-how, or interest in not using the list-serve. One who used technology frequently reported she just didn't have time to use the list-serve. Most, however, reported that they rarely used technology outside the requirements of the classroom. These were all teachers near retirement who did not have extensive professional experience with technology, nor 
offices with computers, nor time in the classroom to correspond. Many did not use their computer at home to do any more than word processing. The interviews and phone calls were our primary ways of communicating.

\section{Analysis of Data}

Data collection and analysis were simultaneous processes in this qualitative research (Merriam, 1988). During and after data collection, the data were analyzed inductively by emic coding (terms used by the participants themselves) (Johnson \& Christensen, 2000). Code words and phrases were applied to the questions of the study. Inductive analysis meant that the themes and patterns of the analysis came from the data themselves rather than from categories selected prior to collection and imposed then on the data (Patton, 1990). However, I did develop a priori codes based on the research questions to initially sort out relevant data related to my questions.

New questions that arose during the research process were included in the analysis. I used Computer Assisted Qualitative Data Analysis Software (CAQDAS), in the form of the Non-numerical Unstructured Data by Indexing, Searching, and Theorizing (Nud*Ist) software for qualitative analysis for several reasons. First, it was sequential and linear in structure that was easier for me as a novice to use. It is also primarily verbal, rather than pictorial or spatial, as are other similar software packages such as Atlas/ti (Barry, 1998). Nud*Ist also has searching options which can separate and categorize data many different dimensions (Barry, 1998). Because this was a multi-site study, the ability to sort information and in many different ways was advantageous. Nud*Ist is recommended for this kind of more complex structured case analysis (Barry, 1998). 
Even with the sophisticated help of Nud*Ist, the construction of the categories was ultimately my responsibility as a researcher. The coding was partially done during data collection based on the research questions and then finished after collection as coding patterns emerged from the data itself. Patton (1990) recommended judging the classification on two criteria: 1) internal homogeneity or the extent to which the data belong in the category, and 2) external heterogeneity or the extent to which the categories are clearly differentiated. It was part of my job to verify the meaningfulness of the classification system by continually going from data to classification. Ultimately, the total experience resulted in an analysis of relationships and patterns that revealed meaning about the phenomenon under study, in this case induction-year mentoring as experienced by the participants (Patton, 1990). I created both free nodes and cooccurring nodes that could handle overlapping codes. In this way I was able to compare the data on an individual case-by-case basis and to look at the data to compare some codes state-by-state. This ability was important in making sense of the data in light of the research questions that asked about the differences between the three state programs and training.

\section{Validity and Reliability}

An inherent weakness in qualitative research, in the traditional sense, is that of reliability or reproducibility of study results. Qualitative researchers define reliability differently than do quantitative researchers. Because human behavior is not static and people's perceptions of a phenomenon can change as their world changes from day to day, the reproduction of any qualitative study is not a way to measure the "truth" of the results. According to Merriam (1995), "repeated measurements and observations can be 
repeatedly wrong"(p. 55). Qualitative researchers are not seeking to establish laws but to understand a phenomenon from the perspectives of those experiencing it (Merriam, 1995). Instead of reliability, in the traditional sense, qualitative studies seek to establish consistency and dependability. The results of a study should be consistent with the data collected (Merriam, 1995). In qualitative research, reliability concerns the accuracy and comprehensiveness of the data rather than the literal consistency across different observations (Bogdan \& Biklen, 1998).

Reliability was addressed in my study by reporting fully, seeking feedback from peers, and seeking feedback from the participants. I asked the participants to check the transcripts for verification (Wolcott, 1990). Some of the latest qualitative research information has suggested that researchers have "participants read and even alter the text" in an attempt to portray participants as they see themselves (Bogdan \& Biklen, 1998, p. 192). Johnson and Christensen (2000) defined participant feedback as "interpreting the conclusions with the actual participants...for verification and insight" (p. 208). There is a move toward viewing the researcher and participant as partners in the study (Bogdan \& Biklen, 1998). While participants may want to alter the script to put on a good face, Johnson and Christensen (2000) advocated the use of participant feedback because "useful information is often obtained and inaccuracies are often identified" (p. 210). Only one of my participants wanted to participate in the verification phase. Most felt that because the transcripts were verbatim written reports from the recorded interviews that it would be redundant and time-consuming. One of the participants agreed to review the transcript and she was satisfied with the general context, but expressed dismay at her use of "you knows" and her inability to completely finish a thought in 
some of the transcripts. She did verify that the overall response was what had taken place during the interview. I did not always like looking at my exact words transcribed into writing. During the interviewing I didn’t notice my “quirks” such as continually saying "okay" as a transition, but it was glaringly obvious in the transcripts.

The three-interview structure with multiple participants over the course of one to three weeks encouraged internal consistency by accounting for idiosyncratic days. This also allowed me to compare participant interviews over time with one another and with the other participants.

Internal validity is a strength of qualitative research. It is the ability to report accurately exactly what a participant says and does in a study. Johnson and Christensen (2000) referred to this validity as, "research which is plausible, credible, trustworthy, and, therefore, defensible" (207). Triangulation of data, methods, and investigation, extended fieldwork, and participant feedback promote internal validity.

Because one type of validity threat is that of researcher bias (Johnson \& Christensen, 2000), I went into the study examining my own biases on the research subject. I had been trained in the state of Ohio in both the Pathwise mentoring and the Praxis III evaluation. I brought to this study a skepticism about the short-term training in terms of giving mentor teachers a clear understanding of their roles or preparing them to assess the success of their mentoring in terms of student success or transformational teaching practices. As I asked teachers about their own perceptions of this, I attempted to see it through a critical lens in terms of how the experience is socially reproductive or transformative, and how the teachers themselves look upon either of these possibilities. I tried to guard against what Wolcott (1990) referred to as "hearing too little" (p. 128) 
because I presumed to "know" what was happening. This would prevent me from asking the kinds of questions I would normally ask in a situation with which I was less familiar. I feel that externally I was able to suspend any judgement in my questioning and the transcripts verify this, but internally my interpretation was filtered through my previous knowledge. I am not sure if it is ever possible to be completely objective if the researcher has any prior knowledge of the phenomenon at all. My analysis was naturally based on not only my current findings but the sum total of all my experiences and knowledge (including the literature review) of the phenomenon.

External validity, the ability to generalize the results of the study to a particular larger population, is not the purpose of qualitative research (Johnson \& Christensen, 2000). Because the participants are purposefully, not randomly selected, an attempt to generalize would be inappropriate; however, this does not limit a qualitative study's importance to other people in similar situations. The transferability of this study lies in the application of the results to an individual's own experience. Both teachers and administrators should be able to look at the analysis of the data and decide if this has meaning for them in a similar situation.

The use of the methods described provided rich data for answering my research questions. As with most qualitative studies, I view this as an exploratory and evolving study. While I structured the study to focus on a specific phenomenon, I could not develop a hypothesis or predict the outcome of the study even based on the existing literature. The literature showed that there is a need to examine this phenomenon, but insufficient number of studies exist to predetermine what the mentor teacher themselves think about their roles, administrative support, and the influence of the training they have 
received. I went into this study believing that if the results suggested that one type of training or administrative behavior seemed to contribute to a more transformative role for the mentors, then that training and behavior may be worth further investigation. If, however, the study showed mixed perceptions across all three types of training and with different types of administrative support or lack of support, then the cost and type of training and support may not be significant in preparing mentors to know what is expected of them in those roles. 


\section{CHAPTER FOUR}

\section{Mentors and Training}

The last three chapters of my study are designed to discuss and analyze the data and to present implications of the study and questions for further study. Chapter four introduces the mentors and their training programs, Chapter five presents the data in terms of the research questions, and Chapter six summarizes my findings and examines the implications of those findings for administrative leaders and mentors. It also poses questions that have emerged from the research that should be considered for further study.

Introduction to the Mentors: Teachers by default

My mentor participants were all elementary-certified females who ranged in age from 40 to 60 with 18 to 37 years of teaching experience. In Ohio, the elementary certification has just changed from the one under which my mentors are licensed. They are all certified in grades 1-8. In West Virginia the certification is K-6, and in Pennsylvania the certification is K-8 for the interviewed mentors. The demographics are graphed on p. 145 of the appendixes. To keep the mentors and their state programs from becoming confusing as I discuss similarities and differences among the three, I have assigned pseudonyms to each mentor beginning with their state's initial letter. All of Ohio's mentors begin with "O".

One of the most interesting mentors I interviewed was Odessa, the maverick, who has taught 25 years in the same district. Odessa is a single woman, currently living alone. She dresses unconventionally and gives the appearance of being an "earth mother" from the 1960s. Her seventh grade room, which has several tables for students, houses her 
desk in the far corner, facing the room and computers which line one side of the room. The wall beside the chalk board is decorated with signs that encourage students to think critically and examine assumptions such as, "Question authority" and " Live simply so that others may simply live." Odessa is a quiet woman who carefully thought about her answers before responding. While she feels that she is, "A very good teacher. I do this very well," she recently took a year off from teaching because she did not like the person she was becoming. "I looked at myself and said 'You're becoming one of them, a bitter, unhappy teacher. And that can't be good for the kids or for me." She returned after a year's leave of absence with a resolve to change the system that had made her bitter. The bitterness seemed to have dissipated, but she found herself finishing a career that she really never wanted to begin.

One the most profound realizations for me as a researcher was that I was carrying around assumptions about the dedication of teachers who had selected the profession and remained in it for almost a quarter of a century or longer. As a teacher from a family of teachers, I had never considered any other career choice. It was a family business, and I loved it. I soon discovered that that was not the case for the majority of the women I studied. Most came into the profession because they perceived a lack of career choices for women when they began their profession. While the structural barriers for women were disappearing in the 1970s, the social and attitudinal barriers remained. Given a choice now, six of my participants would not have chosen teaching, and these are the successful teachers. Odessa described how she became a teacher.

Odessa: I didn't have any career education. I didn't think there were many options, and I knew I was going to college. I liked to read books. So, in fact, my 
minor is in Language Arts. Later, I mean, I did the whole social studies thing, but I was also interested in elementary. So, why I chose teaching? I really think a lot of it had to do with the lack of career education.

Joy: Any regrets about it? Thinking back, would you have made the same choice?

Odessa: No, I would have pursued some type of thing, something akin to landscaping, that kind of thing.

Joy: Did you discover later that you were interested in that?

Odessa: I've always had an interest in that, but because I was a girl, and I was the first person in my entire clan on both sides to go to college there wasn't any direction in that way. I just didn't have any direction. I am not resentful about that. That's the way it was, and I really think that I'm just a very good teacher. I do this very well. I sort of like knowing I don't work weekends except by choice, and I have summers off. I was ready to get out of school. I didn't have any training, again, I didn't think I could teach high school because you had to be smarter and all that stuff. That's sort of an underlying thing. I think it had a lot to do with not being career counseled.

This sentiment of not being informed enough to choose otherwise was repeated in many of the mentor interviews. The next Ohio mentor began a different career but finally chose teaching because of a positive experience as a teenager.

Olivia, the youngest mentor interviewed, has taught 18 years in three different districts in three different schools. She has taught in her present position in a departmentalized math program for 11 years, but previously had taught various grades. Olivia is married and has two children attending school in the district in which she 
teaches. She is an energetic and athletic-looking woman who seems younger than her 40 years. She is actively involved in coaching and advising cheerleaders. In contrast to Odessa's room, Olivia's math room is sparsely decorated with math posters, and all individual student desks are lined in rows. Her desk is centered at the front of the room facing all students. The room is neat and orderly. Olivia is enthusiastic about teaching and mentoring. In fact, Olivia seems enthusiastic about everything. I was surprised to learn that she was finally inspired to teach by an incident that had happened her senior year in high school. Originally, she had presumed to go into accounting, a family business, but because of her love of horses, she had gone to a horse-training school after high school. She describes how she entered college to pursue a "more traditional career" in teaching.

I had assumed I would be an accountant like my father. We had all girls in our family and I was the elected "boy." In my senior year, I took a course called "Teen Teaching" to avoid having afternoon classes, and I was placed in this building as a teacher's aide. One day my cooperating teacher was called out of the room, and she told me to take over a filmstrip presentation. I loved it. It was at that time that I considered teaching. When I graduated, though, I went to an equine academy. When I decided that I needed a more financially stable career, I went to college to teach. My twin sister is the accountant (she laughs). But I don't regret it. I love teaching, and I still have horses. I decided I could do both, and I do. I know the teachers that are teaching in the middle grades are here because we love it. You know everybody always says how do you like eighth grade, and everybody that's in it loves teaching it. 
The final mentor from Ohio was Olive, a 25 year veteran who has been teaching in the same district in the same school her whole career. Olive is a single, very simple, no fuss-looking woman who speaks and moves slowly. She pays little attention to makeup and fashion, and her room is a warm and busy place with encouraging posters and halffinished projects all over the place. She is pretty relaxed about teaching and life in general. She smiles and laughs frequently. She does not live in the district in which she teaches, and she has traveled 60 miles round trip daily for 25 years to teach here. She, herself, attended a rural elementary school like the one in which she is teaching. Her district is the poorest district in the state of Ohio, and the 80 -year-old building is being replaced next year in the lot beside the school. The construction noise is a constant hum through the closed doors. Because she appears so satisfied with her life, I was very surprised to discover that of all my participants, she is the most dissatisfied with the teaching profession itself. She, too, came to teaching by default rather than design. She also shares a love of horses with Olivia. Olive has a second business in horses; she owns eight of her own, but typically boards 10 more for other families. The care of the horses occupies her spare time. She, too, would have chosen another career had the opportunity been there 25 years ago.

This is my $25^{\text {th }}$ year of teaching at the same school. I came here right out of college. As far as the actual teaching part and the kids, I love that. And the fact that it is different everyday. I have control of my room, and I can basically do what I want to in my own room. I'm my own boss. I like that, but the money part is really the part that I wish I had done something else. Because it is really hard to live off what you make as a teacher. I had entertained thoughts of being a 
veterinarian back in 4th or 5th grade, but that was back in the days when they said girls can't do that. So, I though, "OK", so I went on to think of something else. And when I was little, I wanted to build things because my dad is a contractor. I wanted to be an architect and I really am an artsy-craftsy type of person. I think I would have enjoyed that, but as far as regretting teaching, no. Definitely, if I had a choice as a girl now, I would not be a teacher. I would have been a veterinarian or an architect.

All three Ohio teachers had distinctly different paths to teaching, yet none of them had selected teaching as their first choice of careers nor had they embraced the idea of teaching as a noble profession. Pennsylvania teachers revealed much the same history.

In Pennsylvania, Patty, the maverick, has taught 30 years. She was not so much a maverick in her innovative thinking (remember that the question I had asked of the principal-recommended mentor was to select someone "Who views mentoring differently than you"), but in that she saw everything differently from other teachers. She is in her last year of teaching and has had a history of switching positions by being "bumped" from one school to the next in the same district. She has been in her present position for three years. Patty is a slender and fashionable woman who is married to an administrator in another district. This is her first marriage and his second. While he has grown children, she has never had children. She described her marriage in terms of living separate lives, but being very close. This is only important because much of what Patty had to say about mentoring was also seemingly contradictory. One minute she described her relationships with her mentees as rather aloof, and the next described how close she was to them. What Patty reported should be examined through a lens that understands her immediate mood 
which seems to dictate what she feels and says. We met only once in her room. Her room was lined with desks in rows, but her desk was to the side and separated from the students by a wide space. At her insistence, we met at a local restaurant for the remaining interviews. She had selected a small local Italian restaurant in which to meet so that she could take dinner home to her husband since we had met after school and she didn't have time to prepare his dinner before he came home on those two nights. This seemed to be a concern of hers because she repeated that she wanted to take his dinner home because he did not like crock-pots. I offered to meet at an alternative time, but she felt that this would be the best time. While she had readily agreed to be interviewed and was open and friendly with me, I was never sure if she really wanted to be a participant. She always had a "yes, but" response. She reported that her best advice to her mentees was to eat a bowl of oatmeal before the first day of school. Her focus on the "life" and curriculum advice appeared to indicate that she saw her role of mentor as an advice giver.

They [her mentees] were asking me about the first day because they had been subs and neither one had gone through a first day. So I said, "I don't usually write plans the first week. I kind of see how it goes." And they looked at me like, she's not going to do much. "Then, the first day, just eat a nice big bowl of oatmeal because your stomach will be scared. No matter how many years, the kids aren't used to you. You just feel much better." So Cher laughed and after the first day she said, "I see what you mean. We barely got through the roll and lunch and playground duty, and I did eat my oatmeal.” And I said, “Good because you don't want to be crabby. It helps you not be constipated and people who are constipated are usually crabby. Think about it." 
Patty also seemed to fall into the profession for lack of other choices. Her recollection of the process of becoming a teacher is as follows:

I started college in Pennsylvania. I originally went into nursing, and I finished three quarters at Swickley, but I quit because I cannot stand to see a shot go into the skin. So I quit on the Friday before shots on Tuesday. At that time, growing up in what was in Gloria Steinem's movement my mother said, "Well, even if you marry, he may divorce you or he may die, and if you have children, you're going to need a skill to raise them." Basically you were a housewife, you were a secretary, you were a teacher, or you were a nurse. So I just decided I would do this. I was working at a shoe store the year I graduated college when I interviewed in this district. My manager said that if I didn't get the job I could have hers because she was quitting. I was offered two jobs the same day and took this one. Again, no love of the profession or a burning desire to teach was revealed in this recollection. Perhaps fewer new teachers are entering the profession today because other options with higher salaries are available for women, but the ones who do select teaching may be coming into the field for reasons more closely related to preference. This might be a subject for further study.

The second Pennsylvania mentor I interviewed was Polly, who taught in the same school and district as Patty and was the veteran teacher of the group of participants. Polly had been teaching 37 years in the same district in only two buildings. She had been in her current position since the school had opened seven years previously. Polly is a slight woman with white hair and a soft voice. She has never taught any other grades except first and second. She is single and has recently cared for and lost her mother. Caring for 
her mother was the only time off she had taken in 37 years of teaching. She has no family ties to the area. She is contemplating retirement in the next few years and wants to travel. When Polly interacts with students it is in a very kind and loving way. She touches them on the shoulders and bends down to talk to them. Polly remembers that she, too, had decided to teach by default.

I started more or less like [Patty] did. There was the secretary, teacher, not all the opportunities that there are today. I liked children. My first choice was that I liked sewing and cooking, so it was a toss up. But I felt I didn't want to do that for others forever. I could do that for myself. I still do. So I went to college. And here I am.

Polly is generally satisfied with her choice even though there is no money in it, but she says, "I knew that coming into it."

The participant I had the most difficulty getting to know was Pam. Pam had taught for 22 years in the same rural district of Pennsylvania. She had grown up in the neighboring town and had family in the district in which she now teaches. Her 22 years had been spent in only two districts in two schools. She has been in her current position for 17 years. I know that she has children and that she went to a local university in teacher education and did her pre-service teaching in the school that the university had established on the campus. But that was about all she revealed to me about herself. She would not talk about why she went into teaching, just how. Pam looked muscular and weathered. She was very reserved. She was obviously uncomfortable talking about herself, her feelings, and her speculations about education in general. Her thick accent was evidence of growing up in the coal mining area in which she teaches. She requested 
that we meet in the empty library while an aide took her students to the computer lab rather than to meet after school. She is a private person who responded to questions with one-sentence answers. I had to probe for any explanation. The only time she would begin to open up and express her ideas was when the conversation drifted toward the students. She would then discuss the discoveries she had made about working with children over the years. A typical interview was like the following:

Joy: Has education changed any since you started teaching?

Pam: Yeah, because the kids have changed.

Joy: How so?

Pam: They're more independent.

Joy: Good, bad? Both?

Pam: Actually probably pretty good. It's not easy on the teacher, it's good for them to be that way. It doesn't make my life any easier.

Joy: Give me an example of what you mean.

Pam: Um, they're very independent thinkers. It used to be that you could tell a child, "OK, we're going to do this" and there was no question as to why; they just did it. Now they're saying, "Why do we have to do this?" and they want to know a relationship, and we really have to account to them why you need to do this. Which is good.

Joy: What do you think brought about that?

Pam: I don't know. The parents. The media. They're into a lot.

Of all the mentors who participated, Pam was the most vague and elusive in her answers. She seemed to sincerely want to help during the interviews and she repeatedly 
said that she hoped she had given me information I could use, but her personality was such that we had to stay on "safe" subjects to really converse. She did not seem uncomfortable with me, but I think she felt the interview was a test with right answers. I tried to be very supportive of her responses and not judgmental in any way, but it seemed to be in her nature to be guarded about personal information.

In contrast, the West Virginia mentors were most verbose and comfortable in the interviews. Each also seemed to feel that her agreement to participate was part of her professional obligation and each was eager to share her perceptions of her experiences.

The first West Virginia mentor was Wilma. Wilma has been teaching for 27 years, 25 of which were in the same building. While she described her school as "inner city" and her students are ethnically mixed and typically low income, she is teaching in a small city and her school and students do not fit the general description of an urban school. Wilma, like most of the other mentors, had started her career in another field. Her first career was as a social worker which, she joked, "is a lot like I'm doing now." She switched her focus for financial reasons and went back to college to become a teacher. She said that she "can't imagine being in any other profession. Except I would like to be paid more." Evidently, she is still concerned about the lack of money even in her chosen profession. Wilma is a lead teacher (in charge of coordinating special events and student teacher placements) in her school and is actively involved in coordinating efforts with a local college as a Professional Development School. She seemed to enjoy her extended role. She is open and friendly, outgoing, and professional in appearance and demeanor. She is married to another teacher who teaches across the border in Ohio where they make their home. While she has married step-children that live in another state, her only child, 
a son, is a teacher in the same district as his father. Her whole family is involved in education and so her home life and work life appear seamless. Her school problems follow her home and her home life is consumed with "teacher talk."

I am constantly getting new ideas from student teachers and observers and my mentees, from these young people who are just coming from college. And I have a real personal stake in this, too. I have a son who was a first year teacher, not in this state, who had a mentor but it was not a good mentoring experience, and I guess it's my personal crusade to make it better for others.

Wilma was articulate and had definite ideas about what she had experienced in mentoring and in teaching. With 27 years in education, Wilma has no plans to retire in the near future. Being a teacher is so much a part of her identity that she is not ready to think about giving it up. Because she had a student teacher, we were able to meet in the teachers' workroom during the day, and I had an opportunity to see her students and the school in general busyness. Her room was messy, but organized and very student centered. Students took care of roll and lunch count. The fifth graders knew the routine of the day and came and began their work in a noisy, but constructive way. The teachers' workroom posed its own problems in the interview. We were interrupted by a constant flow of teachers and aides copying materials and using the phone. She went with the flow, stopping in mid-sentence to allow the copier to hum and then continuing.

Wynonna, the second West Virginia mentor, is from another small city in another part of the state. She is a very different person from the other mentors in that her professionalism was not as refined. From our first meeting she addressed me as a familiar friend and confided personal information about other teachers and students. She 
frequently referred to other people by their first names and assumed that I would know whom she was talking about. Many times, I had to stop and ask her if Bob were the principal or Kyle the guidance counselor or another teacher. Her conversations veered off in many directions and no matter what the question, she seemed to have her own agenda. She has been teaching for 26 years in the same district. She has primarily taught either first or second grade in the same building. She mentioned that she had a son in college now who was diagnosed as Learning Disabled. When we first met, she talked about being interviewed once before by a newspaper about her son who had been a high school football star. She was not very clear about the interview, but it had something to do with a rivalry between her son's team and another team in another city that was of state-wide interest. A slim and nervous woman, Wynonna seemed to talk at warp speed about many topics at the same time. While Wynonna was excited to talk about mentoring and welcomed me into her classroom, her conversations quickly turned to personalities and situations involving people not connected to the topic at hand. She tended to bounce between negativism and optimism very quickly. She was judgmental about many situations and challenged me to keep her on track and focused. An example of the type of responses she gave is in the answer to the question, "How did you get into teaching?" in which she, too, explains a circuitous path into the field.

Well, let's see. I quit school when I was a junior and changed my major three times. I went to work at a film processing plant and it was day in and day out. I went to work in the dark and came back in the darkroom. I kept looking at these beautiful pictures of children and I had worked at Headstart and I decided I might as well go back to get my degree in education so that's what I did, and the fourth 
day of working in the college kindergarten, because that's what I did, Dr. M walked in and said to my teacher, "Oh, better keep her. She's a natural." I don't know why he'd say that. I think it is just something you have and I like kids and I wanted to be the kind of teacher I didn't have because my first grade teacher, I think that's what I can remember in my first grade classroom. We had reading groups that were red birds, blue bird, etc. and buzzards and you know darn well the buzzard group the kids who were poor and couldn't read. The teacher just treated them awful. And then my best teacher was third grade. She hugged you every morning and every night. It didn't make any difference what you did in between or if you were poor or red or green you got hugged. Mrs. T was the disciplinarian and a lot of people didn't want to be in her room in fourth grade but I liked her because she was disciplined. I learned a lot of techniques from her and then I had Mrs. S in fifth grade. Now see there, my Kindergarten teacher was wonderful. First or second I don't remember either teacher because they were mean and hateful and I blocked it out. My sixth grade teacher, she was a wonder. We went to every country in the world and turned our room into that country. We went down the Nile and had mummies. I've always been a hands on and I've taught across the curriculum and thematically because I believe the more you immerse the more they're going to know. I've always done the rhyme song on the board back there. That's not new to me. That's just me.

Wynnona's room, while having seating organized into groupings looked very traditional in most ways. A schedule on the board fragmented the day's activities into subject areas. Her rules were typical of first grade (Keep hands to yourself). Her 
perception of how she approached teaching contrasted to what her room revealed. She feels that she is a natural teacher, but did not select teaching as her first, second, or third career choice.

By contrast, Winnie, the maverick and final West Virginia mentor, was the sage from whom the wisdom of mentoring and teaching flowed. A soft, round woman who had been teaching for 35 years, she humbly described her years of teaching, mentoring, and mothering two generations of teachers. "Born and raised" in the county in which she teaches, she had established a reputation of being an excellent teacher and leader within her profession. She serves on both district and state boards in various capacities. She commands so much respect locally, that I had heard her name long before I met her through the other mentor's recommendation. Many educators in both public and higher education had spoken highly of her and her influence on policy and curriculum. I was prepared to be wary of such an influential teacher who had been described as one of the most powerful women in her district, but the moment I met her I found her to be warm, caring, and articulate. She had been thinking about teaching for years and was ready to share with someone everything that she had learned before her retirement at the end of this year. Her concern for students, teachers, and education in general was genuine. Many times we stopped the tape recorder for her tears of joy, pain, and sorrow at leaving the profession that had been her life. A first grade teacher for 27 years, she has been a Title I reading teacher for the last 8 years.

She is a passionate woman who has dedicated her life to this career, and finally, I had found my stereotypical teacher who had "answered the calling of teaching."

I had always wanted to be a teacher. My uncle was a teacher, and I played school 
as a child. My brothers who were five and seven years older than me had to be my students. There was never any doubt that I wanted to be a teacher. Oh, it was definitely the right choice for me. It has changed so much. My husband accuses me of working 12 months a year, seven days a week. It is a job that is all encompassing. It is a job that will absolutely consume you if you let it because it never stops. You always need to learn something and there is always someone else who needs to learn something, too, and if you are on the giving end of that instruction there is always more to learn. Someone asked me one time if I could have another profession what would it be and I said a file clerk (she laughs). I love alphabetical order. I love my ABC's.

Winnie, of all the mentors, seems to value her role as a mentor as much as her role as a teacher. She is also the most optimistic about the present state and future state of education.

I would like to share with young people what I've learned over the years. I know I can't create their lives, but the things that are going on in education right now are so dynamic and powerful and thrilling compared to what they were 35 years ago. Unbelievable change.

While all of the participants shared similar demographic traits in the same profession, they did represent the diversity in seemingly homogenous educators, and I was able to gain perspective on mentoring from nine distinctly different points of view, some of which were influenced by the induction system in which they mentored. Because the training or lack of training played a part in how the mentors saw themselves as 
mentors, I will address training of mentors in each state and how each of the mentor's recollections of that training informed their perceptions of themselves as mentors.

\section{Examination of Training}

One of the most surprising findings of this research was that the Pennsylvania training did not exist for mentors in either of the two Pennsylvania districts. While the Pennsylvania Department of Education approves an induction-year program with mentoring as a component of that program in every district, evidently no plan for training the mentors is required for approval. It is only suggested in the state guidelines for induction year programs that mentors should received training in the role of the mentor, communication skills, coaching skills, effective teaching, problem solving, and knowledge of adult learners. In both local districts that I examined, a program of induction for mentees was in place with orientation programs conducted at the beginning of each school for the induction year teachers, and each mentee was assigned a mentor, but no formal training had been provided for the mentors. In fact, the mentors were not invited to the orientation meetings for the induction year teachers.

Only in one of district did the mentor remember any type of meeting at all. Pam, recalled in a confused way, "I remember getting together and there were forms. There were things we had to fill out. And they [the mentees] went on a tour of the district. I remember that. It was in the administration [building], in a conference room." Later when asked if she received a handbook or guide, she recalled getting, "Probably a paper, a booklet. I don't think we did. I remember there wasn't any compensation and there was a lot of extra paperwork. I remember I had a packet somewhere but I don't know if it was mine." Later it occurred to me that she had been trying to recall her orientation meeting 
as a new teacher 22 years previously. During the next meeting I confirmed this. Because the idea of training experienced teacher mentors was so foreign to her, she had assumed that when I asked about mentor training I was really asking about orientation for new teachers. It did not occur to her that mentors should be trained to mentor.

She had never seen her district's induction-year plan. When asked what she had been exposed to as far as a district explanation for the induction year, she replied, "I know there is a new teacher induction program, but I don't think the mentors go to that." In the other Pennsylvania district, one teacher, Polly, described her frustration at the lack of instruction in mentoring.

Well, I think you should have guidelines. Like here, we don't have any. Like they ask you to mentor and you kind of feel your way through as to what you should do or what you shouldn't do. And I think it's like with anything else. There should be, you know, guidelines so you know what to do because if you do... have a bad experience, then you can refer back to the guidelines. I had asked, when Wendy [the principal] asked me to be Jennifer's mentor, and I said what am I supposed to do? And she says like "help her." And she says, "I'll check and see if there's anything out there." But I was never given a book or anything.

On my second visit to interview Polly, she had doubted her own memory or wanted to verify that she had told me the truth. She had consulted with her mentee to find out what she had experienced, and then reported to me that Jennifer, too, was unaware of any materials or information about the mentoring process.

Before you came today, I asked Jennifer to give her side of this story, 'What was 
told to you?' She said the same thing; she kind of laughed. She says, 'Well, I guess I go to you if I have any questions or problems or what so ever.' And I said, 'Did anyone tell you, you could go to someone other than me?' And she said, "No". So we were in the same boat and nothing was said.

[She calls Jennifer to come to her room and Jennifer appears in the doorway.] The principal told me if I would be mentor to Jennifer. Nothing formal here. Only by word of mouth, right Jennifer? Did you get brochures or pamphlets down there? [Jennifer replies, 'Nothing']. See what I mean?

Patty, the other mentor in the same school and district knew just a little more about the induction year, but confirmed that she had received no formal mentor training and that she had been, "drafted. I was the only game in town." She appeared not to appreciate being asked to mentor two new teachers in her last year of teaching, but she did so because she "wouldn't have wanted to leave the 'poor person' alone" if no one else volunteered. When asked what she knew about her district's induction-year program, she replied:

Our role is day to day, but our district does have a formal training program. It is part of the mentoring program, the new teacher training program. They orient new teachers. They [her mentees] had some meetings at the intermediate unit done by California University and they [her mentees] had one on our assessment. I did spend a few days this summer, women like to come in, I hate to sound sexist, but you know women like to be organized. I took many days this summer...because it seemed like the thing to do and I don't regret it. 
Neither mentor in this district had received training, instruction, or direction for mentoring. None of the three Pennsylvania teachers had ever received any additional training in mentoring or criteria to meet for being a mentor. The most guidance any had received was Polly whose principal suggested she "help" the new teacher.

I called each of the districts' central offices for documentation on their mentor training, and they had only information on the program approval from the state department and an introduction to their district (teacher's handbook) for the mentees. I had no documents, and the mentors had no training. At first I thought that this might make my study weaker, but it actually helped strengthen it by revealing the significance of the difference mentor training had made for the teachers in the two other states by influencing the teachers' self-perceptions as mentors. Not only did the lack of training in Pennsylvania fail to inform the mentors of their roles, but it influenced the degree of value they attached to the very idea of mentoring. Rather than being able to recall the details of how their training influenced them in mentoring a new teacher, all three teachers when asked to describe their mentoring experiences concentrated on the idea of a mentor and mentee working well together and the mentor vaguely "helping" with curriculum or just being there.

While none of the Pennsylvania mentors felt the program was useless, each expressed in a different way a casual attitude toward the process. They seemed as if they had been asked the question, "What do experienced teachers do for new teachers" rather than, "What are some of your experiences as a mentor?" Their answers could have been from any experienced teacher talking about how she had developed a relationship with a new teacher. Polly remarked that she and her mentor had, "worked well together...never 
had a disagreement over any of the teaching. If she had a problem she came to me, and we worked everything out. And to this day, we're very good friends." Patty, in the same school described how she was usually "trying to get through my curriculum and the phone rings and they ask 'Am I using the right ditto? Do you have this, I threw my last one away, or I can't find this' so you make it work. And you just learn to live with it, and there is lots of it." She was less interested in developing a friendship than Polly. While she described her mentees as "sweet and open," she also said that she didn't try to influence them about teaching or the school because, "They make their own way. They're grownups. I don't have many close friends, just friendly acquaintances; it is hard to make close friends. We share a few laughs; it is kind of nice." Again, Patty, seemed to vacillate between enjoying and feeling imposed upon ("trying to get through my curriculum") with the process of being a mentor. In the other Pennsylvania district Pam saw her job as that of a sounding board. She recalled her latest mentee.

She [her mentee] was young and outgoing. We would try to get here early and go over any questions she might have. And we always ate lunch together so we chatted over that so that if there were anything, and that would be it. There wasn't a whole lot extra. I believe there was paperwork to fill out. She wasn't relying on me as the year progressed. Her confidence grew. She didn't rely on me as much. She didn't need me as a mentor in that way. She just needed words of wisdom occasionally like " the kids are driving me nuts" and I would say "I know, I know." You just have to say, "They go through spurts and, yes, you're not the only one having these problems."

Again, in all three of the Pennsylvania districts, the teachers' descriptions of 
what they did sounded much more like what any experienced teacher would do with any new teacher except that they had been officially appointed as mentors. Their dispositions toward mentoring were in direct contrast to how West Virginia and Ohio teachers all of whom had received extensive training saw themselves as mentors. While both states had very different focuses for their training, each state's mentors incorporated that training into their understanding of what they were to do with a new teacher. Their descriptions of their activities and responsibilities were much more detailed and the idea of being a mentor was seen as a very professional function of being a teacher.

In West Virginia, the focus of the state mentor training program and two local district programs was very much like the focus of training for that of clinical supervision with an emphasis on skill development and a de-emphasis on evaluation. Only one West Virginia district did their own training, but it paralleled the training of the state. One of the mentors, Wilma, taught in that district. When I asked Wilma why she did not receive state training she was diplomatic at first.

We were invited to the state conference; our county however refused to release people to go to that because there were too many that given year to supply subs for providing classroom coverage. Our county has a very good mentoring program. Mentors do training on our own time. Last year it was for a day, and we have periodic training throughout the year. I think it is real hard to give released time to attend the statewide function.

Later, however, she revisited her feelings on not being permitted to attend the State training.

We were a little upset that we were not permitted to attend the state development 
program for mentors, but we could see their position, too. At that given year there were just so many new teachers and mentors, and it would put a burden as far as substitute teachers.

By the third interview, she had evidently been stewing about the idea of not being permitted to go to the state training, "Even though we are supposed to be given released time, they say they do provide it, I don't think they particularly like for you to use it." I asked why she felt this way. "Well, the fact that they don't want to release us for state training." Her final suggestion about improving mentoring was "I think release time to go state training. Our county isn't real supportive of that." My question about why the individual county had elected to do their own training was answered. It saved money not only to not hire subs, but to train teachers on their own time. Another interesting phenomenon was in play here. The mere asking of a question had triggered a feeling that had not been explored by the participant in quite the same way before. Patton (1990) called this phenomenon "reactivity" to either the interviewer or the question (p. 245). It is a limitation to the interview process, yet much of the literature suggests that interviewing is the best way to study a phenomenon (Bogdan \& Biklen, 1998; Johnson \& Christensen, 2000; Patton, 1990; Seidman, 1991).

When I attended the West Virginia state training session in Charleston, West Virginia, the introductory session addressed the value of mentoring, and this was discussed in small groups. Both the state training session and the county training sessions that I attended included examining the needs of a beginning teacher, improving communication skills and trust building, learning conferencing and questioning techniques, and observation and scripting practice. A great deal of time was spent on 
examining practical skills that new teachers needed in terms of classroom management. One admonishment from the facilitator at the state training session was to "Remember, college students remember most those professors who taught practical skills rather than theory." I saw this as a way to make the mentors aware that the mentees would appraise the mentoring in a more positive light if the mentor concentrated on tangible skills such as classroom organization, discipline techniques, and acclimation to the routines of the school. The philosophy of the mentoring program in West Virginia seems to be that of acquiring usable knowledge of procedures and reinforcing the basic classroom skills that teachers need to function well.

In Book of Firsts, developed by the West Virginia Center for Professional Development, a checklist is provided for the mentors to use as a reminder of what skills to address with the first year teachers. The first major topic on the checklist includes instructional activities such as scheduling, homework policies, and testing procedures. Classroom management is next with categories such as school rules, classroom rules, discipline policies, and daily routines. Other major topics on the checklist are planning, grades and records, materials and equipment, and collegial relationships which include a county directory of school personnel and norms and traditions of school personnel. The list goes on to encourage mentors to check that they have taken the mentee on a tour of the building and provided maps and school layout. Also insurance, financial planning, payroll savings and professional organizations should be covered, as well as fire drills and over 100 procedural activities (West Virginia Center for Professional Development, 2001). 
The second half of the book is divided into time segments such as first week, first few months, mid-year, and end of school year. Each of these segments provides a checklist of skills for a mentor to record during an observation such as class opening, student movement, collecting work, work areas' use, teacher movement, and work requirements (heading papers, using a pen or pencil, make-up work procedures) (West Virginia Center for Professional Development).

Two of the West Virginia mentors seemed to incorporate the training into their own perceptions of what they were to be doing as mentors. Wilma described her county's training.

Role playing, one group would be the teacher and do the role playing and the other group would tally and do some observations. We also did some preconferencing and we did some post-conferencing to make us aware of the process that they hoped we would participate in when we did our mentoring. Our refresher was very much like that too, observation and conferencing skills and just a refresher type of course for those who already had been trained. There was a section on classroom management. We were given manuals, and we did a lot of work with evaluation. We were shown different methods of evaluating or observing. I shouldn't say evaluating. Mentors do not really evaluate, we observe. And some of the legal rulings for mentors. What we are allowed, but we are not allowed to make recommendations for hiring or firing. That's not our purpose. Our goal is toward the mentee, to serve as assistants to them, so we did a lot of training with that type of different observations tools. 
She described what she does in an actual mentoring situation, and she reveals that she does use much of the training that she has received.

I think my job is multifaceted. I help the mentee with problems they have in the classroom, but I think it is more [a] general function of just being there to answer any questions and to make these new teachers aware of the school culture, county culture, the personality of the school, to make them fit in, to make them a part of the system. I used the observation techniques and if one of them had a specific behavioral problem, I was able to chart the behaviors which they could not do while they were teaching. I could be a third party that sometimes could give them an objective observation when they were too involved to see. We're trained to observe and evaluate and deal with specific problems a first year teacher has. In that respect, a buddy teacher would not undertake those situations.

Winnie, who received state training that had the same focus, reported much the same use of training in the actual mentoring process.

Well, you touch base with them many times just in passing. And I think those times are as important as the formal mentoring. Just to check and see if they need anything if things are going well just that support system that they know that you're there all the time. We would usually have a pre-conference and it might only be a five minute meeting at the mail box to tell me what they're teaching today. If there's something that they want me to look at in particular. And then there would be maybe twenty, twenty-five minute observation with charting. And I try to have a post-conference as close to that observation as I can. Whether it be five, ten minutes at lunch or after school. What was pointed out to us in training 
that survival, just making it through the day, is more important than curriculum for a first year teacher, and I guess it last most of the year for a first year teacher. And the curriculum is secondary, not that it is neglected. And of course, we all know that if they don't have discipline and respect, there will be no curriculum. They have to be taught. One of the things that impacted me [in a course for reading specialist] a lot was how to observe students. Now, I can observe. Wynnona also remembers the state training in much the same way, but does not appear to apply it because she sees the new teachers as already having the skills for which she would observe. Her reluctance to apply the skills probably has less to do with her training than her philosophy that teaching is more intuitive and that she instinctively knows what is best in a teaching situation. It seems as if the influence of any training program is dependent on the receptiveness of those being trained and the value they place on the concept in which they are being trained. Wynonna recalls her training and how she views it in application terms.

I do know they give us that notebook and a lot of papers, and they want us to go in and keep track of how many times the kids are called on and all that. Well, most of the younger teachers I've seen have had that stuff taught to them in college, so they know what they are doing. They've got their sticks with names on them and they know how to cruise the room and go up and down. So, I honestly think there is a lot more teachers being trained well. So I would try to step in and maybe make some suggestions or maybe offer some advice.

In Ohio the focus of mentor training is on a conceptual framework developed by Charlotte Danielson of the Educational Testing Service. Her book, Enhancing 
Professional Practice: A Framework for Teaching (1996), outlined a framework for training mentors based on the criteria of the Praxis III assessment instrument. Praxis III is an observation instrument designed to assess a first year teacher's performance in the classroom. Some states, including Ohio, have adopted this test as a means of licensing beginning teachers. The 19 criteria for the Praxis III are rooted in constructivist teaching theory and were developed by analyzing important tasks required of new teachers, reviews of research on teachers' perceptions of criteria for good teaching, state regulations for teacher licensing, and documents from the standards committees of the National Board for Professional Teaching Standards (NBPTS) (Danielson, 1996). Danielson's assignment for ETS was to design a training program for assessors using the Praxis III criteria. In order for assessors to make professionally and legally defensible judgements, the rates of interrater agreement had to be high (Danielson, 1996). As she trained the assessors, she observed an interesting phenomenon. The assessors conversations turned to how they themselves could improve their own teaching by applying this criteria (Danielson, 1996). From this discovery, ETS developed a packaged mentor-training program, Pathwise, to assist those experienced teachers assigned to help new teachers pass the Praxis III. Danielson's idea was that both the experienced teacher and the new teacher could improve teaching by knowledge of Pathwise (Danielson, 1996).

My research supports the notion that Pathwise training may increase the experienced teachers' awareness of how they teach and actually impacts the teaching of the mentor. Ohio mentors' responses were the only data which in any way suggested that mentoring, or more specifically mentor training, might be anything but socially 
reproductive. Ohio teachers who were trained using Pathwise were the only ones who commented on how the training had influenced what they did in their own classrooms. All three, independently, included remarks about the importance of their mentor training in changing their own teaching.

This is by far the most important discovery of my research. The influence of the mentor training upon the mentors' teaching was not part of my original research purpose, but was revealed through the data. I know that researcher bias did not play a part because I discovered Danielson's claim of this influence after I had discovered this phenomenon in my data. In fact, because of the excessive costs of the E TS "packaged program" for training and assessment, I went into the research with a bias against of spending so much money to train mentors in skills that most experienced teachers probably already possessed. In my interviews, I had initially asked no mentors in any of the three states any questions related to the influence of training on their teaching, and only after transcribing and coding my data did I discover this theme existed in my data, and only in relation to the Ohio Pathwise-trained mentors. I can find no other literature that examined this aspect of mentor training because most studies focus on the benefits to the new teacher, her students, and to education in general through retention of the new teachers.

While this may not be a concern of states in selecting a mentor training program, it is important data to consider in education reform. The program itself is important to review because it combines theory with practice. While I have included a copy of the Pathwise Domains and Criteria, a brief overview of the four domains can serve as a reference point for remarks by the participants. Domain A deals with organizing content 
knowledge for student learning, Domain B with creating an environment for student learning, Domain C, teaching for student learning, and Domain D, teacher professionalism. Because I am a Pathwise-trained mentor and a Praxis III assessor, I have previously received training in both. In preparation for this research, I attended a district refresher course for Pathwise, a regional "recalibration" session for Praxis III, and a workshop by Danielson on Enhancing Professional Practice: A Framework for Teaching. Both training sessions concentrated on the meanings of the Domains and criteria and included practice with videos for recording observations and discussing the teacher's practice in light of the criteria.

All three of the Ohio mentors clearly remembered the Pathwise training domains and criteria and could recall the details of their training. All three mentors had initially taken a training by their districts called "Mentoring." Local administrators had conducted a one-day seminar and all the mentors recalled similar training in that it was focused on communication skills. They reported from these sessions that "We did different activities like pretending we were giving advice to each other as first year teachers. We played a game where you had to trade pieces of your game with other groups. It was to build team work." The Pathwise training was the only training that they all reported being significant in changing their perceptions of teaching and their practice in the classroom.

Olive: It made me really think about my teaching. There[are] some ideas I hadn't thought of myself and I changed myself from taking those classes, or I was more aware of some things. There were a lot of good things. I thought, "Gee, I should do this better," or "Gosh, I do this". Things that I have taken back and are 
beneficial to me as well as to my mentee. Like something as simple as calling students by name or stating your objective before you start your lesson... Definitely stop and think, and there is more things that I have changed about my teaching from taking mentoring classes and looking at things in a different way. I've gotten better at giving more clear goals and directions. Things like that that you just took for granted that they knew already. That you're doing things for a reason, not just because we have to do it. I try to give them the big picture which is something I didn't do before but it is one of the domains that stating the goals of the lessons and objectives to the students. And I've changed how I give directions. I write things down more. In order to get an A you need to do this, this and this, in order to get a B you need to do this. Which is something I never did before because I just figured the kids knew what to do to get an A. And it never really occurred to me that some of them needed to know to make those kinds of judgments. When you've grown up being a good student and that comes naturally to you, it doesn't occur to you that there are people who don't get that. But that was one of the things that I kind of thought, "Oh I never thought of that" while we were doing the Pathwise. I think it could benefit all teachers to take Pathwise and Praxis training even if they never mentored another teacher. They could still look at their own teaching and what they do or don't do in their classroom.

Olive also reported the training having an impact in her personal life. "When it comes to working with kids I don't have any trouble, but when it comes to working with adults, I'm not real people-oriented that way and so it really helped me a lot with the 
people skills. Even in my family like with my sister. When we work together on projects, I tried to use those suggestions and ideas on her, life skills."

For Olive the experience was personally and professionally transformational in a way that she did not expect. She was able to critically examine her own teaching and personal skills and to make changes to enhance education for all students, not just those who were the "good students," rather than teaching in a way that simply reproduced what she had observed in her own educational experiences as a child. This is a significant point in looking at the mentoring process through a critical theory lens as socially reproductive or transformative. The Pathwise mentoring appeared for this participant to be transformative and the possibility exists for mentoring to be used as a tool of change. Olivia also commented on the effects of the Pathwise training on her perceptions of her own teaching.

I don't know if it's impacted my perception of teaching, because I was a veteran for several years before I was a mentor, but it has certainly impacted my perception of things I do in the classroom. It's made me sit back and examine some of the things I do and ask "Well can I do this differently? Is there someway to improve this? It's made me introspective about what I do. I've gotten a lot of freshness back in my classroom, and I've also taken on some ideas from the people I've mentored. Three or four things that I do I'm sure had a positive impact on my students.

Odessa also related her training to an increased awareness of what teaching was all about.

I remember seeing the video and thinking this job is complicated and you have to 
remember so much stuff. It amazed me when I thought about what I'm doing. And I still think it is an awesome job. Most teachers don't think about it. For me, this experience, this is what came out for me. You can talk about what teaching really is. I think in education we do a lot of things the same old way for the same old purposes. We need to question why it is we're doing what we're doing, and I think education the kind of education in this area without magnet schools, we are still catering to a certain type of kid that schools have always catered to - the academically and scientifically inclined - and if you don't fit that little hole, then you're the square peg and we have a lot of square pegs. And so they do not meet success in school and then they have low self-esteem which goes all into society and goes on and on and on and circles and circles. Uhm, Education should be for all students, I think. That's what education should be. There are kids who don't play this game called school, and we should find out what game they're playing.

This was the strongest statement that I encountered that lent support to mentoring having the potential, through its training, to make teachers begin to think about changing the way they teach to benefit all students. Odessa was a maverick to begin with and obviously some of the ideas she had she may have held before mentor training, but she, herself, says that the training triggered in her an appreciation for the real purpose of education and allowed her a forum for discussing this with other teachers. It reaffirmed her resolve to do things differently. The data I gathered simply revealed that for the three Pathwise-trained teachers in Ohio, the training was something that triggered in them a need to examine and change their own teaching. This did not happen for the three 
mentors in Pennsylvania, who did not receive training, or for the three in West Virginia who experienced a state-developed training program. 


\section{CHAPTER FIVE}

\section{Research Questions}

This chapter examines how the data address the research questions posed at the beginning of the study. The following concepts are discussed in this chapter mentor selfperceptions as influenced by mentor training, perceptions of successful mentoring, the influence of administrative support on self-perceptions of successful mentoring, and responses viewed through the lens of critical theory.

\section{Self-perceptions as influenced by mentor training}

This study implies that mentors understand their roles in various ways, but that their conception of those roles is shaped in part by the training they received. While some of their self-perceptions are probably unique to their individual personalities, some of the influence of the training and initial explanations of what a mentor does influenced the mentors' perceptions in this study.

When I asked the mentors to use a metaphor in describing their roles, the Pennsylvania mentors, who had no mentor training, had varied answers that revealed widely different perceptions of what the mentoring relationship was supposed to be. Patty likened it to "a guiding light, something, I just kind of like help. A shoulder to cry on when you're down. That's all." A guiding light seems to suggest that what Patty does is model accepted practice skills. Her descriptions, though, of being interrupted by calls in her own classroom by mentees with questions as her primary contact with them does not demonstrate modeling. When she describes advising her new mentees to eat oatmeal to avoid constipation, she may model this activity, but this activity does not represent the guiding in teaching that would be expected from her metaphor. Her metaphor might be 
her conception of what mentoring should be, but her descriptions of what she does do not support this concept. There is a discrepancy between what she believes mentoring is and what she actually does as a mentor.

Polly felt mentoring was more of a helping role in the classroom. "I felt that I could help somebody because when I started there wasn't anybody to help you. I feel it's my job to help them be better teachers." Her descriptions of what she does with her mentee seem more closely aligned with being emotionally supportive. She explains that she helps them to feel better about teaching, "They're just starting up, and you don't want them to feel overwhelmed...So I felt that I should help them or kind of guide them like you kind of do a first grader, so that they enjoy teaching."

Pam, on the other hand, felt that being a mentor was more evaluative and parental, like raising a child. "Well, you're checking on them all the time, making sure they're doing what they're supposed to be doing and when they ask you questions they are like your kids at home when they need something. Otherwise, they leave you alone. More like a teenager, not a child." While Pam's metaphor of "raising a child" did describe the functions she performed in mentoring, the other two Pennsylvania mentors' metaphors did not have much relationship to the job that they described doing as mentors.

The Pennsylvania mentors came to these perceptions without the influence of any training or explanation of their roles from their districts or their administrators. Each had independently been left to decide what a mentor is and what a mentor does based on their perceptions of the connotations of the word itself. Their conclusions about what a mentor is and does were more closely aligned with what Ballantyne and Hansford (1995) called "buddy" mentoring. Elliott and Calderhead (1992) discovered that mentors who viewed 
themselves in this way typically did not feel it was their responsibility to pass on craft knowledge or to challenge the status quo, but that their function was to offer emotional support and advice on "getting along." The Pennsylvania mentors seem to support this model in the descriptions of what they did with their mentors.

West Virginia mentors who had all taken either the state-sponsored training or district training based upon the state mentor program goals gave metaphors more consistent with each other and more related to goals of their training program. The metaphors and descriptions of what they did with their mentees were more detailed. Most of their metaphors were closely related to both skill development and building a professional relationship. Wilma likened it to "watching a cocoon develop into a butterfly. Teachers develop and refine skills over a period of time, so it is very selfsatisfying." Her understanding of this slowly developing process is revealed in her description of her first mentee.

It was interesting to watch her grow on her own. She had been an excellent preservice teacher but she grew even more that first year of teaching. And I think she felt very comfortable coming to me with problems in the classroom. Most of the problems that I helped her with were classroom management.

Again, she was primarily focused on skill development and very practical classroom behaviors. Winnie, too, referred to skill acquisition and the emphasis that was placed upon it in her training.

Mentor training taught us how to look at mentees and the classroom, and how the mentee is relating to the classroom and how to handle things so we could teach them management skills. 
Winnie felt mentoring was more like "Mothering." In contrast to Pam from Pennsylvania, she saw mothering as more nurturing than supervisory. But the parent analogy implies a paternalistic attitude toward another professional adult. Already, the stage is set for an unequal relationship in terms of power and influence. While Winnie was very much a social reformist in terms of educating children, she did see her role as an experienced teacher as very traditional in "training" the new teacher in the skills of teaching. True to her belief in her state's training philosophy, she concentrated on the skill development of the new teacher.

It's a situation where you are nurturing and training and guiding. It's very much like raising a child. Some children want to be molded and some don't. That's the way it is with teachers. The person who really wants to be a teacher and wants to grow appreciates nurturing, so I think, motherhood. It was pointed out to us that survival, just making it through the day, is most important for a first year teacher. Sometimes the years of experience and the knowledge that has been gained over the years really are the right way. And when it ever gets to be that I know that I am right and this is the shortest and best way to get there and teach, then I am pretty strong abut my encouragement. Hopefully, not rude, but strong and firm and try to prove my point.

Ohio mentors all felt that mentoring was complex. In fact, the Pathwise training emphasizes that good teaching is complex and assessors must recognize their own "filters," or biases (Pathwise Orientation Guide, 1995, p.1) through which they view good teaching and must strive to work independently of them. To sum up an activity designed to address a complex concept in a single metaphor proved more difficult for the 
Pathwise-trained mentors. No one had an easy metaphor for what it was like. Most descriptions contained ideas of developing professionalism and the awesome burden having responsibility for someone's career development. Olive responded that the first thing that popped into her mind was guidance and then friendship.

That's tough. When I think of guidance, I think of helping point somebody in the right direction, not necessarily pushing them but saying, "Here's the path." The second thing that came to mind was friendship because when you're a friend, you ask advice and basically that's what you want your mentor to do. To ask you "What would you do?" Those are the first things that pop into my head.

Olivia had less trouble comparing mentoring to something familiar. She compared it to math, which she teaches.

Mentoring is like solving an algebra problem. Actually that's not bad. Mentoring is like taking Calculus II 128. I did it as an independent study. It was something I had to keep at, but that I enjoyed. As long as I worked at it, things went fine. I think mentoring is the same way. You just have to keep going and sometimes one approach isn't the right one and you need to be flexible and look at it from different perspectives.

The maverick, Odessa, found it difficult to find a metaphor.

I find it intense. Worrisome in some ways because you're taking on responsibility for someone's professional life. I mean it's pretty scary stuff. Maybe sort of like paying bills. You've got to have it right and that's where I'm coming from. You've got to make sure it's right because mistakes are hard to correct and it's important. That doesn't mean I don't enjoy it. 
As the data reveal, each state's mentors' responses were more closely aligned with each other than with other mentors from other states. Pennsylvania mentors, without the benefit of training or information, relied on their own understandings of the word mentor to inform their self-perceptions as mentors. West Virginia mentors concentrated on skill development for the new teachers, just as had their training. Ohio mentors described the responsibility for helping a mentee develop professionally, thus "enhancing professional practice." Additionally they perceived their training as an enhancement of their own professional development and a means of critically examining their own practice. This suggests, in this small sample at least, that a state's overall induction year, mentor-training program and the philosophy about mentoring as revealed through the mentor training and literature influences the mentors' perceptions of what a mentor is and does.

One problem that much of the literature addressed in terms of role confusion was the conflict that mentors feel about being observers and supporters as opposed to evaluators (Chubbuck, Clift, Allard \& Quinn, 2001; Evertson \& Smithey, 2001; Jones, 2001). While the mentors in this study clearly stated that they did not see themselves as evaluators, their use of vocabulary that revealed evaluation of their mentees' performances indicated some conflict. The West Virginia training literature states that a mentor is a nonjudgmental guide. The mentors in all three states agreed by repeatedly saying things such as " the assessor and mentor are different roles," and "we are not allowed to make recommendations for hiring or firing," or "I'm there to observe, not evaluate," but at other times the mentors would use language that suggested a more evaluative role. Popkewitz and Brennan (1997) cautioned critical theorists to look 
closely at the language that is used by participants to determine disposition. Critical theory focuses not only on practice, but on linguistics, semiotics, and behavior. By listening to the words used by the mentors, subtle perceptions of the conflict between what they want their roles to be and their awareness of what the roles actually entail are revealed.

Most of the mentors used the terms evaluate and observe interchangeably. Olive described what she did when observing by using the term evaluate "If I was going to evaluate a lesson for them." Wynnona admitted that "When we evaluate, they take to heart what we say." Wilma said that, "As mentors we're trained to observe and evaluate and deal with specific problems a first year teacher has," and Olive reflected that the hardest part of mentoring would be "to say to somebody that they should consider another profession" and that "it might be easier, sometimes it is easier to take criticism from someone who is not a friend." She went on to say that she "would want to make suggestions or criticism, which is what you end up doing, even though you don't want to make it criticism."

The word "mentor" and the fact that an experienced teacher is appointed to "guide" a new teacher to successful teaching imply an evaluative situation. Olivia stated that she did not want to be a "boss" or a "leader" but she wanted to be a "team" with her mentee. So while the mentors agreed that they did not see their role as one of an evaluator, the element of evaluation is imbedded in the connotation of the word and in the process, itself. The language the mentors use in describing their activities with mentees reveals an awareness of this conflicting role. 
The additional pressure that is experienced by the Pathwise mentors to prepare the mentees to pass the Praxis III for licensure against the 19 criteria is inherently evaluative. Olive admited that the responsibility of this concerns her.

I think that it has to be in the back of your mind. You really don't want to be an evaluator, you don't want to be judgmental. But in the back of your mind that person is going to be evaluated and they have got to be ready if they are going to keep their job. You have to at least be giving suggestions that would really improve their chances of passing the Praxis III.

This study reveals that the mentors interviewed had internally conflicting views about the place of evaluation in mentoring. The literature shows that a perception by the mentee of the mentor as an evaluator can have a negative impact on the mentoring (Chubbuck et al., 2001). Olivia saw a problem in that eventually the mentee might attempt to hide problems from a mentor, "She might really want your help on something and she'd be afraid you might see her as being weak." There is a contradiction in term "peer mentoring" in that any mentoring places the mentor in a more dominant position than the mentee. The peer mentors appear to be uncomfortable with that reality. Perceptions of Successful Mentoring

When asked a series of questions about successful mentoring, the goal of all induction-year mentoring programs, there were no discernable differences in the mentors' answers no matter in which state they were mentoring. All mentors reported that success was both intuitive (how they felt about the relationship and the success of the new teacher) and concrete (the mentee stayed in teaching). Jambor and Patterson (1997) found this to be the common perception of success by mentees who had received support 
from colleagues as well. The idea of mutual, professional gain and positive relationships as successful mentoring is reflected in the following mentor comments:

Olive: The problems that the mentees have are mostly due to lack of experience. All of mine have been good experiences. It's really an equal relationship. The only bad experience I've witnessed was another mentor had a teacher who they were really considering firing and I think the mentor helped move that out a little bit and gave them a second chance. It wasn't all one sided. She was definitely having problems and no one, short of the mentor, was helping her out. The situation improved and she's having a good year this year. She would have definitely been fired or she would have quit if it hadn't been for her mentor. I would have quit.

Olivia: My principal said what a good pairing we'd been. And that he saw it made a difference with me, too. He made the comment to my mentee that he could see how excited I was to do projects with her. Now I had a mentee who says "Great let's do this, too." What an impact it made on both our teaching.

Mentees staying in the teaching field as a measure of success is reflected in the following comments:

Wynonna: Well, I mentored Tanya and it turned out OK. She's still teaching in our district.

Winnie: The testimonials from the mentees have been wonderful. Some say, "I could not, I don't know how I would have gotten through my first year without my mentor." 
Only one mentor had experienced a mentee leaving the teaching profession and that was to begin a family. Most of the mentored teachers were still teaching in the same district and many in the same school in which they had begun their profession, so most of the mentors were still colleagues and friends with their mentees. Most equated this with success in mentoring. Interestingly, I asked Olive if she were closer to her former mentees than to other new teachers, and she replied, "Not really. I may know a little more personally about the person I've mentored, I've spent a little more time talking with them at the beginning, but I don't really think it's made that much difference in our relationship." So, having a special relationship with the mentee was not part of the equation that this mentor used in judging success.

Most of the mentors felt that they had had successful mentoring partnerships within the parameters of the work context such as limited time together and lack of proximity. Given the support they had received and the design of the program, most felt that they had seen professional relationships formed and the new teachers experience relative success in the first year of teaching.

\section{Administrative Support}

Administrative support is critical in maximizing the effectiveness of mentoring for all parties (Ganser, 2001; Harby, 2000; Hope, 1999; Janas, 1996). While the mentors from all three states believed that training, or the lack of training, provided by the state or district had influenced their self-perceptions, the administrative support was much the same in all three states. There was no discernable difference in the responses of the participants as to how administrative support influenced their perceptions of mentoring. 
For the most part, mentors felt that administrative support from the state, the district, and the building principal was necessary for successful mentoring, but none of the mentors felt that they received the kind of support that allows for the collaborative relationship to establish the needed "synergy" between practice and theory (Hargraves, 2000) that would improve their mentoring and increase teacher efficacy. The issues that the participants addressed were the kinds of issues that the literature supports as being necessary to have a successful mentoring program: time, compensation, close proximity, and administrative decisions affecting teacher assignments (Sweeny, 1994).

All participants agreed that having more released time to spend with their mentees was the main factor that would increase the success of their mentoring.

Odessa: I wouldn't say that either of my experiences were excellent. Both lacked for time. I think the biggest problem in mentoring is getting comfortable. Getting comfortable takes a little more casual time. You can’t just go into someone's class and say, "Here's what we'll talk about. Do you have any concerns?" It is sort of an awkward thing between an adult and an adult. They don't want to appear stupid and you don't want it to appear that to let them think you know more than they do. To insult them in any way.

Patty: I'll take time over money anytime.

Olive: It would be nice to have a little more time. If you mentor a new teacher you get one half a day twice a year. It would be nice if they could figure out a way so you had a little bit of time every week that you could go to that new teacher's room and even if you just sat there or could help them during a planning time or lesson planning or just talk about things. It would be a lot more helpful. 
Scheduling is such a problem like fitting in the specials, art, gym, music, and library. Most of the time you're just lucky if you have those things. We don't usually have a common planning time. It doesn't work out that way. It would be wonderful if it did.

Polly: If you had time to get together. If you are not on a duty or if you don't have the same prep time, then it is like you're hurrying back and forth to get something worked out. There should be time given that we could plan together, work out problems together.

Olivia: We had to plan and ask to have duty together once a week so we would definitely see one another.

Wilma: I imagine if I requested a sub once a week to observe and conference, someone would surely track me down and request that I do it a little less often. That's just my gut feeling. It hasn't happened. Wynonna: I think they also need more observation time. I think they gave him [mentee] two and a half days off during the year for observation.

Winnie: One thing that would improve mentoring would be time for the mentees to observe master teachers.

All the mentors felt that teachers in general have little time to prepare for or reflect upon their craft themselves. Finding time, then, to help a new teacher is just one more duty imposed upon them by the system. As Olive says, "You don't have time to breathe during the school day." Things are more hectic than they have ever been. All the teachers complained about added "paperwork" and the stress of additional teaching responsibilities in their routine teaching assignments. 
Wynonna: There is way too much paperwork put on teachers, outside of class paperwork. There is always some new thing they want us to do. Maybe because I've been teaching for a while that there isn't anything new they want me to do; they just put a new title on it and attach paperwork.

Wilma: Teachers have so much to do. They are so responsible for curriculum that hadn't been thought of when I started, like the computer lab. Computer education, character education, drug education, things we never dreamed that we would have to be working with our children. In order to get the basic skills covered and covered well and meet the standards set by the state, you are always robbing minutes from one program or the next.

Winnie: We found, while the state guidelines [mentoring guidelines] read very well, they are almost impossible to follow because they require so much time. Odessa: The state department people change things, but they are so far removed from the classroom that they don't know the impact.

Patty: They have added and added and we keep up with it, but with all the state programs and requirements, it becomes Mission Impossible.

Olivia: Sometimes we have things forced upon us in education whether you want them or not, and I think it is the mentor's responsibility to help with that transition. I think we're all more aware that new teachers have to get their masters in such a short time. One more thing to eat into classroom teaching.

Related to making the mentoring more time efficient was the perceived need of all the mentors to have mentors and mentees in the same building. In addition to saving time, proximity was seen as important in introducing the new teacher to the building culture. 
All mentors felt that the idea of acclimating a new teacher to the school and its culture was an important part of mentoring. According to Winnie, "We have learned from experience that it is better if the mentor be in the building and out of field than the reverse. We've tried that, and it just failed." Of course these were all elementary teacher mentors. Secondary teachers who are completely departmentalized may have not shared these sentiments.

Winnie: We spent a fair amount of time discussing this. Should your mentor be in field to help you in the classroom or should they be in building to help you become part of the culture. The culture, how a building is run. And every building has its own personality as we know from experience. So we decided that the mentor needs to be in the building.

Wilma: I don't find a connection so much when I mentor out of building. Mentors are more likely to see obvious problems in the building, in the classroom. It follows through better if they are in the same building. I think it is imperative that the mentee be in the same building.

Olivia: It is critical to have somebody in the same building.

Patty: It is more important that they be near by so they can talk and share and with the politics of the building. Someone from outside the building doesn't know the politics and how to get along.

While I have sorted the concerns for which administrators have control into the general categories that other literature divides them, in truth many overlap. As Odessa puts it, "Everything cost money. If you ask for time, you ask for money. Time cost money. Time is money." So while compensation, stipends, and money in education is an 
issue, it is closely aligned with time and reward and value. Money in teaching is an issue for most teachers because they typically make less than those in other professional fields. Olive talked about not having her check as a "second income." "That's a problem, when I came into the field, I thought I would have money for a house, a nice car. It didn't happen." Wynnona thinks new teachers need to be warned that "You're going to walk in somewhere and have to spend your own money. In the long run, they don't make enough money to make ends meet." Despite the general unhappiness over teacher's salaries, these mentors didn't place as much value on the dollar amount received as on the idea of some recognition or stipend to recognize the value of their job. This also supports what Rowley (1999) found that while mentors generally work without compensation, further studies need to examine the impact of providing money and time on the mentors' perceptions of the value of their work. The following statements from different mentors reflect this.

Olive (who receives $\$ 300$ for mentoring): I don’t see how a raise could hurt, but I think most people give it all they've got no matter the stipends. Most teachers are the kind of people who over-achieve, go-getters and don't think about the money they're getting.

Patty (no stipend): I don't do it for the money.

Polly (no stipend): You need some reward other than you've helped them to get started off with a teaching career. Maybe even giving something to the mentees that would show, you know, that they're being rewarded for their good job. It's not a valued program because it lacks for time and lacks for money. Wynonna ( $\$ 600$ stipend): Doug and I will be splitting the $\$ 600$. I'm not in it for the money, but honest to God. 
Pam (no stipend): I want them to buy my materials. Money.

Odessa (no stipend): It's not a competitive profession. We don't get any financial rewards for getting ahead. I get no benefits from it [mentoring], not personal, not professional. Education is a volunteer business. I don't say that happily, and it has to stop.

Olivia (no stipends): Are we wasting time and money. Money, no. I don't get any. And if they're wasting any time, it's just ours. And maybe that's why I suspect if we were getting paid for it, they'd pay a little more attention to it.

"Paying attention to it" by administrators seems to be what most mentors want. While all agreed that administrative support from the state, the central office, and from the principal were needed to make any changes in the mentoring program, most felt that the program was valued more by the teachers than by the administrators. Olivia pointed out the lack of economic sense of saving money by not investing in mentoring.

In the long run, I think that's false economy because if you've got a first year teacher who is really struggling, then you have wasted a year, you've wasted their salary and you've wasted tax dollars and I just think it's a little more important. It could use more interest from people a little higher up. I think the building principal is interested and that's good. I think he is the primary person who needs to stay interested in "Is the person in my building doing OK?" But he's not the only person affected if the first year teacher is not doing well. I think we need to have a little more contact at the district level in putting together a comprehensive program. 
While Olivia got support from her principal, most of the mentors were not impressed with the role of a building principal at all. Pam thought that the role has changed, “They're just paper pushers anymore. And they don't principal the way they used to principal. Ours is doing the best he can to get around so the kids know who he is and everything. They're just not as available as we would like them to be." Winnie states that, "They're not doing any harm; I'm not sure how supportive they are. A lot of our administrators do not evaluate teachers like they should. That's another bump in the road. I've been observed once in 35 years." Olive expressed frustration over the constant turnover of new principals and their lack of knowledge about mentoring.

Usually, they are not too involved. I guess not sort of into it, but basically ignore it. They usually don't even know about the mentoring program. The mentor and mentee usually have to inform the principal about what they do and what it is about. It would be nice if they were just aware. Every year we have to educate a new principal as to what the mentoring program is and it would be nice if they would take a few minutes to find out about it on their own, and actually be involved instead of saying "OK, you guys take care of it." If all they did was read the manual and knew what was supposed to be happening. I know they're busy and have a lot, but it's an important thing and if they would look at it, just review the policy. I'm sure they do what they are supposed to do, but so many of us have been here so long, we just sort of know what is supposed to happen and we do it. It would be nice if they acted just a little bit more concerned. 
On the other hand, Winnie thought the whole program can collapse without supervision. She directly addresses what Janas (1996) referred to as "monitoring" the mentoring.

You do need someone with authority to observe what is going on, see if records are being kept. You know the farther you get from the inception of something, the weaker it becomes if it is not watched. I think that would really strengthen a program. We don't supervise it. It's left to everyone's options. There is an old rule that "what gets watched gets done" something like that and there is a lot of truth to that.

This laissez-faire administrative attitude concerns teachers not only because the program is not valued by the principals, but real harm can be done if the wrong people are selected as mentors. If principals see the program as a requirement that needs to be filled for the state, then real mentoring will not take place. Wilma feared that her district might become like other "areas of West Virginia where they just plug people in to say 'yes, we have a mentoring program." Winnie felt it is the principal's job not to "place a first year teacher with just anyone."

We tend to take whoever is willing. Finding personnel is difficult. Your master teachers have all they can do just to do what they do and they don't want to spend any more time after school. There's money there, but there's no one to do it. The people are qualified but don't want to do it. It becomes, “OK, who's going to take one?"

Some teachers do not make good mentors. Olivia recalls that the only complaints about the mentoring program came from mentees who had never seen their mentor after 
the first day. Wilma makes a distinction between good teaching and good mentoring, "Some people don't have the patience to work with student teachers or new teachers. They prefer to be in their rooms doing their own thing. They should not be selected as mentors." Very little literature addressed criteria for selection of mentors. While the mentors I interviewed thought the building principal was in the best position to select mentors, in reality, the selection process is very political. In collective bargaining states such as Ohio, the selection must be negotiated with the union in a master contract. Even building politics and seniority come into play in any position that may involve a stipend or released time.

No two districts selected mentors in quite the same way, and few policies outlined how they would be selected. Only Pennsylvania and West Virginia suggested guidelines for selecting mentors, but no criteria that had to be implemented were established in any program. In Pennsylvania, mentors were chosen by the principals because they taught the same grade level. In Ohio, some mentors were selected by central office, the superintendent or curriculum director, and in other schools by the building principal. In Olive's school the faculty themselves divided up the mentees to "take turns so no one person received the stipend every year." In West Virginia, one teacher was selected by her building principal, another by the superintendent, and another by faculty senate. All agreed that the building principal is the one person that should do the selection because the principal would or should have the most knowledge about her staff and their ability to mentor a new teacher.

An additional suggestion that kept appearing from interview to interview in different states was the idea that mentoring new teachers and mentoring experienced 
teachers who were new to the district should be done very differently. Many of the "bad" mentoring stories involved experienced teachers who had been assigned a mentor because they were new to a building. Patty reported that, "One of mine was an older woman. She was the one I had difficulty with. She had come from junior high to elementary, and she was already set. When you talk about this whole teacher change. Right here is what I would change." Wynonna commented, "We just kind of think that even though she was 15 years in education it was her first time in regular education and she needed a mentor." Odessa felt that she was not qualified to do the same type of mentoring with an experienced teacher. "Who am I to say to someone with experience; I just felt awkward about that." Winnie had also mentored a veteran teacher who had switched buildings. "I consider it a failure. She didn't want mentored. She wanted to be left alone. I was totally useless in that situation because she was not receptive at all.” Wynonna recalled another situation in which she didn't feel as if the teacher needed to be mentored, "She didn't need a mentor. She was a new teacher who had spent her first year in a B.D.[behavioral disorder] position. Well, my goodness the first year she had been thrown to the wolves, and she didn't need me. She had the best technique with the fifth graders." In summary, Winnie suggests that "Mentoring is easiest with young people. When you try to mentor an older person, they might be new to a situation, they still are set in their ways to do certain things. We tend to get that way when we get older." Most of the mentors suggested that there be two separate mentoring programs, one for new teachers and one for experienced teachers in new positions. According to Odessa, "It seems that there needs to be something different for someone not new to teaching, just to the district." Most agreed that the mentoring focus for the experienced 
teacher should be on the building culture and on those procedures unique to a specific school.

\section{The Lens of Critical Theory}

In viewing my data through the lens of critical theory to determine whether the mentor training perceptions of these mentors was transformational or socially reproductive, I looked at a number of different interview responses, some on learning, some on curriculum, teachers, and support. Primarily, though, I looked at the responses the teachers gave about changes in education and students and how they had perceived them. By examining their perceptions of change and how they interpret their response to change, I was able to understand their perceptions of the inequities in the educational system.

Most of the mentors considered mentoring an important part of career development for both the mentee and the mentor. Most saw mentoring as a mutually beneficial relationship in that both partners learned form one another. Comments such as, "I get rejuvenation. It's been so renewing for me because I think sometimes you get burned out" from Wilma, were common.

What I found, though, was that the three Pathwise-trained mentors in Ohio had attributed an actual change in their critical examination of their teaching and changes in teaching behavior to their training and mentoring experience. All three had reported becoming more acutely aware of teaching all types of students in different ways.

Villegas and Lucus (2002) found that teachers who validated all students raised expectations of learning and became change agents in the schools. Likewise, these Ohio mentors' choices of vocabulary revealed classrooms where students were respected and 
where students were engaged in constructing meaning. Olive talks about knowing her students and changing the curriculum because of her mentor training in Pathwise.

There is [sic] things that I have changed about my teaching just from taking mentoring classes and looking at things in a different way...There is a lot of things that kids bring to school with them that you don't ever think about, but if you know, you can help them with their school work. When I started teaching and when I was a student, it was always, "Read the book and answer questions." Now I try everything to get the kids more involved in their own learning. A lot more hands on, question-oriented, discovery activities. I let them make up their own test questions.

Changing her concept of what "teaching" was from what Paulo Freire (1997) called "banking," making deposits in the minds of students, to a more constructivist view which empowers students to take responsibility for their own learning is a manifestation of critical pedagogy. Cline and Necochea (1997) encouraged critical teachers to allow students to take more control of their own learning "by engaging in meaningful instructional activities" (p.142). Olive demonstrated that she has made this paradigm shift in the way she practices teaching.

Olivia, too, engages students in their own learning. She explains a math marathon to demonstrate this. She credits her mentor training as causing her to rethink her teaching methods.

We do a mini-metric Olympics. It's based on track and field events. They throw a discus, and estimate how far they threw it and then they actually measure it... The kids have to work in stations. Any time you make a change in curriculum, you 
make a change in education. Pathwise has caused me to take a second look at things I do and I've taken on a lot of the ideas of the people I mentor. More often than not, I think the mentee can be instrumental in change because a lot of them are fresh out of college and a lot of them have taught many miles away and may have already seen some things they can bring to a mentor who may have been in the same district for years. The principal has noticed not only what it did for the mentee but what an impact it made on my teaching, too.

She also goes on to describe the new roles that she has had to assume in her teaching career that made her more aware of her students' needs.

I've seen more and more required of us, especially along the lines of responsibility for identifying drug or alcohol problems, potential abuse. Things that are really hard to spot in an eighth grader. They are getting to the age where they don't confide in their teacher that much. But if you're not interested in the kids, they aren't interested in hearing what you have to say...it's total preparation for their future, not just academic. But I think we've got a huge responsibility socially, emotionally.

Odessa says she really does believe in the 19 Pathwise criteria and that all teachers could benefit from putting the criteria into practice.

People who work in schools should bend over backward to respect students. I think it would end a lot of confrontations. We've spent too much time in education sorting and labeling. Facilitator is a new word, isn't it? It wasn't a word when we went through teacher training. That's a tongue and cheek remark, but if we talk about a facilitator, we didn't use the word. We weren't taught the word in 
college. I mean I was not taught the word. Facilitate, guide, that sort of thing. Teaching was sorting. Everything in its little box. Pegs and squares. Teaching was about, a teacher up here calls it the "get and spit method." You get it and then spit it back. Get, spit, forget. Tell them and test them and if they don't learn it that's their own problem, right? Back to the word facilitator. I don't have to be instructing. I don't have to be more active than the students. They can be doing stations. I can watch. Now that's a lot of work and all at once. But to watch them interact with themselves and make decisions and to be self-responsible. They like it and I think they learn from it. I mean that's what it is all about.

The Ohio mentors were not the only mentors who exhibited the constructivist views and recognition of the necessity to change teaching and schools to become more just for all students and to provide better opportunities for learning for all students. At times the other mentors also expressed an awareness of this, but the Ohio mentors were the only ones to attribute the changes in some of their classroom practices directly to their mentor training program.

Transformation is a complicated process. The commitment to transformative change that enhances educational opportunities for all students involves letting go of some ideas that have been part of our cultural consciousness for generations (Cline \& Necochea, 1997). While the continuum of attitudes stretched from a teacher who was unaware of how the system itself created problems for marginalized students to a teacher who had made it a mission to change the system, most of the mentors were complex in that they exhibit both reproductive beliefs in some areas and transformational beliefs in others. Some of the mentors' comments reveal the contradictions in thinking and practice 
that Popkewitz and Brennan (1997) said are revealed when situations are examined in terms of critical theory. The following comments by the mentors are typical of the kinds of remarks that reflect ideas grounded in social reproduction. Olivia is very much aware of the inequities in educating her "lower level" kids and wants to "motivate" them by asking herself, "Can I do something to change my own teaching to get them more interested in doing well?" However, she still at times resorts to what Cline and Necochea (1997) refered to as "blaming the victim" (p. 146) which is typical of teachers who perpetuate the status quo. The reasoning is that if students are to blame for their failure to learn, then the teacher does not need to critically examine her own practice. Olivia's ability to switch perspectives demonstrates how complex the notion of transformation is and how embedded the traditional ideas of social reproduction are, "Sometimes you get a bad group of kids and you can do back handsprings and cartwheels to get them, and they just don't want to work with you."

In some ways Wilma, too, expresses the "blame the victim" orientation, or in this case, the "blame the situation" for student failure, "Twenty-five years ago you had more family support, strong family values. I find it has deteriorated over the years." Pointing fingers at other causes of student failure prevents examination of the system of education and teacher practice.

Pam and Wynonna's comments support the idea of the authoritarian rather than democratic methods of the classroom with an emphasis on conformity rather than individualism.

Pam: Routine is very important for this age group. I don't think they have enough routine in their lives. They really thrive on routine. I have my schedule and they 
really know how I do what I do. I try to be firm in discipline and I think it needs to be fair across the board, too. If that's the law, they work harder, even the ones that may not get there.

Wynonna (proudly): My mentee was very firm and got right in his [student's] face and told him what he had to do and if he didn't get it done, he wouldn't go to phys. ed. [physical education class].

Patty's ability to "guess the profiles" of her students when their parents walk in for open house is probably the most glaring example of perpetuating stereotypes and stratification within the school system.

Patty: After you've been here a while, you've seen the whole spectrum. You've seen great things that human beings can do and you see the gutters that they put themselves in. I told my husband, there aren't many surprises after 30 years. You kind of guess the profiles when parents walk in for open house.

While the two true mavericks Odessa and Winnie were the most consistent in reporting both beliefs and behavior that reflected reform in the classroom, almost all the other mentors at one time showed recognition and insight into the necessity to change education for the benefit of all children. This is in direct contrast to the previous remarks. Pam understands that the playing field is not even for students upon entering the school system. This can be compared to the way our own society understands the inequity in our own democratic system. John Dewey (1916) used the example of equality before the law. Equal legal rights are built into the constitution, but we hope to hire the best attorney we can afford to ensure those rights. Those who cannot afford the best attorney, may not be quite as "equal" when forced to use public counsel. 
Pam: The system isn't fair. All education is political. You have kids who don't have a fair shot at first grade.

Wynonna offers a way to deal with the inequities that are apparent from the first day of school.

Wynonna: I think you always have to take kids from where they are and not blame someone else because you can't control the environment they come from, the educational environment or home life. You just have to deal with what you have while they're here.

Odessa makes the point that even within the ranks of the professional members of the school system, not everyone is treated with respect. The idea that teachers are just "big children" within the school system plays out in her observation of a workshop sponsored by a regional development center.

Odessa: Our education programs or situations like this talk about methods or organization. I would emphasize communication with the students and talk about respect-respect for students. Respect. Yeah. Sometimes teacher workshops can be really insulting. Don't treat me like a child. Don't tell me as if you think I've never heard this before. I'm a colleague. Even workshops from regional education administration, you know these people have been out of the classroom a long time. But the way it was presented was sort of childlike. They had adults there! They had other teachers and principals there and they were still in the classroom and they hadn't changed form that. I just thought “'Oh, just let me read the book and go off by myself." 
Winnie recognizes the problems associated with middle-class teachers teaching students from lower economic cultures from their own worldview.

Winnie: We tend to be very judgmental and not understand the child who is truant. The child who doesn't do his homework. We don't understand and we have to work at it. It isn't easy to understand that the child can't pick himself up. I mean 10 or 11 years old who gets younger children up and ready for school because mother is in bed. We have several children who are main caregivers. And I know one instance where children were being punished. If you came late you got a slip which did away with some privileges. There's this one little girl. Her mother was home asleep and they got there 10 minutes late and was handed the slip. She says I don't care what you do with that piece of paper. She came to school. And she brought two others. She got all three of them ready for school and she was only 10 minutes late. She was not a special case. This school has a poverty rate of $85 \%$. Our standards are linked to economy. It is hard to teach when our standards are different from the children's standards and these children have to go home every night. We can't come out with just our middle class values, there has to be adjustment. We have to understand this and not condemn it. We have to constantly be ready to change ourselves. We used to be able to teach the same lesson year after year. We had the same books and we knew the kids would be the same. Today, we so have much variety and I have seen teachers stuck in that old mode and those who don't let go are just as rigid and stiff as always. They are ready for retirement but just not old enough. 
The contradiction between what the teachers believe and what they sometimes practice reveals that the issue of reform and social justice is complex. The mentors themselves are products of the same system in which they are now an integral part. They have been educated in schools that were designed to promote success among those students whose culture was closest to the traditional model of white, middle class, protestant, English speaking citizens (Sleeter \& Grant, 1999). They were educated in a system of segregation through academic tracking that resulted in minority and poor students experiencing failure in school and on standardized tests which were also designed for the traditional model citizens (Sleeter \& Grant, 1999). They were part of a system that directed males into career paths with higher salaries and denied females access to activities that promoted community recognition and opportunities for learning leadership skills. Finally, they were part of a system that accepted all of this as normal and fair.

Awareness of these contradictions is necessary to change. Creating this dissonance between practice and belief is the first step to change (Johnson \& Christensen, 2000). If reform is to occur, teachers must be made uncomfortable or experience what Paulo Freire (1997) called "incompleteness" (p.312). This incompleteness pushes people toward action (Freire, 1997). According to basic communication theory, when faced with a contradiction between belief and practice, humans usually will change one or the other or rationalize (Inch \& Warnick, 1998). When rationalizations are removed, they are faced with changing to bring into balance the contradiction. The possibility that teachers would change their beliefs about democracy in the classroom rather than their behavior, then, 
exists. To facilitate a change in behavior, a training program that supports those beliefs might be effective.

Odessa and Winnie were the most consistent in their views of changing the classroom and the educational system to make it more just and to replace social reproduction with reform. I specifically asked them if they thought that mentor training might be a vehicle for changing attitudes and behavior of veteran teachers and then through mentoring the perceptions and behavior of new teachers. I then asked them if this attempted change in both veteran and new teachers might affect student learning. Their responses were interesting.

Odessa: The goal of the mentoring, one of the goals would be to improve education. So, yes, if successful, students would benefit. I've never thought about mentoring teachers for students. Certainly I have talked of and written of that "it's about kids." Even my letter to the state department is about kids. The adults need to get their heads out of the sand. Just because textbooks are written that way doesn't mean we have to do that way because that's not necessarily good for kids. If the mentoring program does not have it spelled out to the mentors that this is our goal, then I don't think it is going to directly reach students. Just like I'm thinking, I have to help that teacher and I'm not thinking about the kids, and I'm a person who thinks about that a lot. I mean if this were...this is sort of eye opening when you say that. The mentoring program will be whatever the powers that be say it is. Whatever the philosophy of it is. Because now this is political, not just educational.

Winnie: The mentor training program would be an excellent opportunity if 
everybody took it as a serious thing. I'm afraid that not all mentors are as eager to make changes. When I was a classroom teacher I had tunnel vision. I saw everything from the perspective of a first grade teacher and how it impacted me and my first graders. I had a hard time seeing how it impacted other people. I was focused in the sense that I lost perspective of how something might be better for my children because I was so intent with what I knew worked that I myself did not give new ideas a chance because I thought the old ideas were working. In retrospect, I should have been more open- minded. I've learned so much from mentoring and I share it. The most successful mentoring will be done by two people who have developed a relationship that is open, trusting, honest, and both will grow, both will learn. The mentor can't have a closed mind anymore than the mentee if there is going to be growth in both directions.

So, while both mentors believe that change is possible through mentoring and mentor training, both express a feeling that it would be difficult for two reasons. One, the goal of the program would need to be articulated as such. At this point, the purpose of mentoring is generally to retain new teachers, and even mentor training programs like Pathwise are intended to increase awareness and skill development in new teachers. No mentor-training program that I have found in the literature is designed to reform the system of education or to make education more equitable for all students. Secondly, they believe that the personalities or attitudes of those taking the training need to be ones of openness and willingness to change, those for whom dissonance would be uncomfortable enough for introspection and critical self-examination. These traits would be difficult to screen in candidates even if a program found it desirable. Giving a personality test such 
as the Myers-Briggs Type Indicator ( 1996) or relying on Adorno's profile of an authoritarian personality from The Authoritarian Personality (1950) might be one means to "check" the future mentor, but no one instrument is designed (and maybe it couldn't be designed) to accurately reveal the complex nature of receptiveness to social justice. Most of the mentors I interviewed clearly expressed mixed and complicated feelings toward reform ideas and the ideas of democracy in the classroom.

Additionally, the states themselves would have to adopt this as a goal of mentoring and of mentor-training. While the literature by those in favor of such reform see the possibilities of using mentoring as a catalyst for change, none of the three states' mentoring program literature expressed this as a goal. However, because the Pathwisetrained mentors did perceive a change in their own assessment of their teaching, and did report changes in their own teaching practices which resulted in more democratic classrooms and more constructivist teaching, the possibility of Pathwise training becoming an instrument of potential change exists. Further study on this phenomenon is needed. 


\section{CHAPTER SIX}

\section{Implications and Question for Further Study}

This chapter summarizes my findings and examines the implications of those findings for administrative practice. Additional questions that have emerged from the study are also posed.

Implications of the self-perceptions of mentors

This study supports the idea that the connotation of the word mentor influences some perceptions of its meaning without any training at all. In tracing the etymology of the word, mentor, throughout history, the evolving meaning of the word has been influential enough on its own to inform those with the title mentor of some notion of what they should be doing. Without specific training, the Pennsylvania mentors had a concept of what they were to do that matched nationally what other studies had revealed that mentors conceived as their role; however, without training, the descriptions were very vague and in some cases did not reflect what the mentors reported actually doing in their mentoring in comparison to the mentors in the other two states. Some of the metaphors that they used such as "raising a child" reflected what the mentor actually did in the mentoring situation (checking up on them, waiting on them to call for help, letting go) but for the most part the metaphors or descriptions did not have much of a relationship to the job that they performed as a mentor. Without a framework expressed in training, the mentors were left to interpret what they should be doing as a mentor. Their own interpretations may or may not have supported the goals of their districts. 
Those mentors with specific training programs, Pathwise in Ohio and statecreated in West Virginia, had self-perceptions consistent with the mentor-training programs that they had experienced. Both groups of mentors were more specific than Pennsylvania mentors in their metaphors and descriptions, and both groups' explanations of what they did in the mentoring relationship paralleled their descriptions of what they perceived as their role as a mentor. In West Virginia the mentors were concentrating on the skills that their training had emphasized were important to new teachers. In Ohio, where training emphasized respect for students and collaborative working relationships, mentors reflected this as the perception of what they were to do as mentors.

As far as self-perceptions, the mentors in both Ohio and West Virginia were able to describe their understanding of what a mentor did based on their training and could articulate in detail how that played out in their mentoring. It appears thatthe participants in this study believe that mentor training did influence their self-perceptions and contribute to how they mentored new teachers. This supports the Salzman (2000) study of Pathwise-trained mentors in which he speculated, "It is possible that training mentors to use any framework is likely to improve their performance in supporting the growth of new teachers. That is an area to explore in future studies" (p. 11). This study reinforces his speculation.

\section{Administrative Support and Perceived Success}

In analyzing the data on administrative support, my mentors reflected what most of the other studies have shown. Direct administrative support by the state, by the central office, and by the building administrator is important to the mentors. This was true across the states despite the mentor training program or lack of training. My data show that the 
primary concern of the mentors involved a combination of time and proximity. The mentors in this study found that their mentoring success could be enhanced by being in the same building as their mentee and being given time to be in each other's rooms and time to discuss and reflect on the mentee's teaching. This is also a major concern of most mentors reported by studies on what successful mentoring requires (Ganser, 2001; Hanby, 2000; Hope, 1999; Janas, 1996; Sweeny,1994). Having relief from extra assignments was also reported as something that would enhance effectiveness. The mentors' concerns about time are consistent with the literature. Administrators need to carefully consider how to effectively provide time for both the mentor and the mentee to ensure more effective mentoring.

Having a stipend and recognition for mentoring was seen as important only in that it made the job seem more valuable. There was little difference in the mentors who received a stipend but at a different rate from district to district in their perception of how administrators valued the program. In fact, because the sum is not substantial, there appeared to be no difference in the responses about how their program was valued by their districts from those teachers who received a stipend and those who did not. All mentors felt that little recognition of the importance of the program was given at the building administrative level.

What did seem to make a difference was that both those who received a stipend or who had received Pathwise training appeared to value the program more themselves. Both West Virginia and Ohio mentors valued the mentoring programs more than the Pennsylvania mentors who received neither training or stipends. Further study is needed to determine if the value of a program is judged by its participants as more valuable when 
it is supported with a stipend. If so, how much money is equated with more value? This was not established by this study. This study only reveals a difference in value between participants who had either Pathwise training or a stipend or both and those who had neither. A quantitative study of this issue would reveal an answer that would be able to be generalized to the larger population of mentors, but this study does frame the question.

Most of the mentors considered mentoring an important part of career development for both the mentee and the mentor. Most saw mentoring as a mutually beneficial relationship in that both partners learned from one another. This, too, supports previous studies in that both teachers benefit from the relationship (Darwin, 2000; Field, 1994; Hargraeves \& Fullan, 2000). The conflict between mentoring and evaluating that is perceived by the mentors needs to continue to be addressed. To avoid creating a hierarchy of teachers and to keep mentoring collegial, those charged with implementing a mentoring program will be challenged to find a way to minimize the idea of assessment in the mentoring process.

Primarily this study informs building administrators that mentoring can be a way to improve teaching and, therefore, to enhance student learning. According to Haller and Kleine (2001), “At its core, the practice of school administration consists of deliberately establishing, maintaining, and changing programs that have prescribed effects on learners" (p. 12). The mentors in this study reported making changes in their own practice that affected learners. One of the limitations of this study was that the mentors were not observed teaching or mentoring. Observing the mentors would be a way to follow up on this study. Administrators then need to be concerned about how to ensure that the effects of mentoring on students are beneficial to all students. It is important for 
administrators to realize that they play an important role in creating an environment where mentoring that benefits students could occur. Paying attention to logistics is important in the perception of the mentors about how successful the mentoring could be. As administrators, according to Gulick and Urwick (1937) in Haller and Kleine (2001) the building principal is responsible for planning, organizing, staffing, developing, coordinating, and evaluating the mentoring program.

Building principals are seen by the mentors in this study as caring little to be involved in the mentoring process or in recognizing mentoring as a valuable way of improving teaching. These mentors wanted more involvement from their building principals in selecting mentors, providing time for mentoring, and recognition of the mentors' contribution regardless of the type of training they had received or how their state conceived of the job of mentoring. While all the mentors viewed their mentoring experiences as successful because the mentee remained in teaching and the relationships were positive, all the mentors thought that the experience could have been enhanced if principals were more involved in providing time and general support in the forms of interest, proximity of partners, and recognition for the mentors. With the support of administration a mentoring experience may become the collaborative catalyst for change that Moir and Gless (2001) believed it could become.

Implications for administrators about training

For state administrators, politicians, or other decision-makers who select and implement mentor-training programs, one of the most significant results of this study was the perceptual difference between Pennsylvania's mentors and those of West Virginia and Ohio. That difference suggests that at least in these three states' cases that training 
may influence self-perception. While there were substantial differences between the two states with training and the one without, there were also more subtle differences between Ohio and West Virginia. The two state programs had different conceptual frameworks, and each of the trained mentors reflected their state's training focus. It seems the mentors' training programs had informed their perceptions of mentoring and their practice as teachers.

It would therefore seem that anyone in a decision-making capacity would need to carefully select a mentoring program that satisfied the goals of the educational system of that state. If in some states, individual districts make that decision, then local district superintendents may need to match a program with both state and local goals. It is important to understand that at least in this study with limited but diverse participants, it was not just that mentors had received training that they perceived as influential on their work as mentors, but it was that they had received and "bought into" their mentor training goals. If indeed, a decision-maker did not take this into consideration and assumed that most mentor-training programs had the same theory base, she might make a decision that would influence mentors to perform in a way contrary to the philosophy of the district.

Unless a mentor-training program is chosen because it supports the philosophy and belief system of what the school system thinks mentors should be doing, trained mentors may engage in mentoring that does not enhance the school system's philosophy and may pass these ideas on to new teachers. If a state wants only a buddy system, which is considered socially reproductive (Ballantyne \& Hansford, 1995), then the Pennsylvania districts' systems of not training mentors would be appropriate. If, however, a system wants to effect real change in the status quo or to improve the teaching profession, then a 
mentor training system, which has this as its goal, would be appropriate. Only through a framework and articulated goals will a mentoring program be likely to achieve any changes in the status quo.

\section{Mentor training as transformational}

Probably the most surprising discovery of this study was that the Ohio teachers, in addition to reporting benefits of mentoring (which most studies indicate that mentors do report, and all of my participants reported) reported using information from their training to critically examine and change their behavior in the classroom. None of the participants in the other two states reported looking at their own teaching in a different way as a result of their training. Only Ohio mentors who had received the Pathwise-training program could explain in detail how the training had influenced them to make changes in their teaching and interaction with students to make the classroom more fair to all students. Except for Winnie, in West Virginia, who had received training in poverty as a culture, none of the other mentors mentioned making critical changes in their teaching to address social justice issues; none had mentioned critical reflection of their own practice. According to Schon (1987), reflection is a necessary part in engaging a teacher as a transformer of current practice. He also argued that it is necessary for a new practitioner to be guided and coached by an expert practitioner who models reflective thought. Critical inquiry is a means by which teachers can change their work to improve education (Schon, 1987). This modeling of critical inquiry by veteran mentors, then, could encourage new teachers to adopt critical examination of their own teaching and of the system of education to improve education for all children. 
While Danielson, who works for ETS, makes this claim in Enhancing Professional Practice: A Framework for Teaching (1996), I found no other empirical support that this training program might be a vehicle for teachers to critically examine their own practices. In this study, those mentors who took the Pathwise training program began to analyze the linkage between their day to day practices and the values that are implicit in the larger social and political realities. As a result of their training, and mentoring using that training, their understanding of how the curriculum and their teaching methods promoted a hidden curriculum which was not necessarily good for all students led them to make significant changes in the way they practiced their profession. Teachers who embody these orientations will create classrooms where students can construct learning that is personally rewarding and socially responsible (Beyer, 2001).

The significant material in the Pathwise training material seemed to be the emphasis on individual learning styles, cultural influences on learning, and an insistence on fairness and respect for students as well as teacher efficacy and collaborative professionalism. I could find no study that had been conducted to pinpoint what domain or criteria actually effected the changes these teachers made. This would be an interesting study. While many professional and government organizations and agencies have developed standards to address these same principles (NCATE, Praxis, Interstate New Teacher Assesssment and Support Consortium (INTASC), ASCD) the mentor teachers in Ohio in this study reported being primarily exposed to them through their Pathwise training.

Olive: I hadn't thought of myself, and I changed myself from taking those classes or I was more aware of some things. 
Odessa: I really do believe in those 19 criteria... Wanting change, it is hard to move the people who don't want change.

Odessa: I think those criteria should be modeled to anyone, not only new teachers. The opportunity for teachers to access information in a number of ways about critical reflection and critical pedagogy exist, but teachers are busy. The mentors in this study repeatedly reported being overwhelmed by too much work to do in too little time. Their first real encounters with any ideas that could be viewed as related to critical theory were in their mentor training sessions. The fact that other influences or the possibility of access to other sources for this same information does not diminish the finding that these particular mentors perceived the Pathwise training to be a catalyst for changing their perceptions of themselves as teachers and their practices in the classroom.

One question I tried to answer was "Is mentor training either transformational or reproductive?" The answer is yes. It can be both, because in this study it was perceived as influential in shaping the mentors' views of what mentoring is or is not. Because it has the potential to influence, mentor training can be either transformational or reproductive. It depends not on whether there is training, but whether the purpose of the training and the focus of the training trigger critical examination of practice and of the institution of schooling, or if the training promotes the same ideas that lead to social reproduction.

Because this study suggests that there are differences in perceptions, not only about mentoring, but about education in general and educator practice among mentors who have had different training programs, further study in this area is necessary. Some of the questions that have emerged from the results of this study remain to be answered. If the mentors become teachers who want reform, will they pass that on to their mentees? 
Can real changes in education come about through this mentoring process? Can induction year programs which focus on social justice and constructivism act as a catalyst for changing school cultures and improving the teaching profession? While this study seems to indicate that these possibilities exist, the answers to these questions are beyond the scope of this study. If this research provides nothing more than a stimulus to build upon the body of knowledge about mentoring as a transformational catalyst then it has been successful.

Induction-year programs are faced with preparing teachers for roles that are changing. Some training programs may focus on the traditional roles of classroom teachers, assuming that teachers and children are the same as they always have been and that time and classes are scheduled in a traditional ways. They may ignore research that encourages different ways of teaching to accommodate the changing faces of American students and to make schools more equitable for marginalized students. Some training programs may recognize a need for social reform and so focus on ways to critically examine all classroom behavior. If administrators are concerned with meeting the challenge of preparing teachers for a more democratic way of schooling, then they will want to look carefully at the programs available and select one which attempts to challenge teachers to critically examine their practices and their classrooms.

I began this research with an idea that all mentor training programs produced the same results, and that some were simply packaged better for a higher price. Pathwise training averages a cost of $\$ 2,000$ for every 25 teachers trained (Salzman, 2000). I questioned the value of a state spending what few education dollars it has on a program that might be developed locally for a fraction of the cost. I have changed my position. 
While I am very uncomfortable supporting an expensive program from a company that has already consumed more than its share of the testing and assessment market, Pathwise by ETS did appear to be the more favorable program of the three when examined in light of teachers' perceptions. The Pathwise-trained mentors reported being more responsive to promoting an equitable and just classroom through empowering students. These mentors were more aware that changes in their own teaching needed to occur to make this happen, and they attributed this awareness to their mentor training.

The final question that further research should investigate is " Are there other mentor training programs as effective as Pathwise in changing teacher perceptions of themselves as teachers and encouraging their critical examination of practice?" While Pathwise was the only program of the three studied (and it is used in 27 states) that successfully informed mentors in the area of self-examination, this study did not examine what it was about Pathwise that made it successful in this area. The possibility exists that there are other training programs as effective in promoting critical self-examination of teaching practice, but that they were not part of this study.

This study offers empirical support to the idea that mentor training in these three state cases did influence teachers' self-perceptions as mentors and their practice as teachers. It warrants a serious consideration by administrators in charge of selecting mentor training programs because the implication is that the selected program will affect how the mentoring is perceived and carried out by those trained in the program. 


\section{REFERENCES}

Adams, C. F. (1875). Familiar letters of John Adams to Abigail Adams. Boston: Houghton-Mifflin, Co.

Adorno, T. (1950). The authoritarian personality. NY: Harper and Row.

Arnstine, D.(1995). Democracy and the arts of schooling. Albany, NY: State University of New York Press.

Ayers, W., Hunt, J.P. \& Quinn, T. (Eds.) (1998). Teaching for social justice. NY: Teachers College Press

Ballantyne, R. \& Hansford, B.(1995). Mentoring beginning teachers: A qualitative analysis of process and outcomes. Educational Review, 47 (3), 297.

Barry, C. (1998). Choosing qualitative analysis software: Atlas/ti and Nud*Ist compared. Sociological Research online 3 (3). http://www.scoresonlile.org.uk

Barbour, C. (2001). A checklist for improving qualitative research: A case of the tail wagging the dog. [Electronic version] British Medical Journal, 322 (7294), 1115 1118.

Beyer, L. (2001). The value of perspectives in teacher education. Journal of Teacher Education, 52 (5), 151-169.

Berrill, D. (1995). Research in Ontario Secondary Schools. Retrieved Sept. 27, 2001 from http://www.oise.atoronto.ca.

Blasé, J. \& Blasé, J. (2001) The teacher’s principal. Journal of Staff Development, 22 (1), $22-25$.

Bogdan R. \& Biklen, S.(1998). Qualitative research for education: An introduction to theory and methods. Boston: Allyn and Bacon. 
Boultte, G. S.(2002). Resounding voices: School experiences of people with diverse ethnic backgrounds. Boston: Allyn and Bacon.

Brock, B. (1999). The principals' role in mentor programs. Mid-Western Educational Researcher, 12 (4), 18-21.

Brock, B., \& Grady, M. (1998). Beginning teacher induction programs: The role of the principal. The Clearing House, 71 (3) 179-83.

Burke, R. \& McKeen, C. (1996). Gender effects in mentoring relationships. Journal of Social Behavior \& Personality, 11 (5), 91-104.

Carroll, D. (2002, January). Mentoring choices in Ohio. Symposium for Praxis III recalibration. Zanesville, Ohio.

Certification in Mentoring (2000). New South Wales Department of Education. Au.

Chase, B. (1998). NEA's role: Cultivating teacher professsionalism. Leadership, 55 (5), $27-28$.

Clark, P. (1984). The metamorphous of mentor Fenelon to Balzac. Romantic Review. LXXC (2), 200-215.

Chubbuck, S., Clift, R., Allard, J. \& Quinn, J. (2001). Playing it safe as a novice teacher: Implications for programs for new teachers. Journal of Teacher Education, 52 (5), 365-377.

Cline, Z. \& Necochea, J. (1997). Mentoring in education: Educational change. Journal for a Just and Caring Education, 3 (2), 141-160.

Congresswoman Carolyn McCarthy. Press Release. Committee on Education and Workforce. Retrieved May 11, 2000 from http://www.house.gov/carolynmecarthy. Conte, A. (2000). In loco parentis: Alive and well. Education, 121 (1), 196-201. 
Creswell, J. \& Miller, D. (2000). Determining validation in qualitative inquiry. [Electronic version] Theory into Practice, 39 (5), 124-131.

Danielson, C. (1996). Enhancing professional practice: A framework for teaching.

Alexandria, Virginia: Association for Supervision and Curriculum Development.

Darling-Hammond, L. (1996). Doing what matters most: Investing in quality teaching. New York: National Commission on Teaching and America's Future.

Darling-Hammond, L. (1997). The quality of teaching matters most. Journal of Staff Development, 18, 38-41.

Darwin, A. (2000). Critical reflections on mentoring in work settings. Adult Education Quarterly, 50 (3), 197-211.

Davis, A. (1995). Mentor and protégé characteristics in relation to role expectation, perceived success and satisfaction. Paper presented at Southwest Academy of Management, March 15, 1995, Houston, TX.

Dewey, J. (1916). Democracy and education. NY: McMillian.

Elliott, B \& Calderhead, J. (1992). Mentoring for teacher development: Possibilities and caveats. In D McIntyre, H. Hagger \& M. Wilkin (Eds.) Mentoring: Perspectives on school based teacher education (pp. 166-189) London: Kogan Page.

Evertson, C. \& Smithey, M. (2000). Mentoring effects on protégés classroom practice: An experimental field study. The Journal of Educational Research, 93 (5), 294-304.

Fairbanks, C., Freidman, P. \& Kalm, C. (2000). The role of effective mentors in learning to teach. Journal of Teacher Education, 51 (2), 102-112.

Feiman-Nemser, S. (1996). Teacher mentoring: A critical review. ERIC Clearinghouse on Teaching and Teacher education. Office of Educational Research and 
Improvement, Washington, DC.

Feiman-Nemser, S. (2001). Helping novices to teach: Lessons from an exemplary support teacher. Journal of Teacher Education, 52 (1), 17-30.

Fenelon, F. (1796). Adventures de Telemaque. NY: Longworth.

Field, B. (1994). Teachers as mentors: A practical guide. London: The Falmer Press.

Foster, W. (1986). Paradigms and promises: New Approaches to Educational Administration. Buffalo, N.Y.: Prometheus Books.

Freire, P. (1997). Mentoring the mentor: A critical dialogue with Paulo Freire. New York: Peter Lang.

Ganser, T. (1998). Metaphors for mentoring. The Educational Forum, 62, 113-119.

Ganser, T. (2001). The principal as new teacher mentor. Journal of Staff Development, 22 (1), 39-41.

Giroux, H. \& McLaren, P. (1996). Teacher education and the politics of engagement: the case for democratic schooling. In P. Leistyna, A. Woodrum, \& S. Sherblom (Eds.) Breaking free:The transformative power of critical pedagogy. (pp. 301326). Boston: Harvard Educational Review.

Greenwald, R.L., Hedges, L. \& Laine, R.(1996). The effect of school research on student achievement. Review of Educational Research, 66, 361-386.

Gulick, L. \& Urwick, L (Eds.). (1937). Papers on the science of administration. New York: Institute of Public Administration.

Haller, E. \& Kleine, P. (2001). Using educational research: A school administrator's guide. N.Y.: Longman.

Hanby, D. (2000). The preparation of mentors and the perceived impact on entry year teachers: A descriptive study. Dissertation. Miami University, Oxford, Ohio (UMI 
AAT9964476).

Hargreaves, A. \& Fullan, M. (2000). Mentoring in the new millennium. Theory into Practice, 39 (1), 50-6.

Hawkey, K. (1997). Roles, responsibilities, and relationships in mentoring: A literature review and agenda for research. Journal of Teacher Education, 48 (5), 325.

Hirsch, E. Program of Education. National Conference of State Legislatures (NCSL). (2002 Jan.). Symposium conducted at Holmes Partnership Sixth Annual Conference. San Antonio, TX.

Holmes Partnership (2001). [Brochure].

Hope, W. (1999). Principals' orientation and induction activities as factors in teacher retention. The Clearing House.

Inch, E. \& Warnick, B. (1998). Critical thinking and communication: The use of reason in argument. Boston: Allyn and Bacon.

INTASC Core Standards (2001). Interstate New Teacher Assessment and Support Consortium. Retrieved Jan. 22, 2002 from http://www.ccsso.org/intascst.html.

Jambor, M. \& Patterson, J.L. (1997). TEACH is for new teachers: An innovative mentoring program for first year teachers is paying big dividends for an Alabama district. Principal, 77, 36.

Janas, M. (1996). Mentoring the mentor: A challenge for staff development. Journal of Staff Development, 17, 2-5.

Jehlen. A. (2001). Rural education gets squeezed. [Electronic version] NEA Today, 19 (6) 29.

Johnson, B. \& Christensen, L.(2000). Educational research: Quantitative and qualitative 
approaches. Boston: Allyn and Bacon.

Johnson, H. (2001). Administrators and mentors: Keys to the success of beginning teachers. Journal of Instructional Psychology, 28 (1): 44-49.

Jones, M. (2000). Trainee teachers' perceptions of school-based training in England and Germany with regard to theft preparation for teaching, mentor support and assessment. Mentoring and Tutoring, 8 (1) 63-80.

Kemmis, S. \& McTaggart, R. (Eds.) (1988). The action research planner. $\left(3^{\text {rd }}\right.$ ed.). Geelong: Deakin University Press.

Kerka, S.(1997). Constructivism, workplace learning, and vocational education. Eric Digest, no. 181.

Levin, P. (1987). Abigail Adams. New York: St. Martins Press.

Lewis, M. \& Wray, D. (1999). Secondary teachers' views and actions concerning literacy and literacy teaching. Educational Review, 51 (3), 273-282.

Little, J. W. (1990). The metaphor phenomenon. Cazden, C. (ed.) Review of research in education ( pp297-351) NY: Longman.

Locke, L., Spirduso, W. \& Silverman, S. (2000). Proposals that work: A guide for planning dissertations and grant proposals. Thousand Oaks, CA: Sage Publications.

McKenna, G. (1998). Mentor training: The key to effective staff development. Principal, 77: 47-49.

Merriam, S. (1991). Case study research in education: A qualitative approach. San Francisco: Jose-Bass.

Merriam, S. (1995). What can you tell from an N of 1: Issues of Validity and Reliability in Qualitative Research. PAACE Journal of Lifelong Learning, 4, 51-60. 
Mills, H., Moor, D., \& Keane, W. (2001). Addressing the teacher shortage: A study of successful mentoring programs in Oakland County, Michigan. The Clearing House.

Moir, E. \& Gless, J. (2001). Quality induction: An investment in teachers.[Electronic version]. Teacher Education Quarterly, 20 (1), 109-114.

Monsour, F. (2000). Winning pairs. Principal Leadership: High School Education, 1 (4), $62-5$.

Myers, P. \& Myers, K. (1996). Myers-Briggs Type Indicator. Consulting Psychologists Press, Inc.

National Center for Research on Teacher Learning (1992). Findings on learning to teach. Ohio Department of Education. Website.

National Center for Education Statistics (2002). Digest of Educational Statistics. Washington D.C.: Government Printing Office.

NCATE Standards (May 11, 2000) The Standards of Excellence in Teacher Preparation. Retrieved Oct. 12, 2001 from http://www.ncate.org/standard/m_stds.htm.

Neito, S. (1996). Affirming diversity: The sociopolitical context of education. White Plains, NY: Longman.

Ohio Department of Education. Website. Retrieved May 10, 2001 from www.state.oh.us/EYT.

Pathwise Orientation Guide (1995). ETS.

Patton, M. (1990). Qualitative evaluation and research methods. London: Sage. Pennsylvania Department of Education. Division of School Based Improvement. (2001). Popkewitz, T. \& Brennan, M. (Summer 1997). Restructuring of social and political theory in education: Foucault and a social epistemology of school practices. 
Educational Theory. 47 (3), 287-313.

Reid, D. \& Jones, L. (1997). Partnership in teacher training. Education Studies, 23 (2), 263-277.

Reiman, A. \& Edelfelt, R. (1991).The opinions of mentors and beginning teachers: What do they say about induction? Research Reports 90-7. University of North Caroling at Chapel Hill. EDRS MF01/Pc02.

Rowley, J. (1999). The good mentor. Educational Leadership 56 (8), 20-22.

Salzman, J. (2000). Talking the same language: Training mentors to use the Pathwise Performance Assessment with induction-year colleagues. Presented at the American Educational Research Association Annual Meeting, April 24-28, 2000, New Orleans, LA.

Schon, D. (1987). Educating the reflective practitioner. San Francisco: Jossey-Bass.

Schwiebert, V., Deck, M., Bradshaw, M., Scott, P. \& Harper, M. (1999). Women as mentors. Journal of Humanistic Counseling, Education and Development, 37 (4), 241-53.

Seidman, I.E.(1991). Interviewing as qualitative research: A guide for researchers in education and social sciences. NY: The Teachers College Press.

Sergiovanni, T. \& Starratt, R. (1993). Supervision: A redefinition. NY: McGraw-Hill.

Shen, J. (2001). Teacher and principal empowerment: National, longitudinal, and comparative perspectives. Educational Horizons, 79 (3): 124-129.

Sleeter, C. \& Grant, C. (1999). Making choices for multicultural education: Five approaches to race, class, and gender. NY: John Wiley \& Sons, Inc.

Spradley, J. P. (1979). The ethnographic interview. NY: Holt, Rinehart \& Winston.

Stake,R. (1995). The art of case study research. Thousand Oaks, CA: Sage 
Publications.

Stansbury, K. (2001). What new teachers need. [Electronic version] Leadership, 30 (3), $18-21$.

Stodolsky, S. \& Grossman, P. (2000). Changing students, changing teaching. Teachers College Record, 102 (1), 125-173.

Stroot, S., Fowlkes, J., Langholz, J., \& Paxton, S. (1999). Impact of a collaborative peer assistance and review model on entry-year teachers in a large urban school setting. Journal of Teacher Education, 50 (1) 27-40.

Sweeny, B. (1994). A new teacher mentoring knowledge base. The Mentoring Leadership and Resource. Retrieved January 12, 2002. http://www.mentors.net/LibraryFiles/Knowlbase.html\#anchor646421.

Tirozzi, G. A conversation with Dr. Gerald Triozzi, executive director of National Association of Secondary School Principals. Retrieved Sept. 26, 2001 from http://www.administrators.net.

Villegas, A. \& Lucus, T. (2002). Preparing culturally responsive teachers: Rethinking the curriculum. Journal of Teacher Education, 53 (1), 20-32.

West Virginia Center for Professional Development (2001). Book of firsts: A checklist for mentoring beginning teachers.

West Virginia Department of Education. Impact Grant. (2000).

Whitaker, S.(2000). Mentoring beginning special education teachers and the relationship to attrition. Exceptional Children, 66 (4), 546-566.

Williams, A. (1993). Teacher perceptions of their needs as mentors. British Education Research Journal, 19 (4), 407-421. 
Wolcott, H. (1990). On seeking and rejecting validity in qualitative research. Eisner, E. \& Peshkin, A. (eds.) Qualitative inquiry: The continuing debate. NY: Teachers College Press. 


\section{APPENDICES}



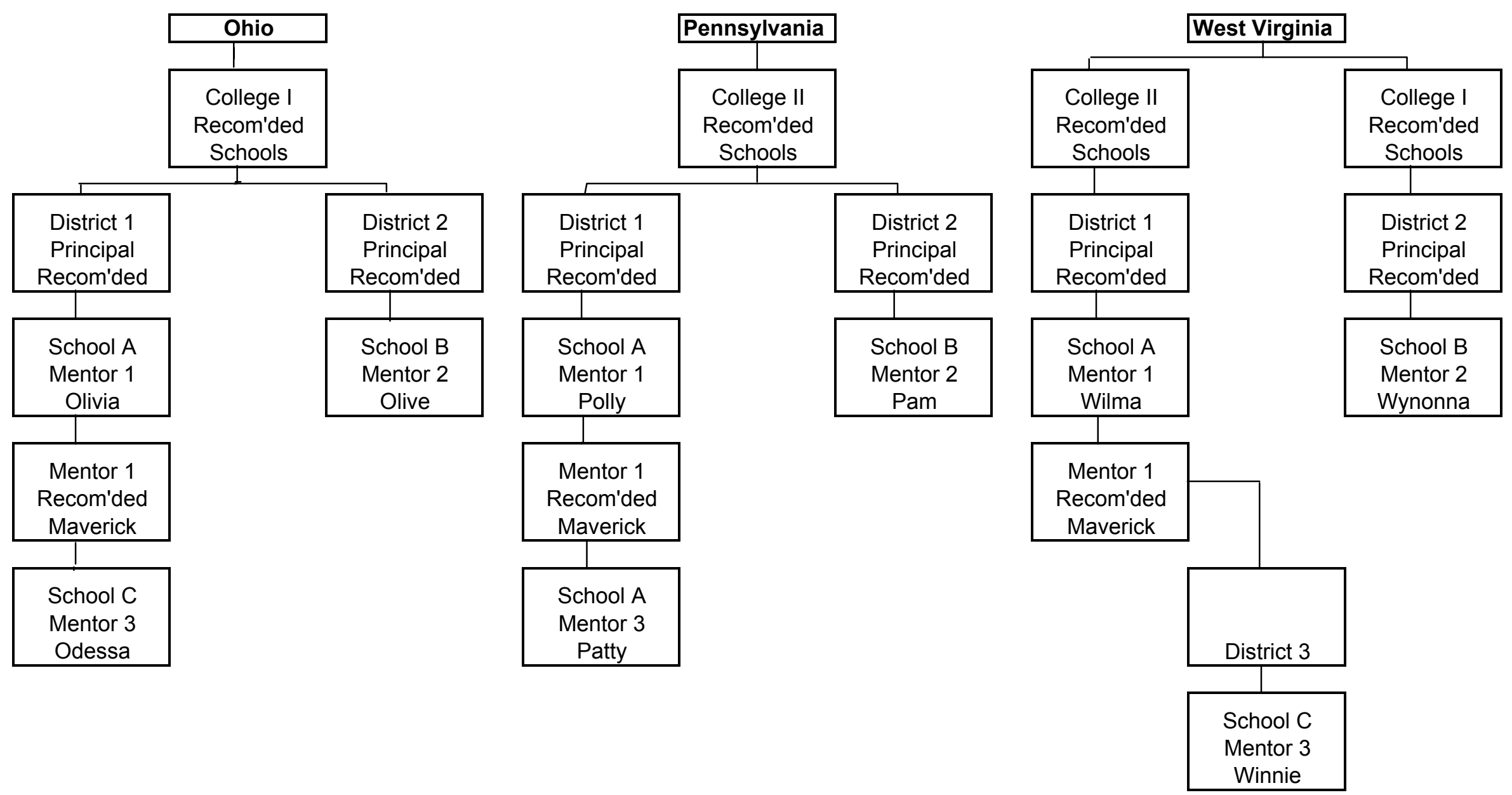
CATEGORY

\begin{tabular}{|c|c|c|c|c|c|c|c|c|c|}
\hline \multirow{2}{*}{$\begin{array}{l}\text { State } \\
\text { District / School }\end{array}$} & \multicolumn{3}{|c|}{ Ohio } & \multicolumn{3}{|c|}{ Pennsylvania } & \multicolumn{3}{|c|}{ West Virginia } \\
\hline & $1 \mathrm{~A}$ & $1 \mathrm{C}$ & 2B & $1 \mathrm{~A}$ & $1 \mathrm{~A}$ & $2 \mathrm{~B}$ & $1 \mathrm{~A}$ & $2 \mathrm{~B}$ & $3 C$ \\
\hline Mentor & Olivia & Odessa & Olive & Polly & Patty & Pam & Wilma & Winnie & Wynona \\
\hline Age & 40 & 48 & 47 & 60 & 52 & 44 & 50 & 55 & 50 \\
\hline Supposed Maverick & & Maverick & & & Maverick & & & Maverick & \\
\hline Years Teaching & 18 & 25 & 25 & 37 & 30 & 22 & 27 & 35 & 26 \\
\hline Years Mentoring & 10 & 7 & 10 & $\begin{array}{l}20 \text { informal } \\
\text { and } 2 \text { formal }\end{array}$ & 2 & 3 & 4 & 10 & 5 \\
\hline \# of Schools Taught & 3 & 2 & 1 & 2 & 7 & 2 & 2 & 2 & 1 \\
\hline \# of Districts Taught & 3 & 1 & 1 & 1 & 1 & 1 & 2,2 states & 1 & 1 \\
\hline Grades Taught & $3-8$ & $5-7$ & $2-5$ & $1-2$ & $1-7$ & 4 & $4-5$ & $1 \&$ Title I & $1-2$ \\
\hline Type of Training & \begin{tabular}{|l} 
Mentor, \\
Pathwise
\end{tabular} & $\begin{array}{l}\text { Mentor, } \\
\text { Pathwise, } \\
\text { Praxis III } \\
\end{array}$ & $\begin{array}{l}\text { Mentor, } \\
\text { Pathwise }\end{array}$ & none & none & none & district & state \& district & state \\
\hline Stipend & no & no & $\begin{array}{l}\text { district } \\
\$ 300 \\
\end{array}$ & no & no & no & state $\$ 600$ & state $\$ 600$ & state $\$ 600$ \\
\hline Released Time & no & no & $\begin{array}{l}\text { half-day } \\
\text { twice a } \\
\text { year }\end{array}$ & no & no & no & $\begin{array}{l}\text { out of building } \\
\text { only, half-day } \\
\text { once a month }\end{array}$ & $\begin{array}{l}\text { yes, whenever } \\
\text { requested }\end{array}$ & $\begin{array}{l}\text { yes, } \\
\text { whenever } \\
\text { requested }\end{array}$ \\
\hline
\end{tabular}




\author{
Script \\ Joy Cowdery \\ Induction-year Mentors' Self-perceptions and Reflections on Their Training and \\ Administrative Support
}

Hello, I am Joy Cowdery, a doctoral student at West Virginia University, and I am conducting research on mentoring for my dissertation. I appreciate your willingness as a mentor teacher to volunteer to be interviewed. I will keep confidential your name and use a pseudonym for you and for your school in my notes and in my final dissertation. Only your state will be designated. I will be interviewing you for $60-90$ minutes today and then we will arrange for another interview of the same length in about a week. The final interview of the same length will be in about three weeks at your convenience. Between interviews, I will provide you with the opportunity to comment on the interview and topics that come up in a list serve. Here is the address of the listserve. Feel free to use it at any time to contact me or to respond to comments by other participants.

Do you mind if I audio-tape the interview? If at any time you would like me to stop taping the interview, please signal by raising your hand. I will be transcribing the tape verbatim and will invite you to check the transcript for accuracy at each successive interview session and then sending the transcript after the last interview.

Are you ready to begin the interview? 


\author{
Interview Guide \\ Joy Cowdery \\ Induction-year Mentors' Self-perceptions and Reflections on \\ Their Training and Administrative Support
}

\title{
First Interview:
}

Purpose: To build rapport and have the participants talk about themselves and their relationship to the situation and setting.

\section{Tentative questions:}

How long have you been teaching?

Can you tell me about your career and where you have taught?

What do you think led you to a career in teaching?

How do you feel about your career choice?

Has teaching changed since you became a teacher?

Do you have any thoughts about what makes a good teacher in today's schools?

How can you tell if a teacher is good? By what do you measure success in teaching?

Any thoughts as to what a "bad" teacher is?

If you were to summarize what the purpose of education is in today's society, what would it be?

How long have you been mentoring new teachers?

Can you tell me how you were selected for mentoring and why?

Why did you decide to become a mentor?

What do you think are the qualities of a good mentor?

What would a bad mentor be like?

What would the essential quality of a good mentor be?

Can you tell me about your mentees? Do you notice any differences in the experiences?

Describe this year's mentoring relationship.

Can you describe what you think is a successful mentoring experience?

What would let you know that an experience in mentoring was successful?

What would a bad mentoring experience be like?

What would a good mentee be like? A bad mentee?

Can you tell me about your training to become a mentor?

What do you remember most from it?

What do you seem to use the most from it?

Tell me what topics your training didn't cover that you think it should have now that you've been mentoring for a while?

If you were to design a mentor-training program how would you design it?

What are some tasks and responsibilities that you associate with being a mentor?

What expectations do you think most administrators have of mentor teachers? Mentees?

Do you receive any support for mentoring from administrators or other teachers?

Is there any support you don't receive that you would like to receive?

How do you think your administrator views the mentoring process?

Would you have been helped by being mentored as a first year teacher?

Would you have liked the process? 
After several experiences in mentoring, what would you say are the benefits for each of the following: mentors, mentees, students, administrators, the process of education itself? Is there anything else about mentoring you would like to add, today?

\section{Questions for list-serve:}

Have you thought of anything else you would like to comment on that we talked about in our interview?

Is there something you wish I would have asked?

Has any thing new developed in your mentoring relationship since we talked?

\section{Second Interview:}

Purpose: To reconstruct experiences in the phenomenon of the mentoring process:

\section{Tentative questions:}

Could you tell me more about the training you've received? What was the typical training session like?

Have you had any follow up sessions? Could you walk me through what those were like?

Can you describe how you plan a typical year with your mentee?

Tell me about this year's mentoring relationship and process?

Could you describe a typical day in which you interact with your mentee?

What has been the worst experience with a mentee?

What has been the best experience with a mentee?

What relationship do you have with your mentee's students?

Is there anything else you want to add to what we've talked about?

\section{Questions for list-serve:}

At this point I would like to post some observations from the different mentors and ask each to respond to them.

\section{Third Interview:}

Purpose: To reflect on the whole mentoring experience

Some of the questions for this interview will emerge from the data already collected. I will be analyzing data as I collect it and with this and the observation notes and official documents, I will have generated specific questions related to the coding that emerges.

Could you give me a metaphor that describes your experiences with mentoring?

How has being a mentor impacted your life as a teacher?

If you think that your mentoring has made a difference in students' lives, could you describe that for me?

If I leave here with one idea about mentoring new teachers, what should that be? 


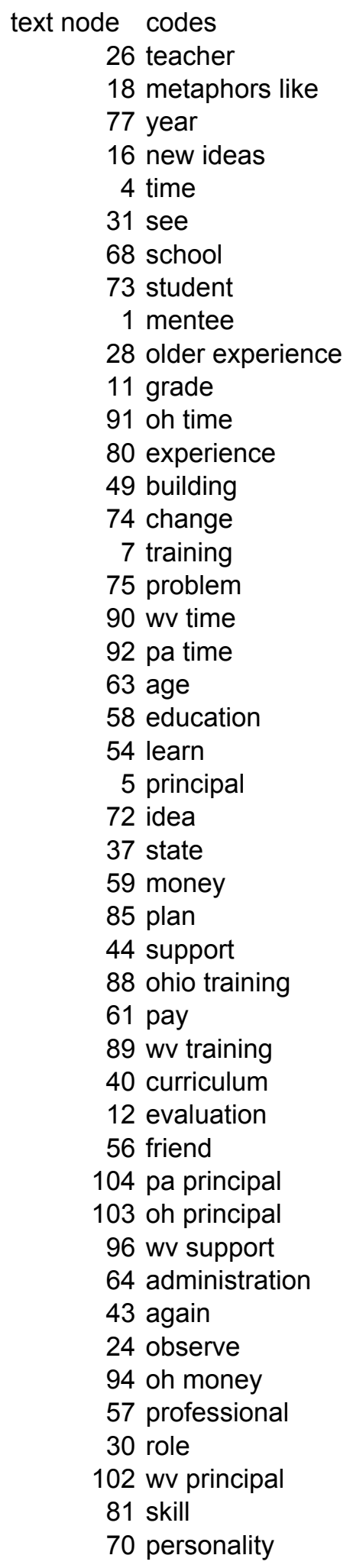

$\begin{array}{rr}\text { \# documents } & \text { \# text units } \\ 29 & 718 \\ 27 & 515 \\ 28 & 451 \\ 29 & 321 \\ 29 & 299 \\ 27 & 295 \\ 27 & 269 \\ 28 & 220 \\ 27 & 181 \\ 26 & 176 \\ 22 & 161 \\ 10 & 156 \\ 26 & 143 \\ 25 & 140 \\ 23 & 137 \\ 24 & 135 \\ 26 & 134 \\ 9 & 131 \\ 8 & 126 \\ 26 & 120 \\ 23 & 102 \\ 24 & 98 \\ 23 & 91 \\ 25 & 90 \\ 24 & 89 \\ 22 & 78 \\ 21 & 70 \\ 15 & 61 \\ 8 & 59 \\ 25 & 51 \\ 8 & 50 \\ 16 & 49 \\ 18 & 47 \\ 17 & 40 \\ 8 & 39 \\ 9 & 39 \\ 5 & 36 \\ 14 & 36 \\ 15 & 34 \\ 15 & 34 \\ 20 & 33 \\ 14 & 32 \\ 14 & 28 \\ & 30 \\ & \\ 9 & \end{array}$


Praxis/Pathwise system is composed of the following elements:

- research-based criteria that applies to all grade levels, classroom structures, and content areas

- trained assessors to ensure that observers accurately and reliably interpret and score the assessment data in order to provide substantive feedback and coaching - various data collection instruments and forms to help the observer analyze and score teaching
performance

- an optional scoring and reporting service to provide various individual and cumulative score reports (through ETS)

PRAXIS/PATHWISE has organized the complex tasks of teaching around four domains with 19 separate criteria

A. organizing content knowledge - planning for instruction

- becoming frmilier with relevent aspects of students' background

knowledge and experience;

- articulating clear leaming goals/objectives for the lesson that are appropriate to the students.

- demosstrating en understroding of the connections between the content that pras learned previousty, the curres

content that remains to be learned in the funure:

- creating or selecting teaching methods, learning activities, and instructional materials or other resources that

- are appropriate to the students and that are aligged with the lesson goals/objectives; lesson goals/objectives.

B. creating an environment

- creating a climate that procoles faimess;

- establishing and maintaining rapport with students:

- communicating challenging learning expectations to each student;

- establishing and maintaining consistent standards of classroom behavior.

C. instruction making the physical environmeat as safe and as conducive to learning as possible.

- making the learning goals/objectives and the instructional procectures clear to students;
making content comprebensible to students.
- meouraging students to entend their thinking.
monitoring students' understanding of content through a variety of means, providing feedback to the students tI
assist learning, and adjusting learning activities as the situation demands;
using instructional time effectively.

D. professionalism - reflecting on teaching and learning

- reflecting on the extent wo which the learning goals/objoctives were met; - building professional relationships with colleagues to share teaching insights and to coordinate learning
activities for students.

communicating with parents or guardims about student learning.

PRAXIS/PATHWISE is a flexible system which is responsive to an individual's personal teaching style - it uses a constructivist theory that fosters growth and the professional development of student and first-year teachers by recognizing strengths and weaknesses. When weaknesses are identified, the mentor can then provide coaching.

'Compiled by Dr. Carmen R Giebelhaus (Ohio State Department of Education) from Pathwise: Qriemtation Guide (1995), Educational Testing Service (ETS), Princeton, N.J. 


\section{TEACHER PERFORMANCE ASSESSMENTS} ASSESSMENT CRITERIA

Domain A - Organizing Content Knowledge for Student Learning

A1: Becoming familiar with relevant aspects of students' background knowledge and experiences

A2: Articulating clear learning goals for the lesson that are appropriate for the students

A3: Demonstrating an understanding of the connections between the content that was learned previously, the current content, and the content that remains to be learned in the future

A4: Creating or selecting teaching methods, learning activities, and instructional materials or other rest the students and that are aligned with the goals of the lesson

A5: Creating or selecting evaluation strategies that are appropriate for the students and that are aligned with the goals of the lesson

\section{Domain C - Teaching for Student Learning}

C1: Making learning goals and instructional procedures clear to students

C2: Making content comprehensible to students

C3: Encouraging students to extend their thinking

C4: Monitoring students' understanding of content through a variety of means, providing feedback to students to assist learning, and adjusting learning activities as the situation demands

C5: Using instructional time effectively
Domain B - Creating an Environment for Student Learning

B1: Creating a climate that promotes fairness

B2: Establishing and maintaining rapport with students

B3: Communicating challenging learning expectations to each student

B4: Establishing and maintaining consistent standards of classroom behavior

B5: Making the physical environment as safe and conducive to learning as possible

Domain D - Teacher Professionalism

D1: Reflecting on the extent to which the learning goals were met

D2: Demonstrating a sense of efficacy

D3: Building professional relationships with colleagues to share teaching insights and to coordinate learning activities for students

D4: Communicating with parents or guardians about student learning

Copyright $O 1994$ by Educational Testing Sevice. All rights reserved. EDUCATIONAL TESTING SERVICE, ETS, the ETS logo and THE PRAXIS SERIES: PROFESSIONAL ASSESSMENTS FOR BECINNINC TEACHERS and its design logo are registered trademarks of Educational Testing Service. 


\section{WEST VIRGINIA BEGINNING EDUCATOR INTERNSHIP PROGRAM}

\section{SCOPE:}

Every person to whom a professional teaching certificate is awarded after the first day of January, 1992, shall successfully complete a beginning teacher internship program under the provisions discussed below, except such persons who were awarded a professional teaching certificate on the basis of at least five years teaching experience in another state.

\section{PURPOSE:}

To provide a continuum of growth from the preservice to the professional teaching level.

\section{PROGRAM REQUIREMENTS:}

1. A professional support team shall be comprised of the following: 1) the school principal, who will chair the professional support team, 2) a member of the county professional staff development council, and 3) an experienced classroom teacher at the school who teaches the same or similar subject and grade level as the beginning teacher (if possible), and who shall serve as a mentor for the beginning teacher.

2. An orientation program for the beginning teacher shall be conducted prior to the beginning of the instructional term, supervised by the mentor teacher.

3. Joint planning periods, when possible, shall be scheduled for the mentor and beginning teacher throughout the school year.

4. When possible, the mentor shall observe the beginning teacher's classroom teaching skills for at least one hour per week during the first half of the school year. Observation time may be reduced at the discretion of the mentor to one hour every two weeks during the second half of the school year.

5. Weekly meeting between the mentor and the beginning teacher shall occur at which the mentor and the beginning teacher discuss the performance of the beginning teacher and any needed improvements.

6. Monthly meetings of the professional development support team shall occur to discuss the performance of the beginning teacher.

7. In-service professional development programs shall be provided through the professional development project of the center for professional development of beginning teachers and for mentors.

8. The mentor teacher shall be released from regular duties, as agreed to by the principal and the mentor teacher, and a yearly stipend of at least six hundred dollars for the mentor teacher for duties as a mentor teacher.

9. A final evaluation of the performance of the beginning teacher shall be completed by the principal on a form developed by the state board of education. 


\section{WEST VIRGINIA BEGINNING EDUCATOR INTERNSHIP PROGRAM}

\section{DUTIES \& RESPONSIBILITIES:}

1. Pre-conference discussion, observation and post-conference discussion with assigned new teacher.

2. Provide classroom assistance to the beginning teacher in the delivery of his/her instructional program.

3. Assist the beginning teacher in acquiring materials and other resources.

4. Attend all staff development sessions and complete necessary assignments for mentor teachers.

5. Establish a constructive beginning teacher-mentor relationship designed to enhance communication and exchange of ideas.

6. Keep the principal informed of interventions with the assigned beginning teacher without betraying confidentiality.

7. Assist the beginning teacher in planning, preparing and conducting classroom instruction.

8. Observe, analyze and provide feedback on the beginning teacher's delivery of his/her instructional program.

9. Advise the beginning teacher on strategies to maintain effective classroom management.

10. Assist the beginning teacher in developing methods to appropriately evaluate student progress.

11. Use the supervisory techniques necessary to improve the beginning teacher's delivery methods.

12. Discuss and put into practice techniques and/or strategies to improve areas of need.

13. Identify professional development opportunities that will enhance the beginning teacher's subject area knowledge.

14. Disseminate information about and encourage the beginning teacher's attendance at workshops, seminars, staff development training and other educational offerings. 